Article

\title{
New AC-AC Modular Multilevel Converter Solution for Medium-Voltage Machine-Drive Applications: Modular Multilevel Series Converter
}

\author{
Gustavo Gontijo *(D), Songda Wang *, Tamas Kerekes (1) and Remus Teodorescu (1) \\ Department of Energy Technology, Aalborg University, 9220 Aalborg East, Denmark; tak@et.aau.dk (T.K.); \\ ret@et.aau.dk (R.T.) \\ * Correspondence: gfgo@et.aau.dk (G.G.); sow@et.aau.dk (S.W.)
}

Received: 29 May 2020; Accepted: 10 July 2020; Published: 16 July 2020

\begin{abstract}
Due to its scalability, reliability, high power quality and flexibility, the modular multilevel converter is the standard solution for high-power high-voltage applications in which an AC-DC-AC connection is required such as high-voltage direct-current transmission systems. However, this converter presents some undesired features from both structural and operational perspectives. For example, it presents a high number of components, which results in high costs, size, weight and conduction losses. Moreover, the modular multilevel converter presents problems dealing with DC-side faults, with unbalanced grid conditions, and many internal control loops are required for its proper operation. In variable-frequency operation, the modular multilevel converter presents some serious limitations. The most critical are the high-voltage ripples, in the submodule capacitors, at low frequencies. Thus, many different AC-AC converter solutions, with modular multilevel structure, have been proposed as alternatives for high-power machine-drive applications such as offshore wind turbines, pumped-hydro-storage systems and industrial motor drives. These converters present their own drawbacks mostly related to control complexity, operational limitations, size and weight. This paper introduces an entirely new medium-voltage AC-AC modular multilevel converter solution with many operational and structural advantages in comparison to the modular multilevel converter and other alternative topologies. The proposed converter presents high performance at low frequencies, regarding the amplitude of the voltage ripples in the submodule capacitors, which could make it very suitable for machine-drive applications. In this paper, an analytical description of the voltage ripples in the submodule capacitors is proposed, which proves the high performance of the converter under low-frequency operation. Moreover, the proposed converter presents high performance under unbalanced grid conditions. This important feature is demonstrated through simulation results. The converter solution introduced in this paper has a simple structure, with decoupled phases, which leads to the absence of undesired circulating currents and to a straightforward control, with very few internal control loops for its proper operation, and with simple modulation. Since the converter phases are decoupled, no arm inductors are required, which contributes to the weight and size reduction of the topology. In this paper, a detailed comparison analysis with the modular multilevel converter is presented based on number of components, conduction and switching losses. This analysis concludes that the proposed converter solution presents a reduction in costs and an expressive reduction in size and weight, in comparison to the modular multilevel converter. Thus, it should be a promising solution for high-power machine-drive applications that require compactness and lightness such as offshore wind turbines. In this paper, simulation results are presented explaining the behavior of the proposed converter, proving that it is capable of synthesizing a high-power-quality load voltage, with variable frequency, while exchanging power with the grid. Thus, this topology could be used to control the machine speed in a machine-drive application. Finally, experimental results are provided to validate the topology.
\end{abstract}


Keywords: modular multilevel converter; wind turbines; pumped hydro storage

\section{Introduction}

The world is going through a change of its energy-consumption paradigm, moving towards a renewable-energy-based energy matrix. Wind turbines are in a constant evolution and units with larger power are emerging [1]. This upscaling process aims at increasing the amount of power generated while reducing the structural costs and weight [2]. This is especially important for offshore wind turbines that require extremely expensive supporting structures and that must be installed at remote areas. With the high penetration of renewable energy sources, with complex predictability, energy-storage systems will be required to maintain the load/generation balance in the electrical grid [3-7]. Flexible hydro turbines in the pumped-hydro-storage configuration constitute an interesting option [8,9]. Most of the pumped-hydro-storage systems currently available are based on doubly-fed-induction generators that use a reduced-power converter. This topology does not allow for a very flexible operation because of its low-torque characteristic at low speeds, leading to the requirement of a dewatering procedure (to remove the water from the hydro turbine in order to reduce the friction force) when changing from pump mode to generation mode and vice versa. In order to obtain a highly flexible hydro turbine, the usage of a synchronous machine along with a full-scale converter is necessary [8-10].

Upscaled wind turbines, flexible pumped-hydro-storage systems and industrial motor drives are applications that operate with variable frequency and that must deal with a considerably high amount of power. These increasing power levels will eventually result in the necessity of higher voltages. Thus, proper power-electronic devices will be required to drive these systems. Conventional modular multilevel converters (MMCs) are the state-of-the-art solution for high-voltage applications such as high-voltage-direct-current (HVDC) transmission systems operating as controlled voltage sources. This converter topology can reach very-high voltage levels using semiconductor devices currently available in the industry, due to its modular structure. Moreover, the MMC allows for a flexible HVDC system, with high reliability, high power quality and low switching losses. The MMC topology in a back-to-back configuration is shown in Figure 1. The HVDC systems operate with fixed frequency at their AC terminals (usually $50 \mathrm{~Hz}$ or $60 \mathrm{~Hz}$ ). Even though many papers have proposed methods to keep the MMC submodule-capacitor voltage ripples within acceptable limits [11,12], at low frequencies, this problem can be much more serious [13,14]. For lower frequencies, the submodule-capacitor voltage ripples increase since they are consequence of the fundamental frequency and double-fundamental frequency current components flowing through the capacitors, and since the capacitor reactance is inversely proportional to the frequency. The voltage ripples can reach intolerable values for very low frequencies. In a pumped-hydro-storage system, the synthesized AC voltage even crosses the $0-\mathrm{Hz}$ operation point as the hydro turbine switches from pumping mode to generating mode, or vice versa. This situation would lead to the destruction of the MMC submodule capacitors, since a $0-\mathrm{Hz}$ current flowing through these capacitors would lead, in theory, to an infinite voltage ripple. Moreover, since the MMC phases are connected to common points at their positive and negative DC terminals, unbalanced grid conditions can cause serious ripple problems at both submodule level and DC-link level [15,16]. Moreover, conventional MMCs have critical problems dealing with DC-side faults, at least, if the submodules are half-bridge $(\mathrm{HB})$ ones $[17,18]$. Full-bridge $(\mathrm{FB})$ submodules could be used but with the downside of increasing the cost and losses of the converter, due to the high number of components required in the converter structure. Furthermore, MMCs must deal with undesired circulating currents that must be constantly suppressed to keep the conduction losses within a tolerable range [19-21]. However, the suppression of the circulating currents increases the problems with the capacitor-voltage ripples. Finally, the MMC has a complex structure, with a high number of components, which leads to high costs, weight and size. Moreover, many internal control loops are required for its proper operation. 


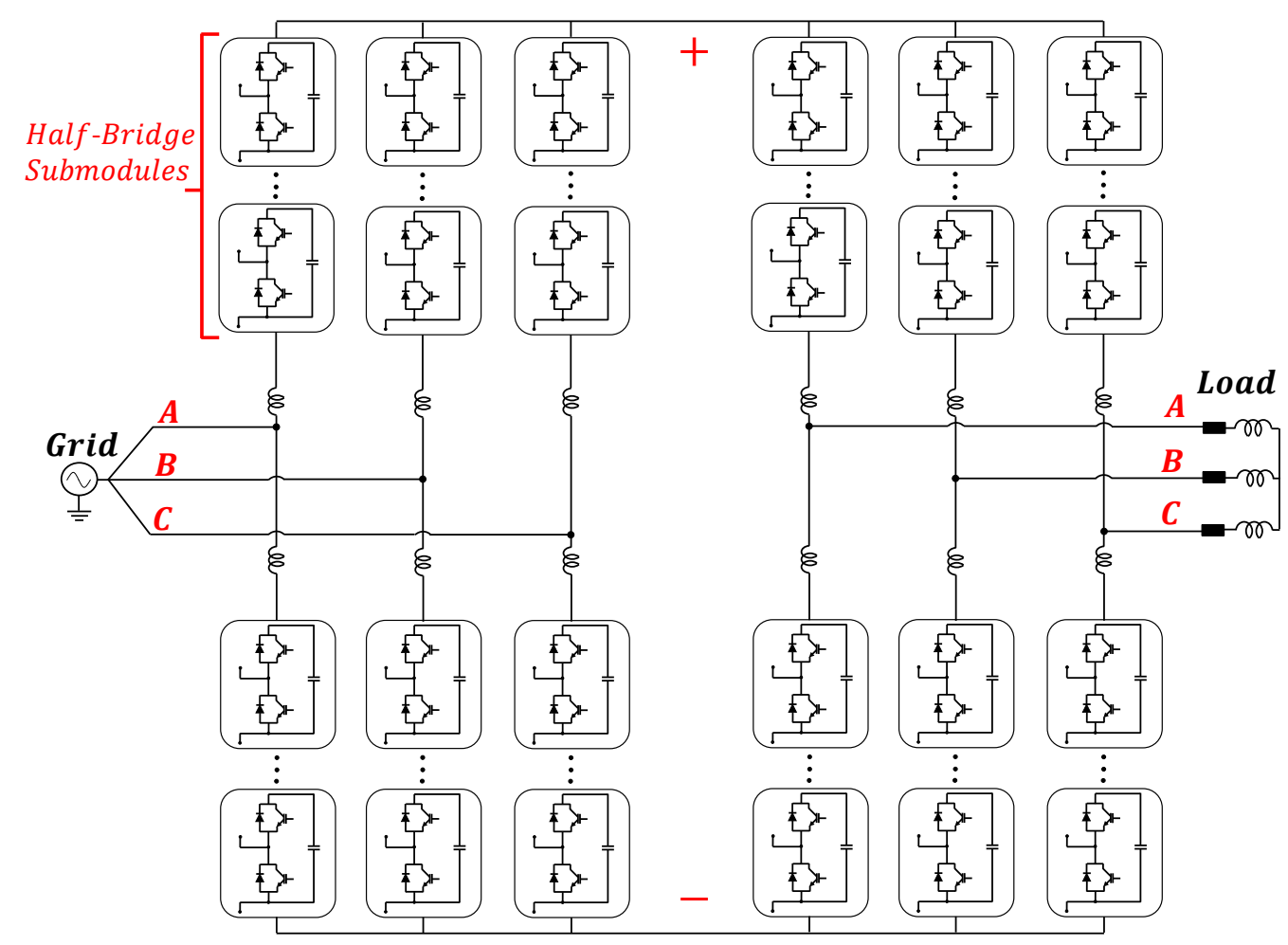

Figure 1. MMC topology.

It seems that in medium-voltage AC-AC applications operating with variable frequency, such as large wind turbines, pumped-hydro-storage systems or industrial motor drives, the usage of conventional MMCs is not very appropriate. Undesired issues, inherent to the conventional MMC, could be avoided. Many different AC-AC converters using a modular multilevel structure have been proposed in the literature [22-42]. Two converter solutions stand out among all the mentioned ones. The first one, is often referred to as the series-connected H-bridge (SCHB) multilevel converter [30-32] and it has attracted a lot of attention from industry, becoming a product regarded as the most proven medium-voltage drive in the market (SIEMENS SINAMICS PERFECT HARMONY GH180). This converter is composed of strings of FB submodules connecting each phase of a given machine to a common neutral point. In order to exchange power with the grid, rectifiers are connected to each of the submodule capacitors. These rectifiers maintain the capacitor voltages regulated as they do not experience voltage-ripple problems. Since this is a converter for medium-voltage applications, a very complex, heavy and bulky transformer structure is required to adapt the grid voltage to the voltage at the terminals of each rectifier. Thus, this solution is not suitable for applications that require lightness and compactness such as wind turbines (especially offshore ones) or maritime drive applications, for example. Probably, the state-of-the-art converter solution for medium-voltage AC-AC drive applications that require lightness and compactness is the so-called modular multilevel matrix converter (MMMC or $\mathrm{M}^{3} \mathrm{C}$ ) $[2,33,34,38-40]$, many times also referred to as direct MMC (D-MMC) [8,9,41] or modular multilevel cascade converter based on triple-star bridge-cells (MMCC-TSBC) [35-37]. This converter can be considered to be a mix of a direct matrix converter (DMC) $[43,44]$ and an MMC, and it presents superior performance, in comparison to the conventional MMC, at low frequencies, regarding the amplitude of the submodule-capacitor voltage ripples. Basically, this converter is composed of strings of FB submodules connecting each phase of the grid to a common point that is connected to one of the phases of the load terminal. Three of such structure are required to be connected to each of the three phases of the load, resulting in a three-phase converter. The MMMC can act as a voltage source to both load and grid side with the absence of a DC stage. However, the MMMC presents some drawbacks. First, this is a converter with high control and structural complexity. Moreover, 
complex modulation strategies are required. Since each phase of the grid is connected, through submodules strings, to a common point, undesired circulating currents are still an issue to deal with. One of the most serious drawbacks is related to the MMMC operation under unbalanced grid conditions [45,46]. Basically, the MMMC is composed of three modular multilevel converters based on single-star bridge-cells and it is widely known that this converter presents critical problems under unbalanced grid conditions [45]. Due to the neutral point of this converter, unbalanced grid conditions can, not only, increase the submodule-capacitor voltage ripples, but even more serious, can result in an uneven power distribution among the phases leading to an unstable operation of the capacitor voltages that might diverge. This paper introduces an entirely new medium-voltage AC-AC converter solution that can overcome some of the previously mentioned structural and operational drawbacks of already established converter topologies. The authors named it modular multilevel series converter (MMSC) and its structure is illustrated in Figure 2.

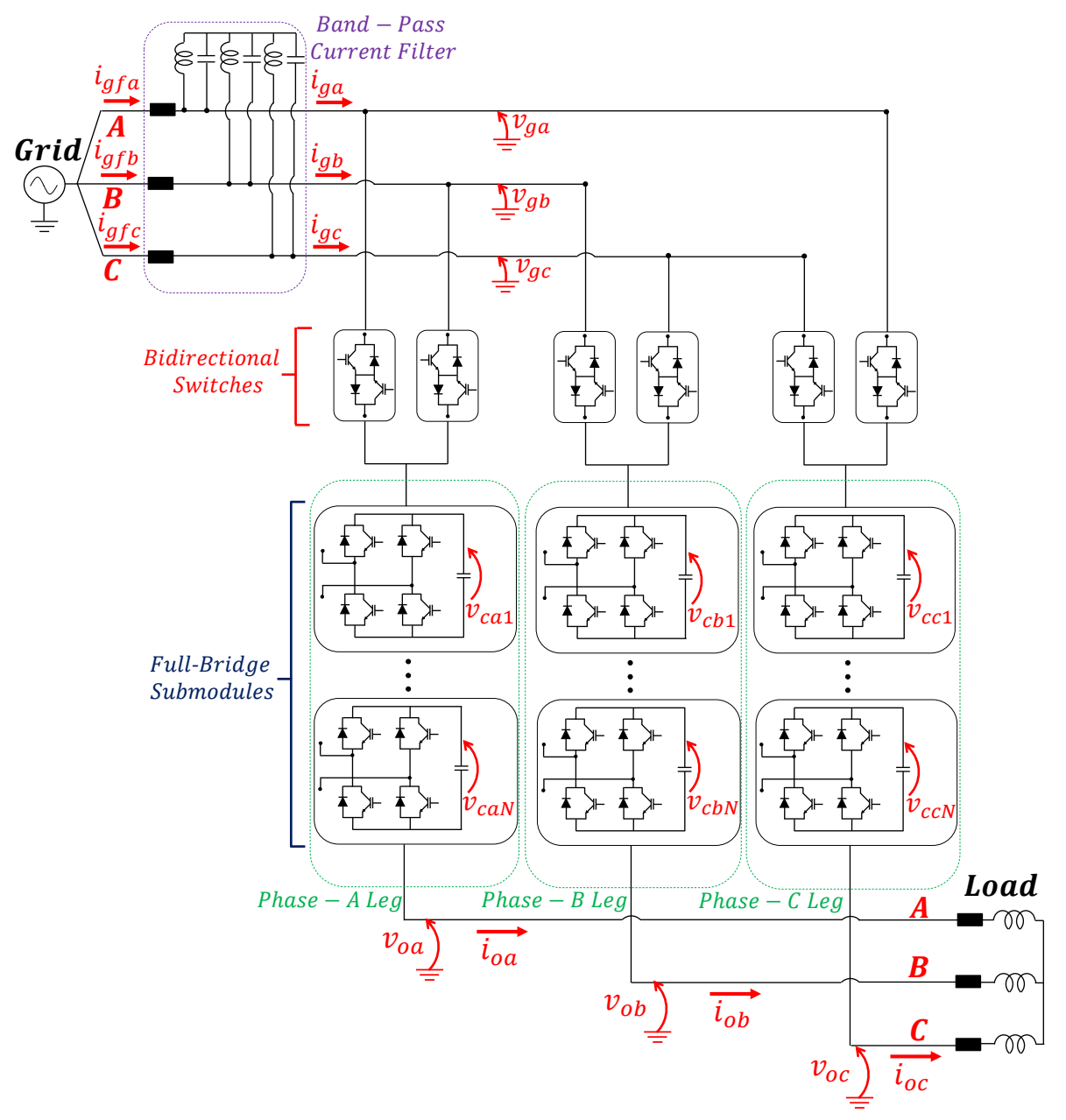

Figure 2. MMSC topology.

The MMSC is a converter solution with simple structure and reduced number of components in comparison to the MMC. The MMSC is a three-phase converter composed of three, completely independent and decoupled, single-phase structures (see Figure 3). Thus, circulating currents are non-existent, which simplifies the converter control and operation, and that results in a topology with no requirements of arm inductors. In both MMC and MMMC, many bulky and heavy inductors are required to avoid internal short circuits, among the coupled submodule strings, and to suppress undesired AC circulating currents. Since the three phases of the MMSC are completely decoupled, unbalanced grid conditions are not a critical problem for the MMSC to deal with as will be further explored in this paper. The proposed converter topology presents very low control complexity. In fact, 
the only internal control loop for the proper operation of the MMSC is the submodule-capacitor-voltage balance, along with a straightforward modulation technique. This is an important advantage over the MMC and the MMMC. Moreover, the MMSC presents a very low requirement of output-voltage filters due to its multilevel structure that generates a high-power-quality staircase-shape voltage, which is a common feature of converters with modular multilevel structure. Finally, as will be explained in detail in this paper, the MMSC presents high performance at low-frequency operation, regarding the voltage ripples in the submodule capacitors, which is a natural consequence of its topology and control. For this reason, the MMSC could be a very promising solution for high-power machine-drive applications. In comparison to the conventional MMC, the MMSC presents a simplified control and a reduction in the number of semiconductor devices and an expressive reduction in the number of bulky and heavy submodule capacitors. In this paper, a detailed comparison analysis is carried out between the MMC and the MMSC, focusing on the number of components, conduction and switching losses of the topologies. This analysis leads to important conclusions regarding cost, size and weight, which are favorable to the MMSC over the MMC. Moreover, the MMSC does not have a DC stage, avoiding problems with DC faults, and does not need to deal with undesired circulating currents. Finally, the MMSC presents higher performance at low frequencies. In comparison to the SCHB multilevel converter, the MMSC is very light and compact due to the absence of the bulky transformers. In comparison to the MMMC, the MMSC presents a reduced control complexity, since the MMMC requires very complex modulation techniques and it needs to have different internal control loops such as the circulating-current-suppression control. Moreover, the MMSC presents high performance under unbalanced grid conditions, which is an important advantage over the MMMC.

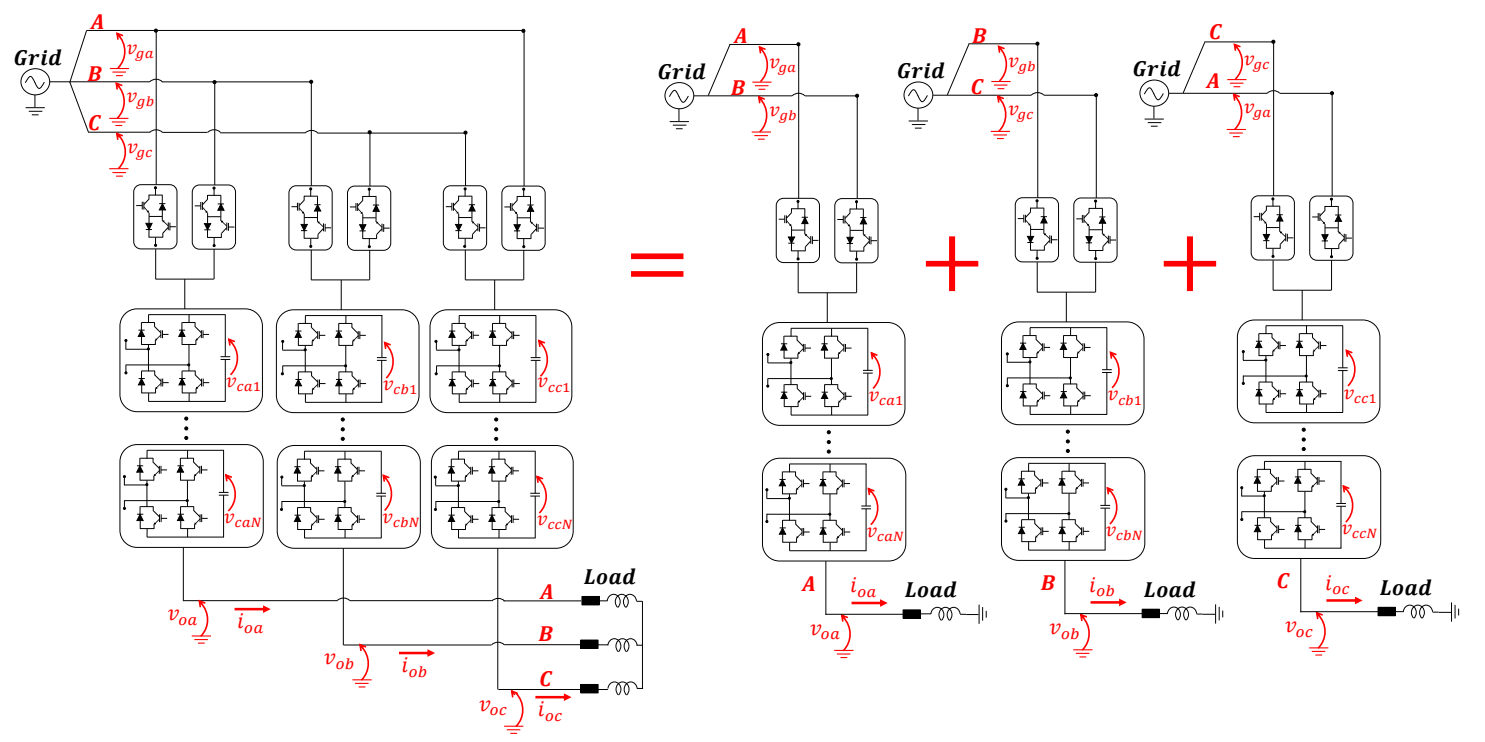

Figure 3. MMSC represented as three single-phase converters.

Facts that are widely described in the literature about the MMC, the MMMC and the SCHB multilevel converter are summarized in Table 1. The characteristics of the proposed MMSC, which are described in Table 1, will be explored and explained in detail in this paper. In Section 2, the authors explain the topology, behavior and operational characteristics of the MMSC. In Section 3, an explanation of the converter control and modulation is provided, which proves the low control complexity of the MMSC. In Section 4, a detailed analytical description of the submodule-capacitor voltage ripples is proposed, which explains the high performance of the MMSC at low frequencies. In Section 5, a detailed comparison analysis between the MMSC and the MMC is carried out, aiming at analyzing the total number of components, conduction and switching losses of the topologies. This analysis leads to interesting conclusions regarding cost, size, weight and efficiency, showing that since the MMSC presents a reduced number of semiconductor devices and an expressive reduction in the number 
of capacitors, in relation to the MMC, then the MMSC should be a solution with reduced cost and considerably reduced size and weight. In Section 6, simulation results are presented showing that the MMSC is capable of synthesizing a high-power-quality load voltage, with variable frequency, operating as a controlled voltage source from the load perspective, while injecting a high-power-quality current into the grid. Moreover, simulation results are presented proving the high-performance behavior of the MMSC under unbalanced grid conditions. Finally, in Section 7, experimental results are presented, validating the proposed converter topology. Due to the mentioned operational and structural advantages, in relation to other alternative converter topologies, the MMSC should be a promising industrial solution for high-power machine-drive applications that require lightness and compactness (offshore wind turbines, for example) and applications that operate at low frequencies (such as pumped-hydro-storage systems or industrial motor drives).

Table 1. Characteristics of Different Converter Topologies.

\begin{tabular}{ccccc}
\hline & MMC & MMMC & SCHB & MMSC \\
\hline Performance at Low Frequencies & Low & High & High & High \\
Structural and Control Complexity & High & High & Average & Average \\
Presence of Circulating Currents & Yes & Yes & No & No \\
Presence of DC Stage & Yes & No & No & No \\
Performance Under Unbalanced Grid Conditions & Average & Low & High & High \\
Presence of Heavy Filters and Transformers & Average & Average & High & Average \\
\hline
\end{tabular}

\section{AC-AC MMC as a Series-Connected Voltage Source}

The MMSC topology is composed of strings of FB submodules along with bidirectional switches. The MMSC is supposed to operate as controlled voltage sources $\left(v_{s}\right)$ connected in series between each phase of the grid and each phase of the load. Strings of FB submodules are required to emulate the controlled voltage source since they allow synthesis of a series voltage with both positive and negative polarities. As higher the number of submodules connected in series $(N>>1)$, closer to a sinusoidal signal will be the series synthesized voltage due to more steps in the staircase-shape waveform. Supposing that the bidirectional switches are connecting each of the grid phases to their corresponding load phases, then, for the phase-A case, the following is obtained through Kirchhoff's law if a balanced system is considered:

$$
v_{g a}+v_{s a}-v_{o a}=0
$$

In which $v_{g a}$ is the phase-to-ground grid voltage, $v_{o a}$ is the phase-to-ground load voltage and $v_{s a}$ is the voltage across the string of submodules in the phase-A leg. Therefore, if one wants to control, for example, phase A of the load voltage $\left(v_{o a}=v_{\text {refa }}\right)$, then they need to synthesize a given series voltage $\left(v_{s a}\right)$, depending on the instantaneous value of the grid voltage $\left(v_{g a}\right)$. In other words:

$$
v_{s a}=v_{r e f a}-v_{g a}
$$

The bidirectional switches perform two essential tasks for the operation of the MMSC. Since the strings of submodules are connected in series between the grid and the load, in steady state, the average voltage of the capacitor of each submodule reaches a value equal to approximately $\frac{V_{g}}{N}$, in which $V_{g}$ corresponds to the peak, phase-to-ground value of the grid voltage and $N$ corresponds to the number of series-connected submodules. It means that the grid voltage is naturally divided among the capacitors of each submodule in one string. The average capacitor voltage is not equal to $\frac{V_{g}}{N}$, in steady state, due to a small voltage drop across the load. If the system is balanced, then both the grid neutral point and the load neutral point can be considered to be grounded. Then, one can follow a closed voltage path (Kirchhoff's law) from the grid neutral point, passing through the string of submodules until the load neutral point. Considering the small voltage drop in the load and considering each 
submodule as a diode rectifier (anti-parallel diodes), then the voltage in each capacitor will be equal to approximately $\frac{V_{g}}{N}$. This is exactly what happens in the pre-charge of the MMSC (see Figure 4). The submodules IGBTs are kept in off state and the grid voltage charges the submodule capacitors, through the anti-parallel diodes, with a value equal to approximately $\frac{V_{g}}{N}$. It is interesting that even when the MMSC starts to operate, the average capacitor voltage still has a balance value that is imposed by the grid-voltage amplitude. The capacitor voltages oscillate according to the current flowing through the string, but their average values are kept constant and regulated. That is how the power transfer between the load and the grid occurs. When there is a power variation at the load side, the average capacitor voltages are kept stable and regulated (imposed by Kirchhoff's law and conservation of energy), and, thus, the grid power varies accordingly in order to meet the new load-power value. The variation of the grid power is a natural consequence of Kirchhoff's law and conservation of energy. If it did not happen, then there would be a power mismatch between grid and load and the average value of the capacitor voltages would vary, as the capacitors would charge or discharge in order to fill the power mismatch. In this case, Kirchhoff's law would not be fulfilled. To sum up, the average value of the capacitor voltages in one string does not need to be controlled as it is kept regulated in order to fulfil Kirchhoff's law. Even if the load varies, there is a balance average value for the capacitor voltages, which is equal to approximately $\frac{V_{g}}{N}$.

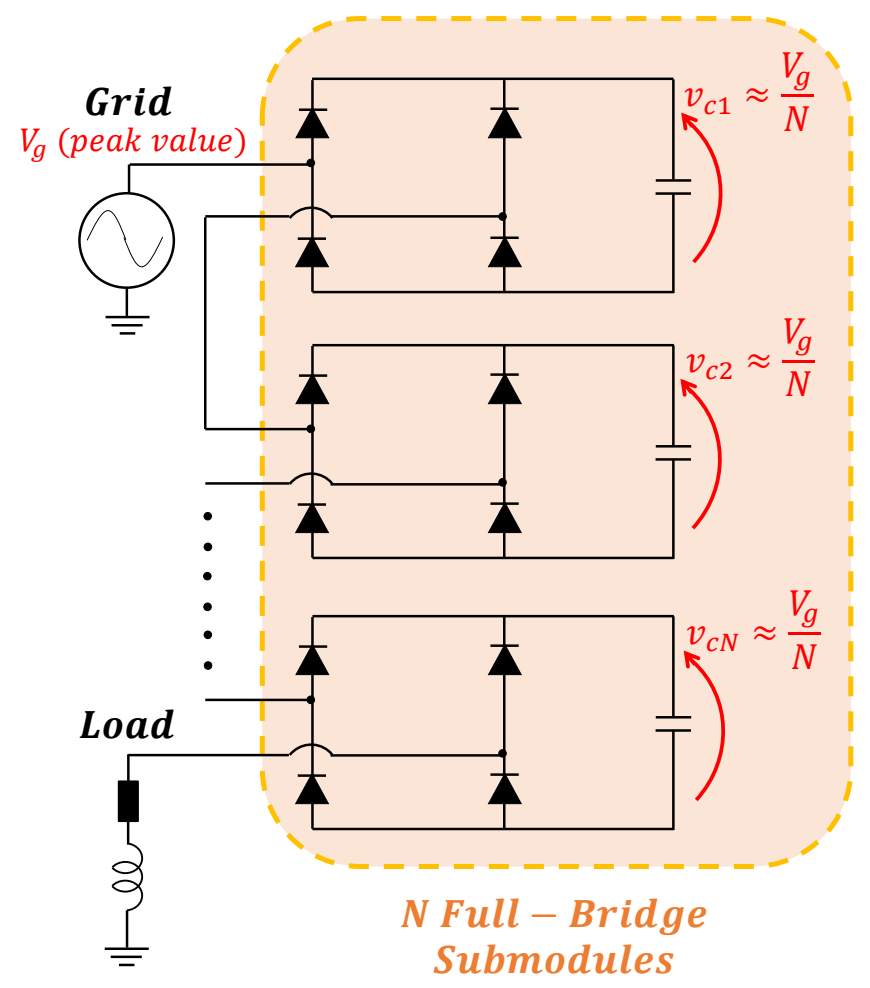

Figure 4. MMSC pre-charge representation.

If all the submodules are inserted in series, the value of the synthesized voltage $\left(v_{s}\right)$ will be equal to $V_{g}$, which is the maximum value possible to be synthesized. However, it is considered that the grid voltage and output voltage have different frequencies ( $f_{i}$ and $f_{o}$, respectively), which means that there will be moments in which the peak of the grid voltage will meet the valley of the output-voltage reference. According to (2), at these moments the instantaneous value of the voltage required to be synthesized in series $\left(v_{s}\right)$ will be higher than the maximum voltage possible $\left(V_{g}\right)$. In other words, at these moments the output voltage $\left(v_{0}\right)$ will deviate from its reference $\left(v_{r e f}\right)$ since the MMSC is not capable of synthesizing the necessary voltage. Therefore, the first essential task of the bidirectional switches is to connect the strings of submodules to a different phase of the grid at the moments in 
which the voltage to be synthesized in series is higher than $V_{g}$. As an example, for the phase-A case, the bidirectional switches will connect the phase $\mathrm{B}$ of the grid to the phase-A leg and, thus, the voltage to be synthesized in series, according to Kirchhoff's law, will then be equal to $v_{s a}=v_{r e f a}-v_{g b}$, which will be lower than $V_{g}$ and, thus, the MMSC maintains control over the load voltage.

In Figure 5, one can observe equivalent electric circuits that represent the behavior of the MMSC from both grid and load perspectives. From the load perspective, the MMSC is a controlled voltage source that generates the voltage reference $\left(v_{r e f}\right)$ at its terminals. It is important to notice, though, that the load and grid are connected in series through a string of submodules. Thus, it would be naturally expected that the load current $\left(i_{o}\right)$ would flow to the grid, which would result in an intolerable operation condition. In fact, from the grid perspective, the MMSC operates as a current source. However, this is a current source that injects, not only, the load current $\left(i_{0}\right)$ into the grid, but also components with other frequencies, including the grid frequency $\left(f_{i}=50 \mathrm{~Hz}\right)$. That is the second essential task of the bidirectional switches. In other words, as will be shown later, the bidirectional switches operate with the grid frequency $\left(f_{i}=50 \mathrm{~Hz}\right)$ resulting in a $50-\mathrm{Hz}$ component in the current injected into the grid $\left(i_{g}\right)$. The $f_{0}$-Hz-current component that flows to the grid (load current) can be filtered out. That is why a band-pass current filter, tuned with the grid frequency $\left(f_{i}=50 \mathrm{~Hz}\right)$, should be added at the point of connection of the MMSC and the grid. Thus, as shown in Figure 5, from the grid perspective, the MMSC can be represented by a current source with the load-current component $\left(i_{o}\right)$, as well as a current source with the $50-\mathrm{Hz}$ component $\left(i_{g f}\right)$, which is the filtered current. The load current $\left(i_{o}\right)$ will be drained by the filter, whereas the $50-\mathrm{Hz}$ component $\left(i_{g f}\right)$ will flow to the grid, interacting with the grid voltage, producing the active power that is exchanged with the load $\left(P_{i}=P_{o}\right)$. The band-pass filter is tuned in such a way as to allow only the $50-\mathrm{Hz}$-current component to flow to the grid.
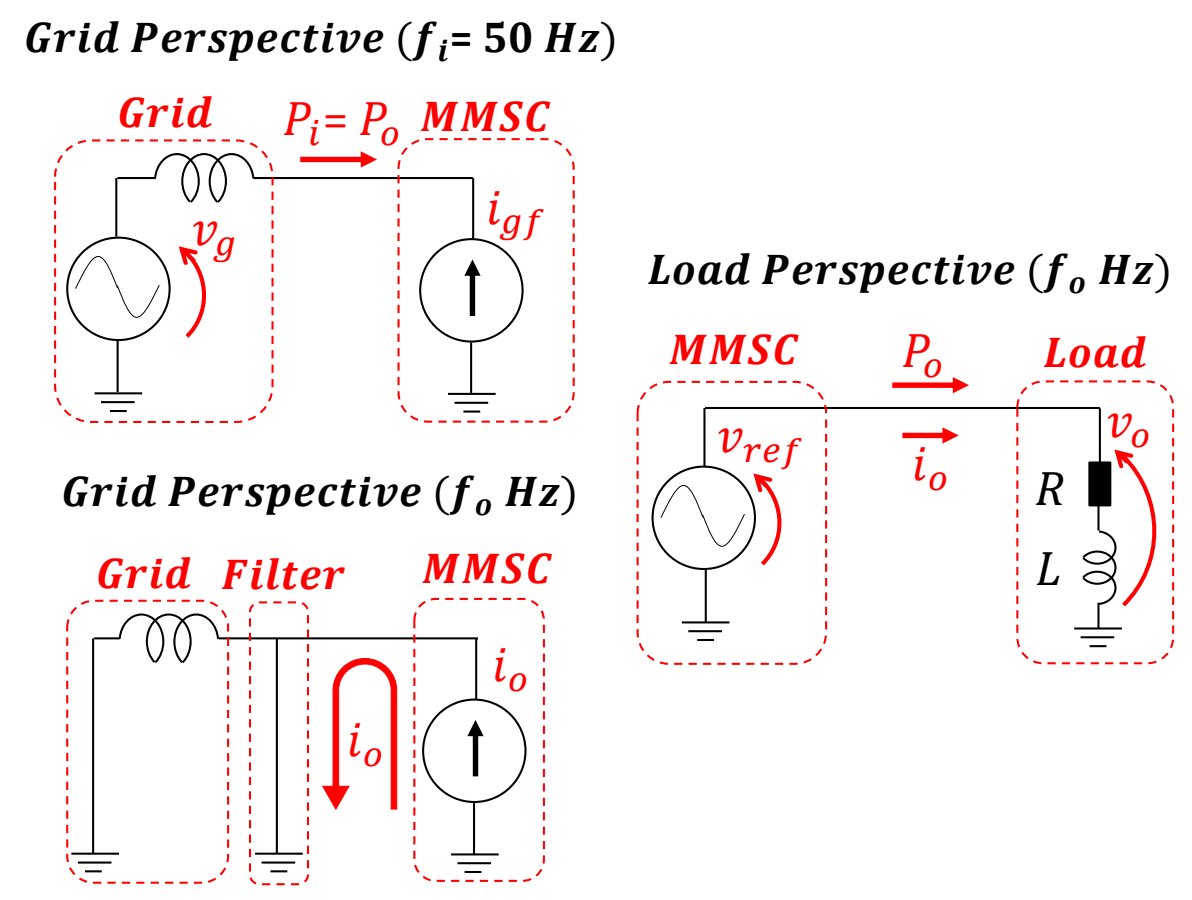

Figure 5. Equivalent electric circuits that represent the MMSC behavior from grid and load perspectives.

The filter used in this paper is the one shown in Figure 6 with the following transfer function:

$$
\frac{i_{\text {out }}}{i_{\text {in }}}=\frac{s L}{(L C R) s^{2}+L s+R}
$$


This is a second-order filter that has the Bode plot depicted in Figure 7 if the following parameters are used: $R=25 \Omega, L=10.13 \mathrm{mH}$ and $1 \mathrm{mF}$. By analyzing Figure 7 , one can notice that the filter has a resonance characteristic with a peak at $314.16 \mathrm{rad} / \mathrm{s}$. In other words, at $314.16 \mathrm{rad} / \mathrm{s}$, the filter presents $0 \mathrm{~dB}$ meaning that the $50-\mathrm{Hz}$ current is allowed to pass through the filter. The Bode plot shows negative magnitudes for other frequencies, meaning that currents with other frequencies will be attenuated. In this paper, the filter design was executed in such a way as to illustrate the proposed idea. However, it is important to emphasize that a more efficient design would be required in an eventual industrial product. Higher order filters could be used to obtain a thinner resonance peak, which would improve the filtering performance.

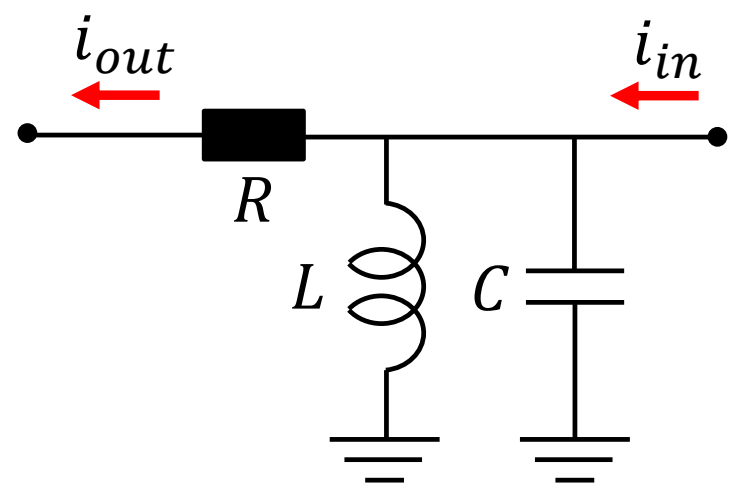

Figure 6. Band-pass current filter circuit.

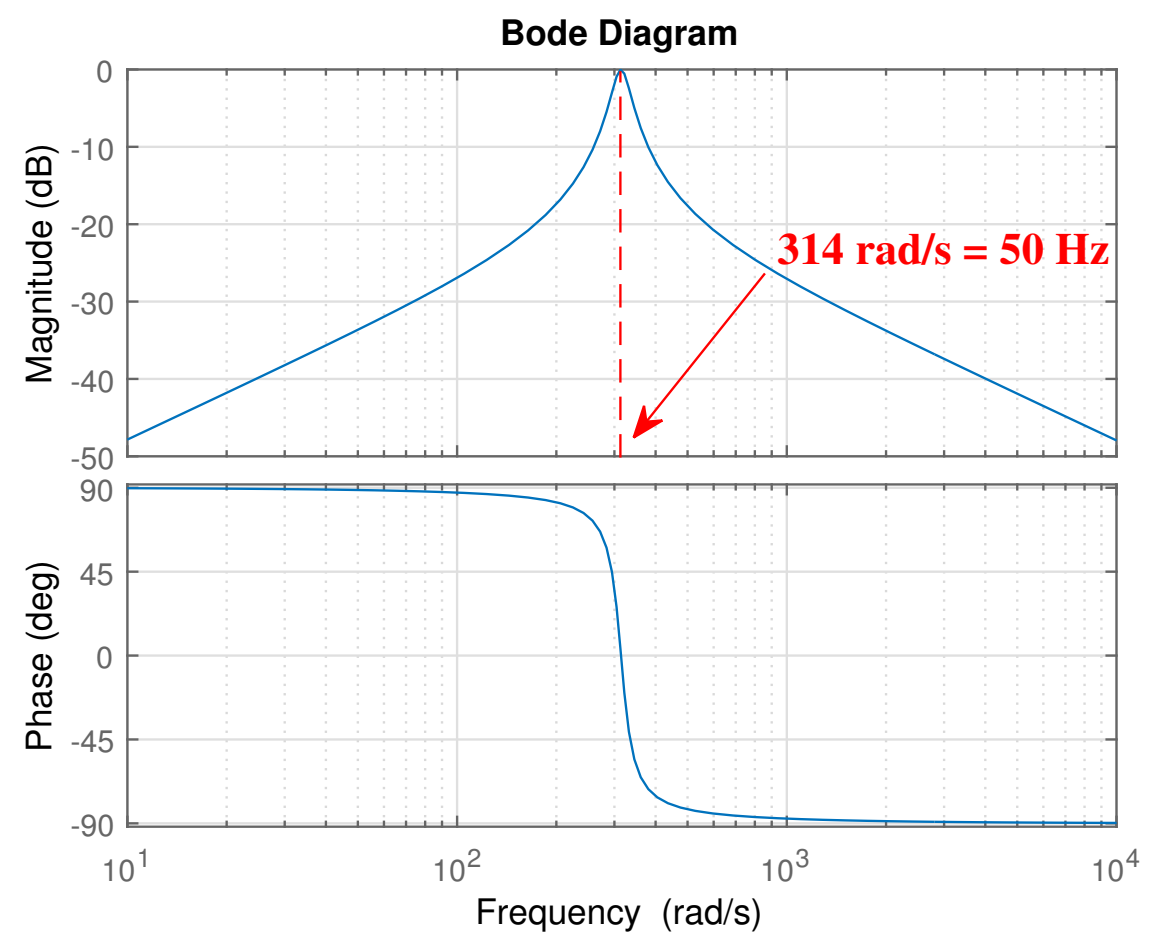

Figure 7. Bode plot of band-pass filter.

A critical component of the MMSC that deserves special attention is the bidirectional switch. The MMSC is supposed to be used in medium-voltage applications, which means that the bidirectional switches should be able to withstand these voltage levels. Thus, series-connected semiconductor devices are required. The operation of these series-connected devices is a challenge commonly faced by power-electronic manufacturers. It is important to emphasize, though, that since these are medium-voltage applications and not high-voltage applications, only a few series-connected devices would be required. There are some products currently available in the industry $[47,48]$ that 
correspond to valves composed of many series-connected semiconductor devices that operate with high reliability, due to advanced drivers that ensure static and dynamic voltage sharing among the semiconductor devices. Moreover, one very important issue about the MMSC is that as previously mentioned and as will be further explained in this paper, the bidirectional switches operate with a very low switching frequency $\left(f_{i}=50 \mathrm{~Hz}\right)$. In other words, even though series-connected devices are required, these devices switch at very low frequencies and, thus, snubber circuits could be used, with tolerable losses, in order to guarantee a safe transient voltage balance among the semiconductor devices connected in series [49-51]. This way, the MMSC can operate in a safe and reliable fashion. Moreover, the low switching frequency results in low switching losses. Another very interesting consequence of the low switching frequency of the bidirectional switches in the MMSC is the fact that the complex multi-step commutation techniques [52,53], commonly used in matrix converters, could be avoided through the use of snubber circuits. In other words, a simple dead-time could be used in combination with the snubber circuit to guarantee the bidirectional-switch current commutation, providing a path for the load current to flow through during the commutation. Due to the low switching frequency, tolerable losses would be obtained since the current would only flow through the snubber circuit during the current commutation.

\section{Internal Control Loops and Modulation Strategy}

As previously mentioned, the converter structure proposed in this paper is very simple and not many internal control loops are necessary for its operation, which is an important advantage over other converter solutions composed of a modular multilevel structure. For example, in the conventional $\mathrm{MMC}$, many internal control loops are required for the correct operation of the converter. One of the internal control loops is responsible for maintaining the equal sharing of the DC-link voltage among the upper and the lower arms. Another internal control loop is the circulating-current-suppression control required to guarantee that the circulating current is only composed of a DC component and that the undesired AC components are suppressed. Finally, the voltage balance among the capacitors of the submodules in one arm is also required for the proper operation of the MMC. In the MMMC case, also many internal control loops are required for its proper and stable operation. Moreover, very complex modulation techniques are necessary in order to operate the MMMC as a voltage source from both grid and load perspectives, while respecting important constraints of not creating short circuits and not creating situations in which a given current does not have a path to flow through, since there are inductors at both grid and load sides.

In the MMSC case, the only internal control loop required for the correct operation of the converter is the voltage balance among the capacitors of the submodules in one string. This control is explained, along with the used modulation technique, in Figure 8, in which the internal control and modulation for the phase-A case are shown. It is important to emphasize that in this paper the MMSC is controlled in an open-loop fashion without any outer control loops. In other words, a voltage reference $\left(v_{r e f}\right)$ is provided to the MMSC, which is a signal with fixed amplitude and variable frequency as will be shown later. The flowchart shown in Figure 8 corresponds to the MMSC internal control (submodule-capacitor voltage balance), plus the control logic of the bidirectional-switch valves, plus the modulation technique that is responsible for tracking the voltage reference. The entire control logic illustrated in Figure 8 is implemented in a $\mathrm{C}$ code.

The error $(E)$ is equal to the voltage that must be synthesized in series $\left(v_{s a}\right)$ in order to obtain the desired voltage at the load terminals $\left(v_{o a}=v_{r e f a}\right)$. Thus, the error is calculated as follows:

$$
E=v_{r e f a}-v_{g a}
$$




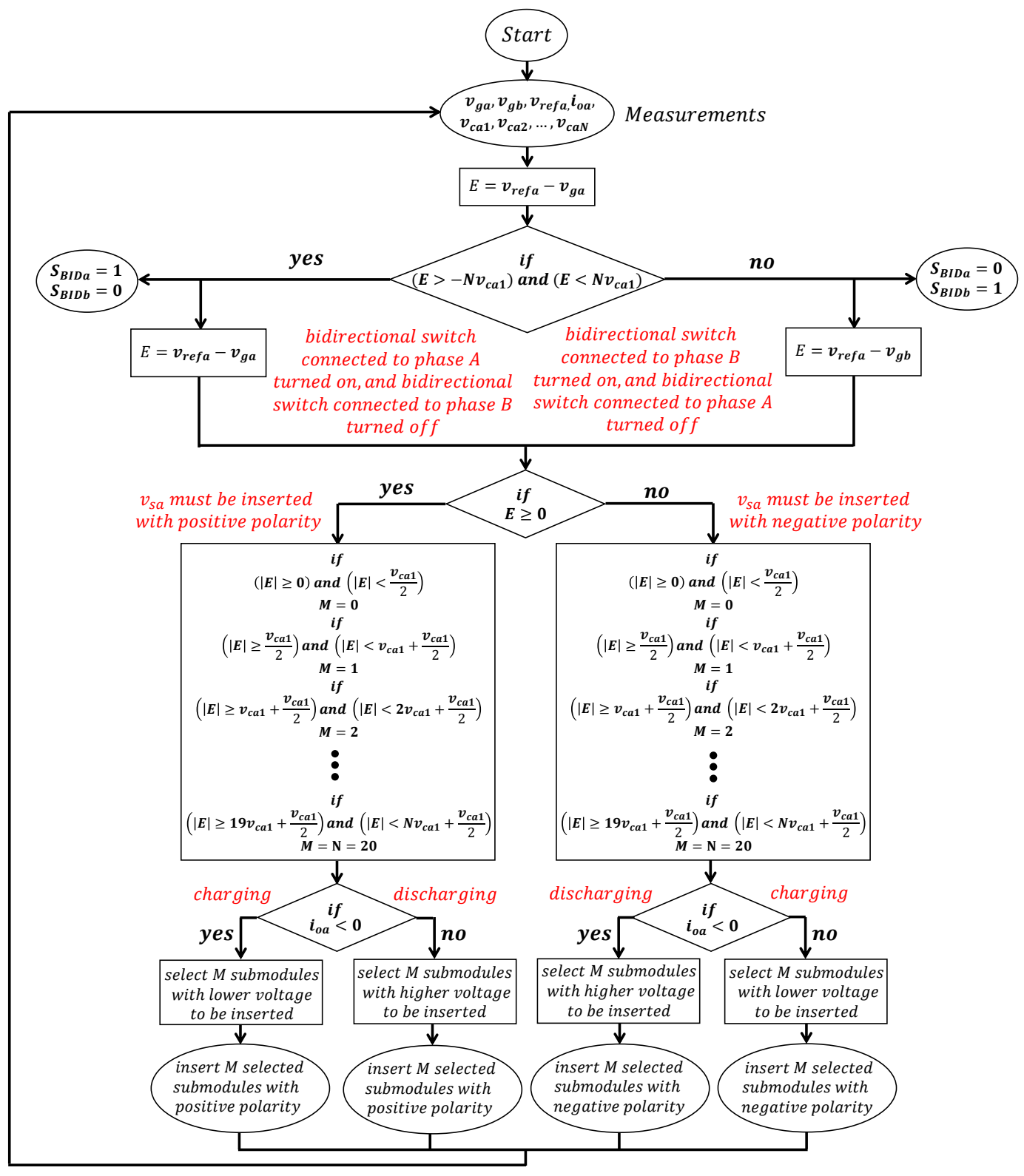

Figure 8. MMSC control and modulation.

While $E$ is within the limits corresponding to $-N v_{c a 1}$ and $N v_{c a 1}$, phase-A leg is kept connected to phase A of the grid, because the voltage that must be synthesized in series is within the limits of voltage that the converter is capable of synthesizing. Even though $v_{c a 1}$ was used in this case, any capacitor voltage could be used considering that all of them have equal values due to the voltage balancing control. As soon as $E$ is not within the mentioned limits anymore, then the phase-A leg must be connected to phase B of the grid through the bidirectional switches. $S_{B I D a}$ and $S_{B I D b}$ are the gate signals sent to the bidirectional switches connected to phase A and phase B of the grid, respectively. If these signals have value equal to 1 , then the bidirectional switch is turned on, whereas if they have value equal to 0 , then the bidirectional switch is turned off. It is important to emphasize that the bidirectional switches of each submodule string operate in a complementary fashion. In other words, if $S_{B I D a}=1$, then $S_{B I D b}=0$ and vice versa. Both IGBTs in one bidirectional switch are activated simultaneously because a snubber circuit was used along with a dead-time technique, avoiding the multi-step commutation approach. In other words, both IGBTs in one bidirectional switch can be seen as a single switch. After checking if $E$ is within the limits corresponding to $-N v_{c a 1}$ and $N v_{c a 1}$, it is 
necessary to analyze if $E$ has a positive or a negative value to know if the submodules need to be inserted with positive or with negative polarity in order to obtain the desired instantaneous voltage at the load terminal. After deciding the polarity of the voltage to be synthesized in series, the number of submodules to be inserted $(M)$ must be calculated. This is a modulation process similar to the nearest-level control [47]. Basically, $N$ submodules with voltage equal to $v_{c a 1}=v_{c a 2}=\ldots=v_{c a N}$ are available to be inserted in series. The control must test in which voltage range the value calculated for $E$ is, in order to decide how many submodules must be inserted in series (see Figure 8). Finally, in order to obtain the capacitor-voltage balance, the direction of the output current $\left(i_{o a}\right)$ should be measured. The capacitors of the submodules to be inserted will be charged or discharged depending on the polarity of the inserted submodules and on the current direction. If this is a charging current, the $M$ submodules with lower capacitor voltages are selected to be inserted and if this is a discharging current, the $M$ submodules with higher capacitor voltages are selected to be inserted. With this technique, all the submodule capacitors, in the string, remain with equal voltage.

\section{Submodule-Capacitor-Voltage-Ripple Analysis}

To understand the submodule-capacitor voltage ripple, one can observe the behavior of the voltage that must be added in series $\left(v_{s}\right)$ in order to obtain the desired voltage $\left(v_{r e f}\right)$ at the load terminal:

$$
v_{s}(t)=v_{r e f}(t)-v_{g}(t)=V_{r e f} \sin \left(\omega_{0} t\right)-V_{g} \sin \left(\omega_{i} t+\phi\right)
$$

In which $V_{r e f}$ is the phase-to-ground peak value of the voltage reference. The voltage that the MMSC is capable of synthesizing in series, however, neglecting the submodule-capacitor voltage ripple, can be described as:

$$
v_{s}(t)=V_{c a p} S(t)
$$

In which $V_{\text {cap }}$ is the average value of the voltage in each submodule capacitor and $S(t)$ is an insertion index pattern that varies periodically, in a discrete fashion, from $-N$ to $N$ representing the instantaneous number of submodules inserted in series. However, in this analysis $S(t)$ is approximated by a continuous signal, normalized by $N$, that varies from -1 to 1 , resulting in the following equation:

$$
v_{S}(t)=N V_{c a p} S(t)=N \frac{V_{g}}{N} S(t)=V_{g} S(t)
$$

To sum up, (5) is the voltage that must be added in series in order to obtain the desired voltage reference at the load terminals, whereas (7) is the voltage that the converter is capable of synthesizing in series, if the bidirectional switches are disabled. By analyzing (7), one can observe that this is a signal that varies periodically with amplitude equal to $V_{g}$. However, if one analyzes (5), they will notice that in order to obtain the desired voltage at the load terminals, the required series voltage should have an amplitude higher than $V_{g}$ at some moments. This fact explains the necessity of using the bidirectional switches to commutate between different phases of the grid. The ideal insertion index pattern required to reach the desired load voltage can be obtained by substituting (7) into (5) resulting in:

$$
S(t)=\frac{V_{r e f}}{V_{g}} \sin \left(\omega_{0} t\right)-\sin \left(\omega_{i} t+\phi\right)
$$

Equation (8) is illustrated in Figures 9a, 10a and 11a for the cases in which the output-voltage reference has frequencies equal to $1 \mathrm{~Hz}, 10 \mathrm{~Hz}$ and $45 \mathrm{~Hz}$, respectively. These signals represent how the submodules in one string should be inserted to obtain the desired voltage at the load terminals. However, these are insertion-index values that do not correspond to reality. One should notice that these signals vary periodically reaching values higher than 1 . Since the insertion index was normalized by the number of submodules $(N)$, then a value higher than 1 represents an unfeasible insertion-index value that would correspond to more than $N$ submodules inserted in series. Thus, the real insertion 
index pattern that represents how the submodules would actually be inserted if the bidirectional switches were kept disabled, is a signal represented by (8), but that saturates when it reaches the values equal to 1 or -1 . This signal is represented in Figures 9c, 10c and 11c for the cases in which the output-voltage reference has frequencies equal to $1 \mathrm{~Hz}, 10 \mathrm{~Hz}$ and $45 \mathrm{~Hz}$, respectively. In other words, this is exactly how the MMSC behaves if the bidirectional switches are disabled and, when the insertion index reaches the saturation limits, the MMSC loses control over the load voltage as it deviates from its reference. The MMSC is only capable of synthesizing the desired output voltage because it connects different grid phases to each of the submodule strings through the bidirectional switches. Therefore, the real insertion index pattern, considering the bidirectional switches enabled, is a signal represented by (8) if $-1<=S(t)<=1$ and represented by (9) if $S(t)<-1$ or if $S(t)>1$. The addition of the term $-\frac{2 \pi}{3}$ means that the submodule string is connected to a different phase of the grid. This signal is represented in Figures 9e, 10e and 11e for the cases in which the output-voltage reference has frequencies equal to $1 \mathrm{~Hz}, 10 \mathrm{~Hz}$ and $45 \mathrm{~Hz}$, respectively.

$$
S(t)=\frac{V_{r e f}}{V_{g}} \sin \left(\omega_{0} t\right)-\sin \left(\omega_{i} t+\phi-\frac{2 \pi}{3}\right)
$$

Let us analyze the frequency spectrum of the insertion-index-pattern signal for the case in which the output-voltage reference has frequency equal to $1 \mathrm{~Hz}$ (Figure 9a,c,e). In Figure 9b, one can notice that, as expected, the insertion-index-pattern signal contains only the frequencies $f_{o}=1 \mathrm{~Hz}$ and $f_{i}=50 \mathrm{~Hz}$. However, in order to analyze the more complex signals represented in Figure 9c,e, the fast Fourier transform (FFT) is necessary. The FFT tool of the software Matlab is used in this article. It is very important to notice that for the real insertion index pattern (see Figure 9e,f), the amplitude of the $1-\mathrm{Hz}$ component becomes very small. In fact, the main harmonic components of the signal frequency spectrum are represented by the following pattern:

$$
f_{S(t)}=\sum n f_{i}+\sum m f_{i} \pm f_{o}
$$

For $n=1,3,5, \ldots \infty$ and $m=2,4,6, \ldots \infty$.

Considering that the MMSC is supplying power to a RL load, the current that flows through the load (and, thus, through the submodule string because of the series connection) is equal to:

$$
i_{o}(t)=\frac{v_{r e f}(t)}{\left|R+j \omega_{0} L\right|}=\frac{V_{r e f} \sin \left(\omega_{0} t+\theta\right)}{\left|R+j \omega_{0} L\right|}
$$

In which $\theta$ is the load angle that is neglected in this case since $R>>L$ is considered. The current that flows through the submodule capacitors $\left(i_{c a p}\right)$, generating the voltage ripples, can be obtained as follows:

$$
i_{\text {cap }}(t)=S(t) i_{o}(t)
$$

The output current $\left(i_{o}(t)\right)$ is a sinusoidal signal with the output-voltage frequency $\left(\omega_{o}=2 \pi f_{o}\right)$. The insertion index pattern $(S(t))$ is a signal composed of many different frequencies (see Figures $9 \mathrm{f}, 10 \mathrm{f}$ and $11 \mathrm{f}$ and Equation (10)) including the output-voltage frequency $\left(\omega_{0}\right)$, even though with a very small amplitude. Thus, the frequency spectrum of the capacitor current $\left(i_{\text {cap }}\right)$ can be calculated based on the two following trigonometric identities:

$$
\sin \left(\omega_{1} t\right) \sin \left(\omega_{1} t\right)=\frac{1-\cos \left(2 \omega_{1} t\right)}{2}
$$

and

$$
\sin \left(\omega_{1} t\right) \sin \left(\omega_{2} t\right)=\cos \left(\left(\omega_{1}-\omega_{2}\right) t\right)-\cos \left(\left(\omega_{1}+\omega_{2}\right) t\right)
$$


In Figure 12a-c, one can observe the frequency spectrum of the capacitor current $\left(i_{\text {cap }}\right)$ obtained by multiplying the output current $\left(i_{0}\right)$, calculated according to (11), by the insertion-index signals $(S(t))$ shown in Figures 9e, 10e and 11e, respectively.
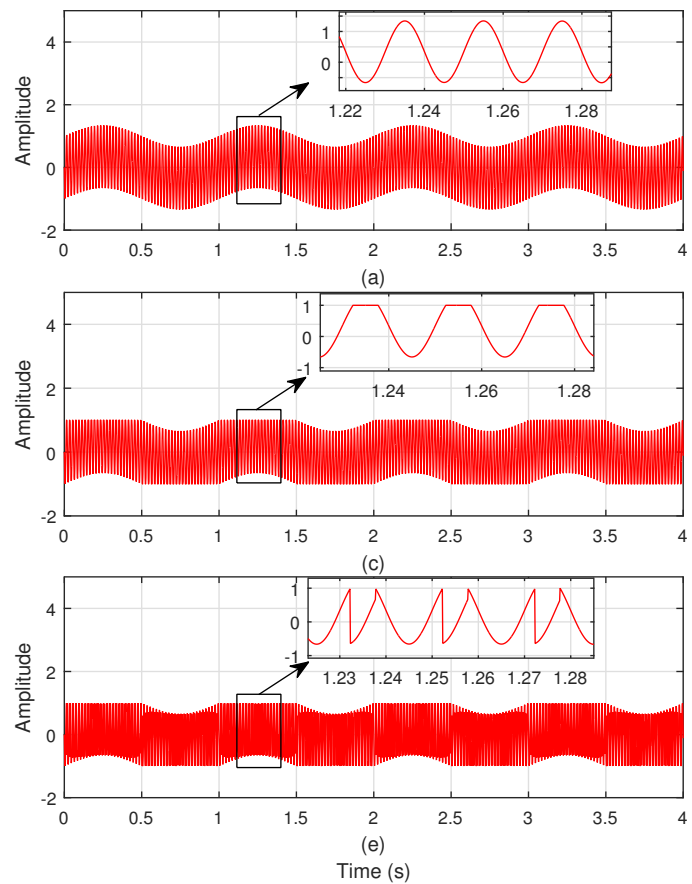
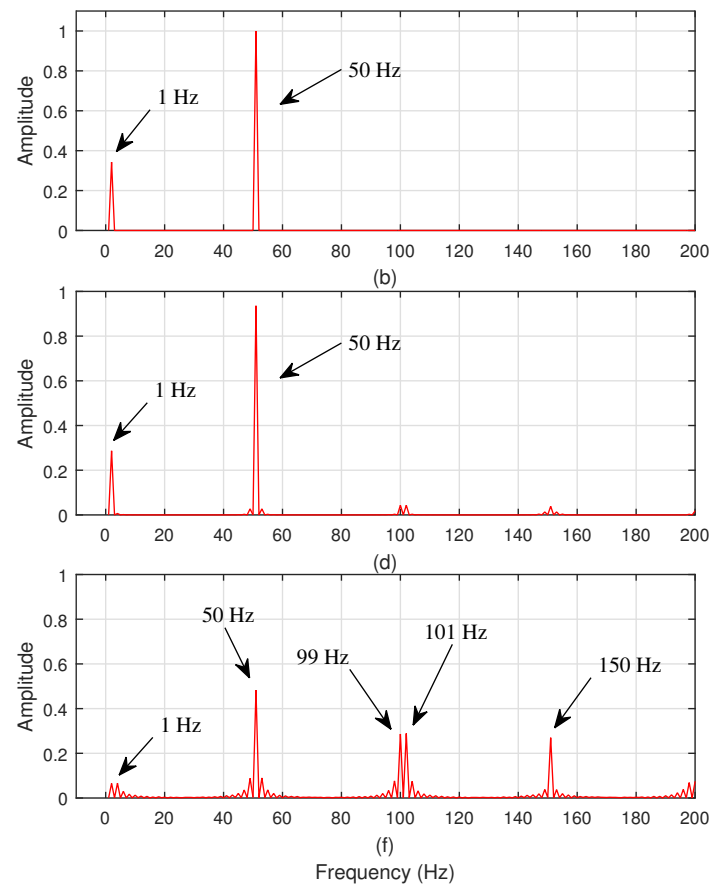

Figure 9. 1-Hz output-voltage reference: (a) ideal $S(t)$, (b) Fourier spectrum of Figure 9a, (c) real $S(t)$ with bidirectional switches disabled, (d) Fourier spectrum of Figure $9 \mathrm{c},(\mathbf{e})$ real $S(t)$ with bidirectional switches enabled and (f) Fourier spectrum of Figure 9e.
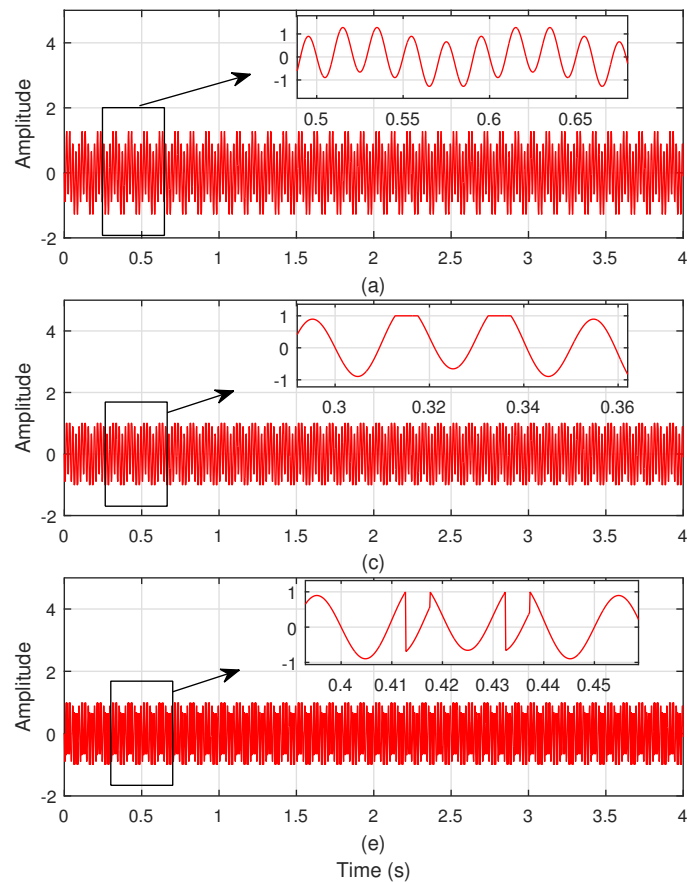
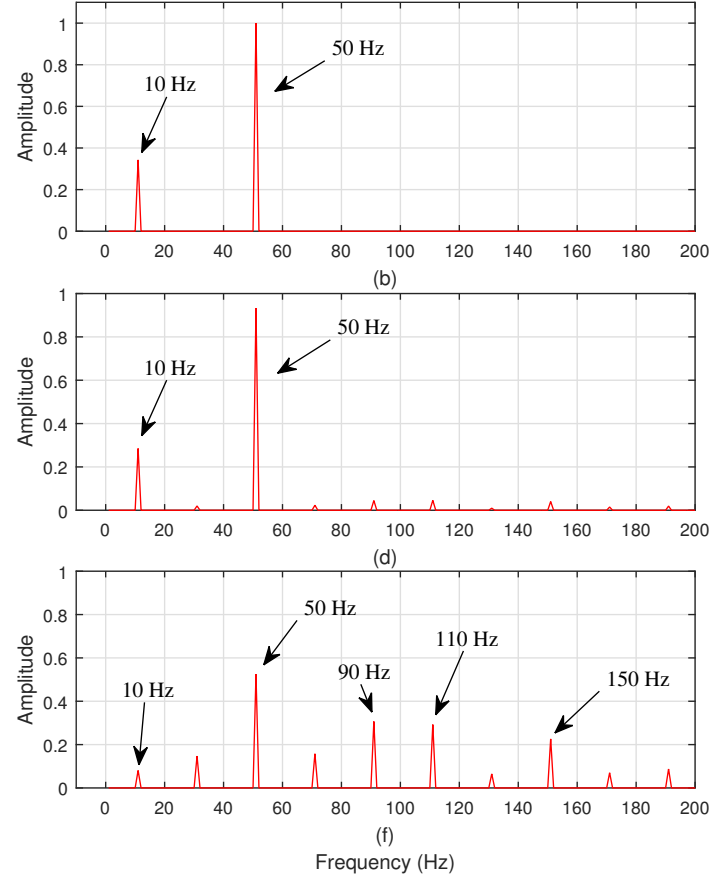

Figure 10. 10-Hz output-voltage reference: (a) ideal $S(t),(\mathbf{b})$ Fourier spectrum of Figure 10a, (c) real $S(t)$ with bidirectional switches disabled, (d) Fourier spectrum of Figure 10c, (e) real $S(t)$ with bidirectional switches enabled and (f) Fourier spectrum of Figure 10e. 

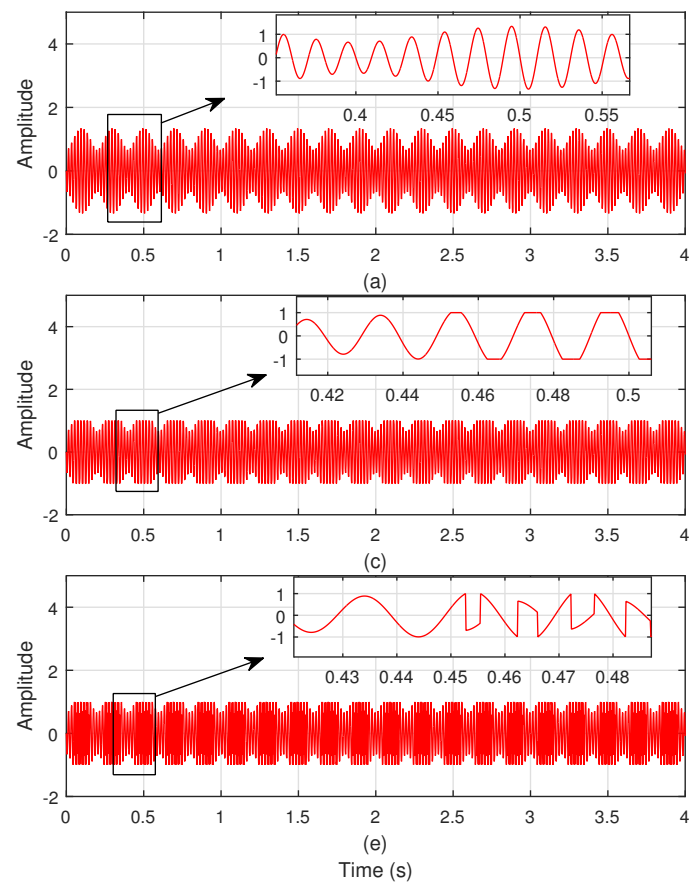
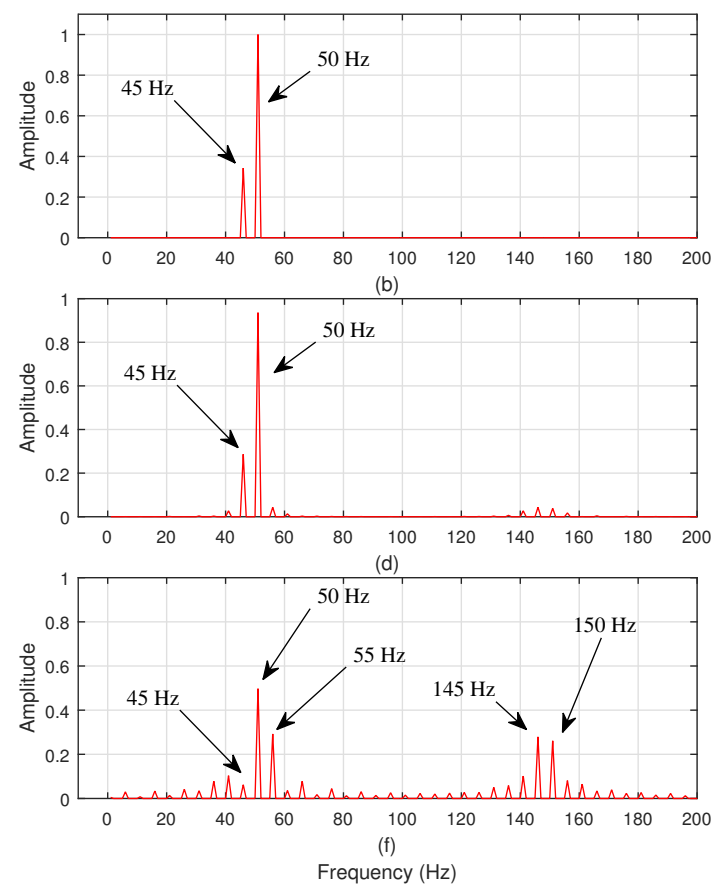

Figure 11. 45-Hz output-voltage reference: (a) ideal $S(t),(\mathbf{b})$ Fourier spectrum of Figure 11a, (c) real $S(t)$ with bidirectional switches disabled, (d) Fourier spectrum of Figure 11c, (e) real $S(t)$ with bidirectional switches enabled and (f) Fourier spectrum of Figure 11e.

The trigonometric identity shown in (13) is used to analyze the product of the sinusoidal components with frequency equal to $\omega_{0}=2 \pi f_{0}$ that are present in both $i_{o}(t)$ and $S(t)$. The result obtained is a DC component and a sinusoidal component with frequency equal to $2 \omega_{0}$, as one can confirm by taking a close look in the left-hand side of Figure 12a-c. Since the amplitude of the sinusoidal component with frequency equal to $\omega_{0}$ is very small in $S(t)$, then the DC and the $2 \omega_{0}$ components are also very small in the frequency spectrum of $i_{\text {cap }}$. In fact, this DC component is a residual component that appears due to the approximation of considering the insertion index as being a continuous signal. The DC component does not exist in reality as will be shown in the Simulation Results section. Moreover, the very small amplitude of the $2 \omega_{0}$ component illustrates the high-performance behavior of the MMSC at low frequencies. For example, this converter is able to synthesize a $1-\mathrm{Hz}$ output voltage with a capacitor current $\left(i_{\text {cap }}\right)$ without a $1-\mathrm{Hz}\left(\omega_{0}=2 \pi f_{0}\right)$ component and with a $2-\mathrm{Hz}\left(2 \omega_{0}\right)$ component with very small amplitude (see Figure $\left.12 \mathrm{a}\right)$, resulting in a submodule-capacitor voltage with low ripples. This is a huge advantage over the traditional MMC that when synthesizing a $1-\mathrm{Hz}$ output voltage, a $1-\mathrm{Hz}$ and a $2-\mathrm{Hz}$ component, with considerably high amplitudes, appear in the capacitor current, which results in intolerably high voltage ripples. This capacitor current is a consequence of the arm current (composed of a 1-Hz component and a DC component) and the MMC insertion-index pattern, which is a 1-Hz signal in this case [54].

Finally, the trigonometric identity shown in (14) is used to analyze all the other harmonic components resulting from the product of the $\omega_{0}$ component present in the output current $\left(i_{o}(t)\right)$ by all the different frequency components present in $S(t)$ (see Figures 9f, 10f and 11f). As an example, one can observe the $50-\mathrm{Hz}$ component present in $S(t)$, as illustrated in Figure 9f, for the case in which $f_{o}=1 \mathrm{~Hz}$ and, thus, $i_{0}$ is a $1-\mathrm{Hz}$ signal. The product of these two sinusoidal signals, with frequencies equal to $1 \mathrm{~Hz}$ and $50 \mathrm{~Hz}$, results in a $49-\mathrm{Hz}$ and a $51-\mathrm{Hz}$ components in the capacitor current $\left(i_{\text {cap }}\right)$, according to (14). This fact is confirmed in Figure 12a.

It is important to emphasize that as the load-voltage frequency $\left(f_{o}\right)$ comes close to the grid frequency $\left(f_{i}=50 \mathrm{~Hz}\right)$, the performance of the MMSC is deteriorated, regarding the amplitude of the voltage ripples in the submodule capacitors. By analyzing Figure 12c, and according to Equation (14), for the $45-\mathrm{Hz}$ case, a $5-\mathrm{Hz}$ current component appears flowing through the submodule capacitor. 
If the load-voltage frequency was $49 \mathrm{~Hz}$, instead, then a 1-Hz current component would appear flowing through the submodule capacitor. The MMSC performance, regarding submodule-capacitor voltage ripples, is opposite to the performance of the conventional MMC. The conventional MMC presents good performance for frequencies close to the grid frequency, but poor performance at low frequencies. The MMSC has improved performance at low frequencies, but deteriorated performance as the load-voltage frequency comes close to the grid frequency. It is important to highlight that this is a similar behavior in comparison to the MMMC.

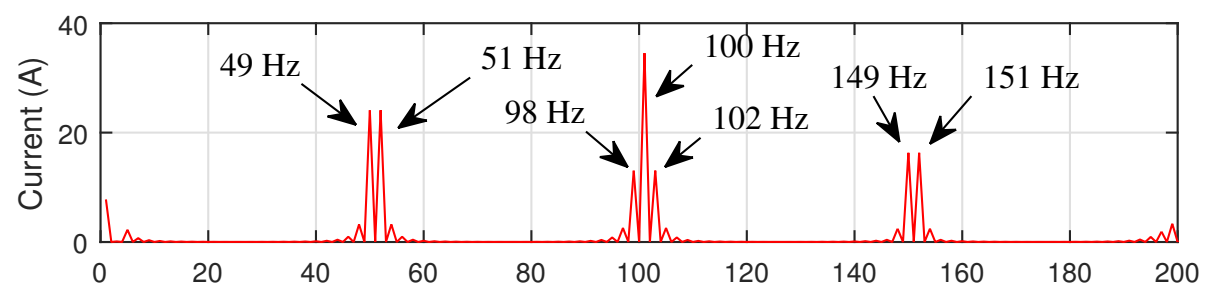

(a)

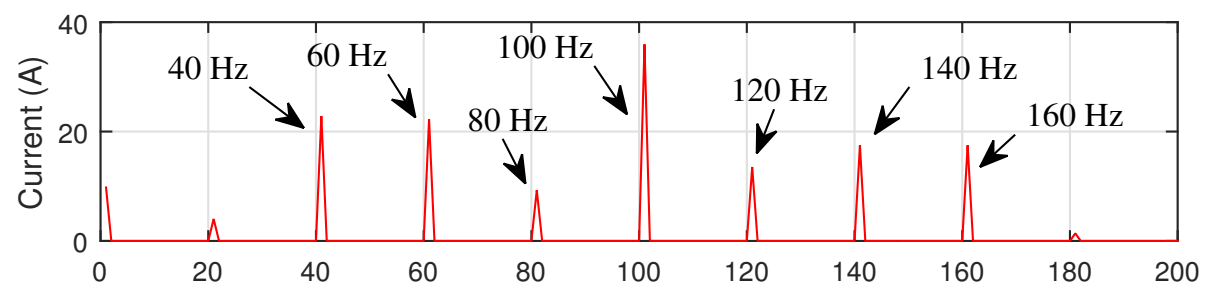

(b)

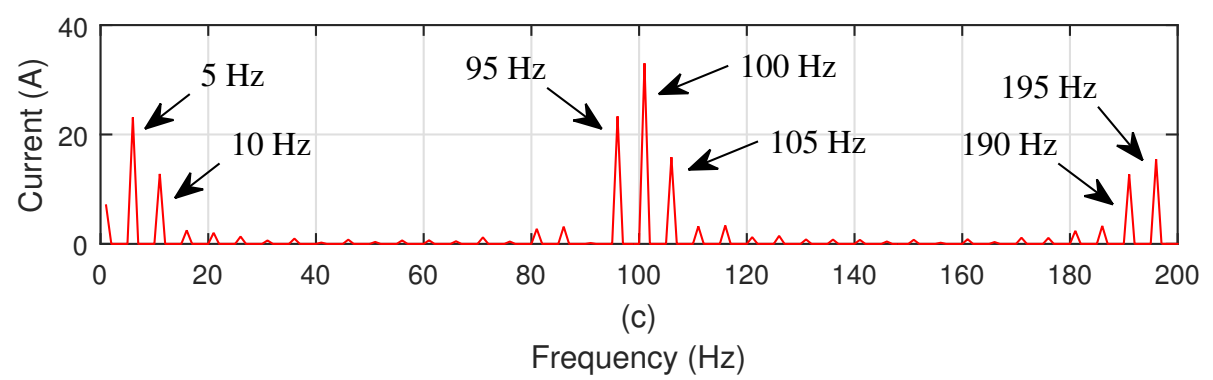

Figure 12. (a) Calculated $i_{\text {cap }}$ for the $1-\mathrm{Hz}$ output-voltage reference, (b) calculated $i_{\text {cap }}$ for the $10-\mathrm{Hz}$ output-voltage reference and (c) calculated $i_{\text {cap }}$ for the $45-\mathrm{Hz}$ output-voltage reference.

\section{Comparison Analysis}

To prove the structural advantages of the MMSC, a detailed comparison analysis is carried out between the MMSC and the MMC, which is the most established converter topology for high-power applications. This comparison analysis is divided into two parts: First, the cost, size and weight analysis is carried out, which is based on the total number of components of each converter solution; Second, the efficiency analysis is carried out, which is based on both conduction and switching losses. In these analyses, two assumptions are made to obtain a fair comparison between the two topologies. First, it is considered that in both converter solutions, the same semiconductor devices are used. In other words, the same diodes and the same IGBTs with same voltage and current ratings are used. The authors selected as a reference the commercial IGBT SEMITRANS 2 SKM 145GB176D from SEMIKRON. This semiconductor device presents the following characteristics: $V_{C E S}=1.7 \mathrm{kV}, i_{C n o m}=100 \mathrm{~A}$, $t_{d(o n)}=250 \mathrm{~ns}, t_{d(o f f)}=630 \mathrm{~ns}$ and $V_{C E(s a t)}=2 \mathrm{~V}$, in which $V_{C E S}$ is the collector-to-emitter voltage (maximum voltage that the IGBT can block), $i_{C n o m}$ is the nominal collector current, $t_{d(o n)}$ and $t_{d(o f f)}$ are the commutation period when the devices are turned on and turned off, respectively, and $V_{C E(s a t)}$ 
is the collector-to-emitter saturation voltage in on state. Two simplifications are made: First, is to consider $V_{C E S}=2 \mathrm{kV}$, which simplifies calculations; The second is to consider $t_{d(o n)}=t_{d(\text { off })}=250 \mathrm{~ns}$. The second assumption is to consider that both converters must synthesize an output voltage equal to $V_{o}=10 \mathrm{kV}$ (phase-to-ground peak value), while providing power to the same RL load, resulting in an identical AC current with rms value equal to $I_{A C}=100 \mathrm{~A}$.

\section{1. $M M C$}

The topology of the MMC analyzed in this paper is shown in Figure 1. This is a converter in a back-to-back configuration that is composed of 12 arms. Each arm is composed of $N$ HB submodules, along with an arm inductor. Each HB submodule is composed of two IGBTs, two diodes and one capacitor. In Figure 13, one can observe a representation of the MMC in which each of its submodules is represented by a DC-voltage source. If a given AC voltage $v_{A C}$, with a given amplitude $V_{o}$ (phase-to-ground, peak value) is to be synthesized, then, ideally, the minimum value required of the DC-link voltage should be equal to [47]:

$$
V_{D C} \geq 2 V_{o}
$$

In other words, if the MMC DC-link voltage is equal to $V_{D C}$, then the maximum possible amplitude of the voltage synthesized at its $\mathrm{AC}$ side $\left(v_{A C}\right)$ is equal to $\frac{V_{D C}}{2}$. Moreover, the sum of the average values of the capacitor voltages of all submodules in one arm should be equal to $V_{D C}$, so that it is possible to keep the DC-link voltage regulated, with the reference value equal to $V_{D C}$, in every operation point. Thus, the average value of the capacitor voltage in each submodule should be controlled to be equal to $\frac{V_{D C}}{N}$. In order for the MMC to synthesize a given AC voltage $\left(v_{A C}\right)$, with a given frequency $f_{o}$, the upper and lower arms should operate according to an insertion-index pattern $(S(t))$ described by a discrete signal that varies from 0 to $N$, with frequency equal to $f_{0}$, representing the instantaneous number of submodules inserted in series. In Figure 13, one can observe the representation of an inserted and a by-passed HB submodule, in which the green color represents the current path, whereas the red color represents the open-circuit path. When the HB submodule is inserted, the MMC arm current $\left(I_{\text {arm }}\right)$ flows through one of its IGBTs, and through the submodule capacitor, and the submodule terminal voltage is equal to the capacitor voltage $\left(\frac{V_{D C}}{N}\right)$. When the HB submodule is by-passed, the MMC arm current flows through the other IGBT and the submodule terminal voltage is null. In a three-phase MMC, the arm current is represented by:

$$
I_{\text {arm }}=\frac{I_{A C}}{2}+\frac{I_{D C}}{3}
$$

In which $I_{A C}$ is the rms value of the AC current $\left(i_{A C}\right)$ and $I_{D C}$ is the DC-link current. In order to analyze the switching losses, it is necessary to observe the currents and voltages in each IGBT in the commutation process between each switching state. In this paper, the authors analyze the average switching losses since the rms values of the AC quantities are considered, instead of their instantaneous values. Every time a new HB submodule is inserted or by-passed, two IGBTs change their switching state (from on state to off state or from off state to on state). In the commutation process, one IGBT changes from conducting $I_{\text {arm }}$ to conducting null current, and from blocking null voltage to blocking $\frac{V_{D C}}{N}$, whereas the other IGBT changes from conducting null current to conducting $I_{\text {arm }}$, and from blocking $\frac{V_{D C}}{N}$ to blocking null voltage. During the commutation, both IGBTs present current and voltage values different of zero. The commutation occurs during the times $t_{d(o n)}$ and $t_{d(o f f)}$, depending if the IGBT is being turned on or turned off, respectively. The switching losses are equal to the energy lost in this process, or the integration of the instantaneous power values of both upper and lower IGBTs during the commutation period. According to the graphs shown in Figure 13, the peak of the power curve presents a value equal to: 


$$
P_{I G B T}=\frac{V_{D C}}{2 N} \frac{I_{\text {arm }}}{2}
$$

In this paper, two approximations are made: First, it is considered that $t_{d(\text { on })}=t_{d(\text { off })}$; The second is to consider that during the commutation, the power is a constant signal with value equal to the peak of the power curve as described in (17) (see Figure 13). The same approach will be adopted in the MMSC case and, thus, a fair comparison between the two converters can be carried out. Instead of considering that every time a new submodule is inserted or by-passed, two IGBTs present switching losses with value represented by (17), the authors consider that one equivalent IGBT presents double the losses, which is equal to:

$$
P_{\text {Loss } H B}=\frac{V_{D C}}{2 N} I_{\text {arm }}
$$

In other words, (18) represents the switching losses that occur every time one HB submodule is inserted or by-passed.
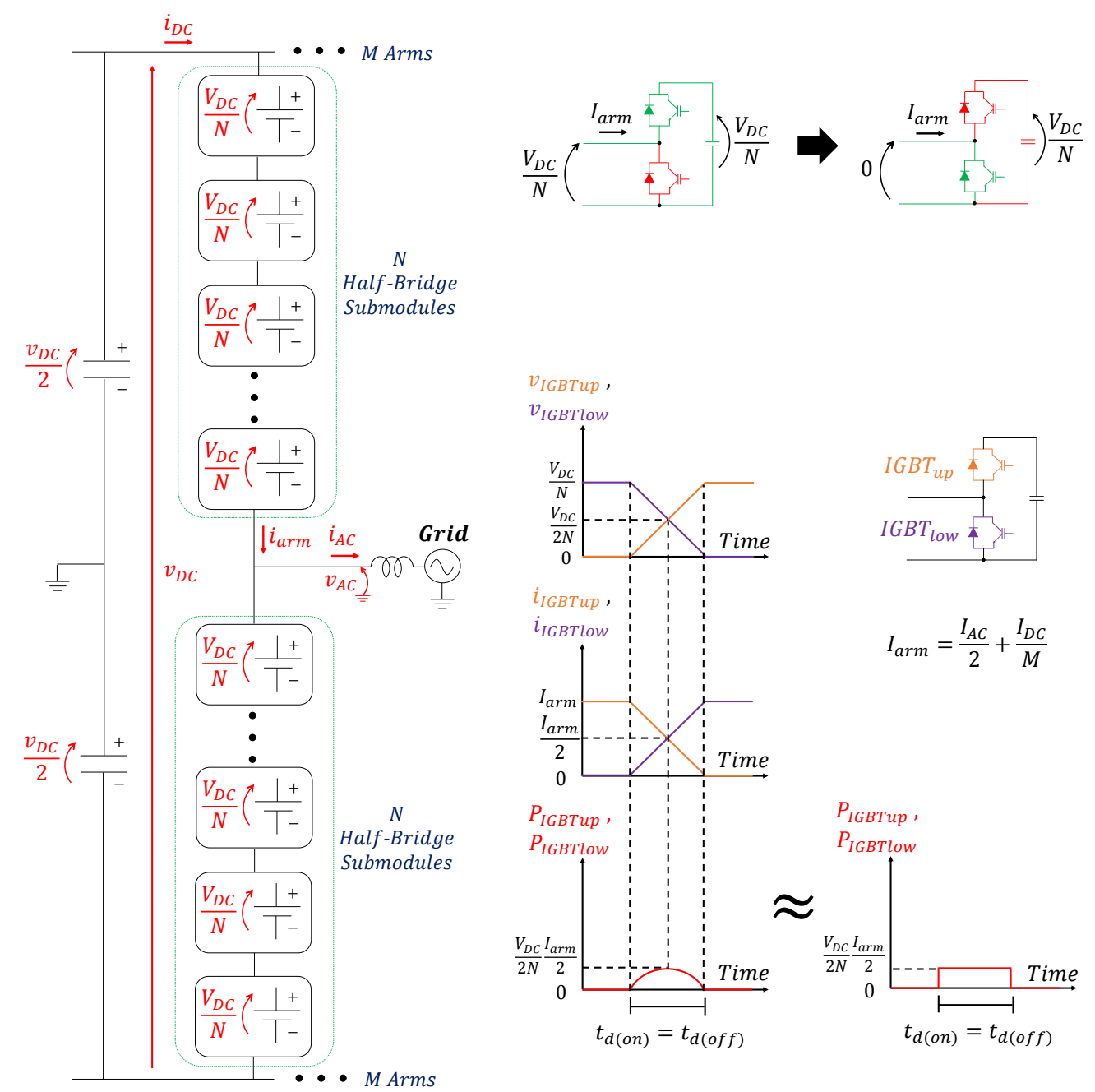

Figure 13. MMC characteristics.

\subsubsection{Number of Components}

The MMC DC-link voltage should be designed according to Equation (15), which means that the optimal value of the DC-link voltage is equal to $V_{D C}=20 \mathrm{kV}$. Then, considering that $V_{C E S}=2 \mathrm{kV}$ and considering that the submodule capacitor voltage must be equal to $\frac{V_{D C}}{N}$ (see Figure 13), then the ideal number of submodules in each arm can be calculated as follows: 


$$
\frac{V_{D C}}{N}=V_{C E S}
$$

which leads to $N=10$ submodules per arm. Since this is a back-to-back MMC, then the entire solution presents 12 arms. Each HB submodule is composed of two IGBTs, two diodes and one capacitor, besides DC-voltage sensor and driver. Thus, the MMC solution is composed of $12 \times 10 \times 2=240$ IGBTs, 240 diodes and $12 \times 10 \times 1=120$ capacitors. Other components that should be considered are the arm inductors. The back-to-back MMC requires 12 considerably bulky arm inductors, used to avoid short circuits between the converter arms and to mitigate undesired AC circulating currents.

\subsubsection{Conduction Losses}

As previously mentioned, the current that flows through each arm of the $\mathrm{MMC}$, considering that all the undesired AC-circulating-current components are suppressed, is the one described in Equation (16). In order to obtain a relationship between the MMC AC and DC currents, the approximation $P_{A C}=P_{D C}$ is considered, which leads to:

$$
\sqrt{3}\left(\frac{\sqrt{3}}{\sqrt{2}} V_{o}\right) I_{A C}=V_{D C} I_{D C}
$$

Considering that the reactive power is null. Equation (20) can be rewritten as follows:

$$
I_{D C}=\left(\frac{3}{\sqrt{2}}\right) \frac{V_{o}}{V_{D C}} I_{A C}
$$

By substituting $V_{o}=10 \mathrm{kV}$ and $V_{D C}=20 \mathrm{kV}$ into (21), the following is obtained:

$$
I_{D C}=1.06 I_{A C}
$$

By substituting (22) into (16), the following is obtained:

$$
I_{\text {arm }}=0.85 I_{A C}
$$

Once again, this is a back-to-back MMC and it is considered that the same AC voltage that is synthesized at the load side (with amplitude equal to $V_{o}=10 \mathrm{kV}$ ) is also synthesized at the grid side, in such a way that the AC current that flows to the grid has the same rms value as the load current, which is equal to $I_{A C}$. Thus, the arm current, represented in (23), flows simultaneously through each of the 12 arms that compose the MMC. Since the MMC is composed of HB submodules, then the arm current flows through one IGBT per submodule, no matter if the submodule is inserted or by-passed. Thus, the arm current will flow simultaneously through $12 \times 10 \times 1=120$ IGBTs. Finally, the MMC total conduction losses can be calculated as follows:

$$
P_{C L o s s}=120 V_{C E(s a t)} I_{\text {arm }}
$$

By substituting (23) into (24), and by remembering that $V_{C E(s a t)}=2 \mathrm{~V}$ and $I_{A C}=100 \mathrm{~A}$, the value obtained for the MMC conduction losses is equal to:

$$
P_{\text {CLoss }}=20.4 \mathrm{~kW}
$$

\subsubsection{Switching Losses}

As highlighted in Figure 13, every time a HB submodule is inserted or by-passed, a switching loss occurs, for a period equal to $t_{d(o n)}=t_{d(o f f)}=250 \mathrm{~ns}$, which is described by Equation (18). Then, by substituting (23) into (18), and by remembering that $V_{D C}=20 \mathrm{kV}, N=10$ and $I_{A C}=100 \mathrm{~A}$, the following is obtained:

$$
P_{\text {LossHB }}=85 \mathrm{~kW}
$$


The energy that is lost every time a HB submodule is inserted or by-passed $\left(E_{o n H B}=E_{o f f H B}\right)$ can be calculated as follows:

$$
E_{o n H B}=E_{o f f H B}=t_{d(o n)} P_{\text {Loss HB }}=0.02125 \mathrm{Ws}
$$

To obtain a fair comparison with the MMSC, the level-shifted-carrier pulse-width-modulation (LSC-PWM) technique will be used, in the MMC case, with carrier frequency equal to $f_{c}=1500 \mathrm{~Hz}$, which is selected with the following criteria: lower frequency possible in order to obtain an AC current with similar power quality in comparison to the MMSC case. Still considering that $V_{D C}=20 \mathrm{kV}$, $V_{o}=10 \mathrm{kV}, N=10$ submodules per arm and that the MMC provides power to a RL load ( $R=100 \Omega$ and $L=50 \mathrm{mH}$ illustrating the impedance of a high-power electrical machine), let us suppose that the frequency of the AC voltage to be synthesized assumes three different values equal to $f_{o}=1,10$ and $45 \mathrm{~Hz}$. The insertion-index signals $(S(t))$, of both upper and lower arms of one phase of the MMC, are illustrated in Figure 14a-c for the frequency values equal to $f_{o}=1,10$ and $45 \mathrm{~Hz}$, respectively. In Figure $14 \mathrm{~d}-\mathrm{f}$, one can observe the synthesized load voltage for the frequency values equal to $f_{o}=1,10$ and $45 \mathrm{~Hz}$, respectively. In Figure $14 \mathrm{~g}-\mathrm{i}$, one can observe the resulting load current for the frequency values equal to $f_{o}=1,10$ and $45 \mathrm{~Hz}$, respectively.

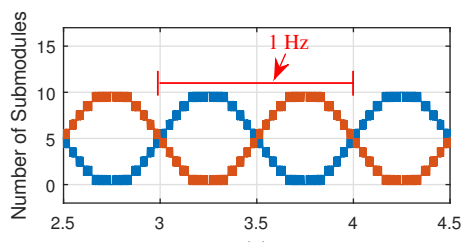

(a)

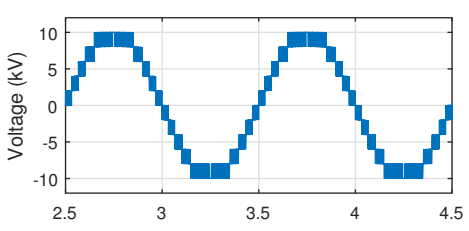

(d)

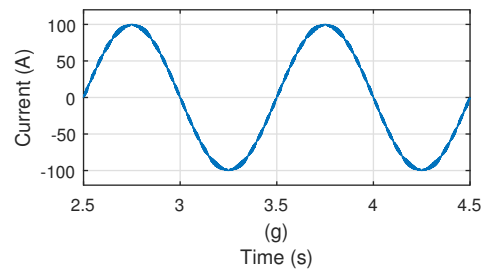

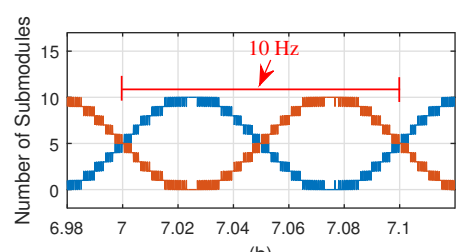

(b)
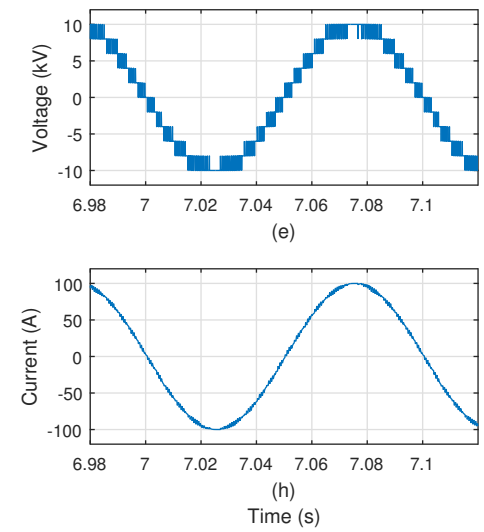

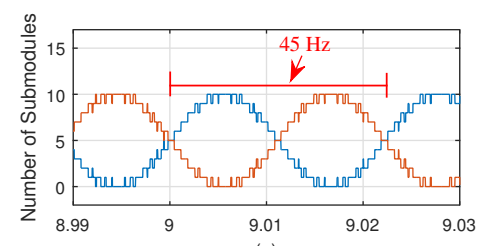

(c)
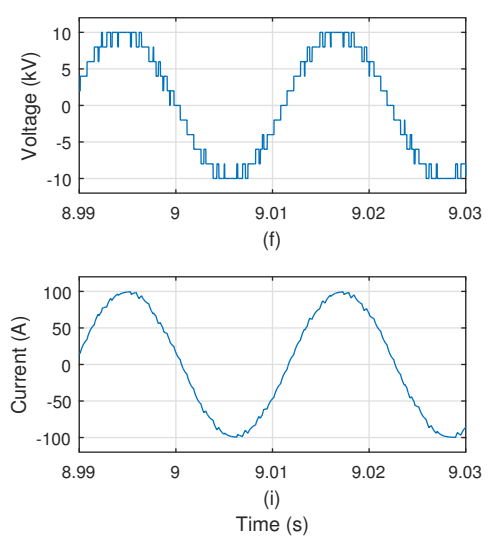

Figure 14. MMC upper and lower-arm insertion-index signal: (a) $f_{o}=1 \mathrm{~Hz},(\mathbf{b}) f_{o}=10 \mathrm{~Hz}$ and (c) $f_{o}=45 \mathrm{~Hz}$. MMC load voltage: (d) $f_{o}=1 \mathrm{~Hz}$, (e) $f_{o}=10 \mathrm{~Hz}$ and (f) $f_{o}=45 \mathrm{~Hz}$. MMC load current: (g) $f_{o}=1 \mathrm{~Hz}$, (h) $f_{o}=10 \mathrm{~Hz}$ and (i) $f_{o}=45 \mathrm{~Hz}$.

Let us analyze the $f_{o}=10-\mathrm{Hz}$ case. In Figure $14 \mathbf{b}$, one can observe the insertion-index signal for the $f_{o}=10-\mathrm{Hz}$ case and the total number of steps, in one period of the fundamental frequency, is equal to 264 steps and it is obtained by counting. Every time there is one step change, one HB submodule is inserted or by-passed, which corresponds to a switching loss with value represented in Equation (26). However, this power loss only occurs for a short period of time equal to the commutation period $\left(t_{d(o n)}\right)$, and the total energy lost is the one represented in (27). In order to understand the actual switching losses, it is necessary to know the frequency in which the submodules are inserted or by-passed. As previously mentioned, one arm of the MMC will present 264 step changes in the period of $t=\frac{1}{10 \mathrm{~Hz}}=0.1 \mathrm{~s}$. Since the load side of the MMC is composed of six arms, then it is possible to say that there will occur $264 \times 6=1584$ step changes in the period of $t=\frac{1}{10 \mathrm{~Hz}}=0.1 \mathrm{~s}$. Thus, in $1 \mathrm{~s}$, there will occur 15,840 step changes. In other words, it is possible to say that the HB submodules are inserted and by-passed with a frequency equal to $15,840 \mathrm{~Hz}$, or that, in $1 \mathrm{~s}$, one new submodule 
will be inserted or by-passed 15,840 times. Every time one new submodule is inserted or by-passed an energy loss occurs, which is represented by (27). Thus, the switching losses of the load side of the MMC can be calculated as: $15,840 E_{\text {on } H B}=336.6 \mathrm{~W}$. However, the grid side of the MMC operates with a fixed frequency equal to $f_{i}=50 \mathrm{~Hz}$. In this case, the total number of steps, in one period of the fundamental frequency, is equal to 50 steps, in the period of $t=\frac{1}{50 \mathrm{~Hz}}=0.02 \mathrm{~s}$, and it is obtained by counting. Since the grid side of the MMC is composed of six arms, then it is possible to say that there will occur $50 \times 6=300$ step changes is the period of $t=\frac{1}{50 \mathrm{~Hz}}=0.02 \mathrm{~s}$. Thus, in $1 \mathrm{~s}$, there will occur 15,000 step changes. In other words, it is possible to say that the HB submodules are inserted and by-passed with a frequency equal to $15,000 \mathrm{~Hz}$, or that, in $1 \mathrm{~s}$, one new submodule will be inserted or by-passed 15,000 times. The switching losses of the grid side of the MMC can be calculated as: $15,000 E_{\text {On } H B}=318.75 \mathrm{~W}$. Finally, the total switching losses of the MMC, when operating with $f_{o}=10 \mathrm{~Hz}$ at the load side, is equal to:

$$
P_{\text {SLoss }}=336.6+318.75=655.35 \mathrm{~W}
$$

The MMC switching losses for different load-frequency values are summarized in Section 5.3.

\subsection{MMSC}

The MMSC is composed of three strings of FB submodules along with six bidirectional switches and a band-pass current filter. Each FB submodule is composed of four IGBTs, four diodes and one capacitor. Each bidirectional switch is composed of two IGBTs and two diodes. However, since this converter is proposed for medium-voltage applications, then series-connected semiconductor devices are required to build the bidirectional-switch valve that must be able to block the line-to-line grid voltage. In Figure 15, one of the three single-phase converters that composes the MMSC is represented by a string of DC-voltage sources (that can be connected with positive and negative polarities representing the FB submodules) and two switches connecting the string to two different phases of the grid. As previously explained, the average value of the MMSC submodule-capacitor voltages is equal to approximately $\frac{V_{g}}{N}$, in steady state. Thus, the DC-voltage sources, in the representation shown in Figure 15, present value equal to $\frac{V_{g}}{N}$. Once again, the basic operation of the MMSC consists of synthesizing a given series voltage $\left(v_{S}\right)$, depending on the instantaneous value of the grid voltage $\left(v_{g a}\right)$, in such a way as to obtain the desired voltage at the load terminals $\left(v_{A C}\right)$. In other words, according to Kirchhoff's law:

$$
v_{g a}+v_{s}-v_{A C}=0
$$

Therefore:

$$
v_{S}(t)=v_{A C}(t)-v_{g a}(t)=V_{o} \sin \left(\omega_{o} t\right)-V_{g} \sin \left(\omega_{i} t+\phi\right)
$$

in which $V_{o}$ corresponds to the phase-to-ground, peak value of the AC voltage to be synthesized at the load terminals, and $\omega_{0}$ and $\omega_{i}$ are the angular speed values corresponding to the load-voltage frequency $\left(f_{o}\right)$ and grid-voltage frequency $\left(f_{i}\right)$, respectively. Since the DC voltage of each submodule is equal to $\frac{V_{g}}{N}$, then if all the submodules are inserted, the voltage synthesized in series will be equal to $V_{g}$ or $-V_{g}$, depending on the polarity of the FB submodules inserted. In other words, this is the maximum voltage value that the MMSC is capable of synthesizing in series. Considering that the grid-voltage frequency and the load-voltage frequency are different, then, according to (30), there will be moments in which the absolute value of the instantaneous voltage to be synthesized in series $\left(\left|v_{\mathcal{S}}\right|\right)$ will be higher than $V_{g}$ and, thus, the converter would lose control over the load voltage. At these moments, the bidirectional switches are used to connect the submodule string to the other phase of the grid, phase B in this case. Then, the new instantaneous value of the voltage to be synthesized in series will be equal to:

$$
v_{S}=v_{A C}-v_{g b}
$$


In other words:

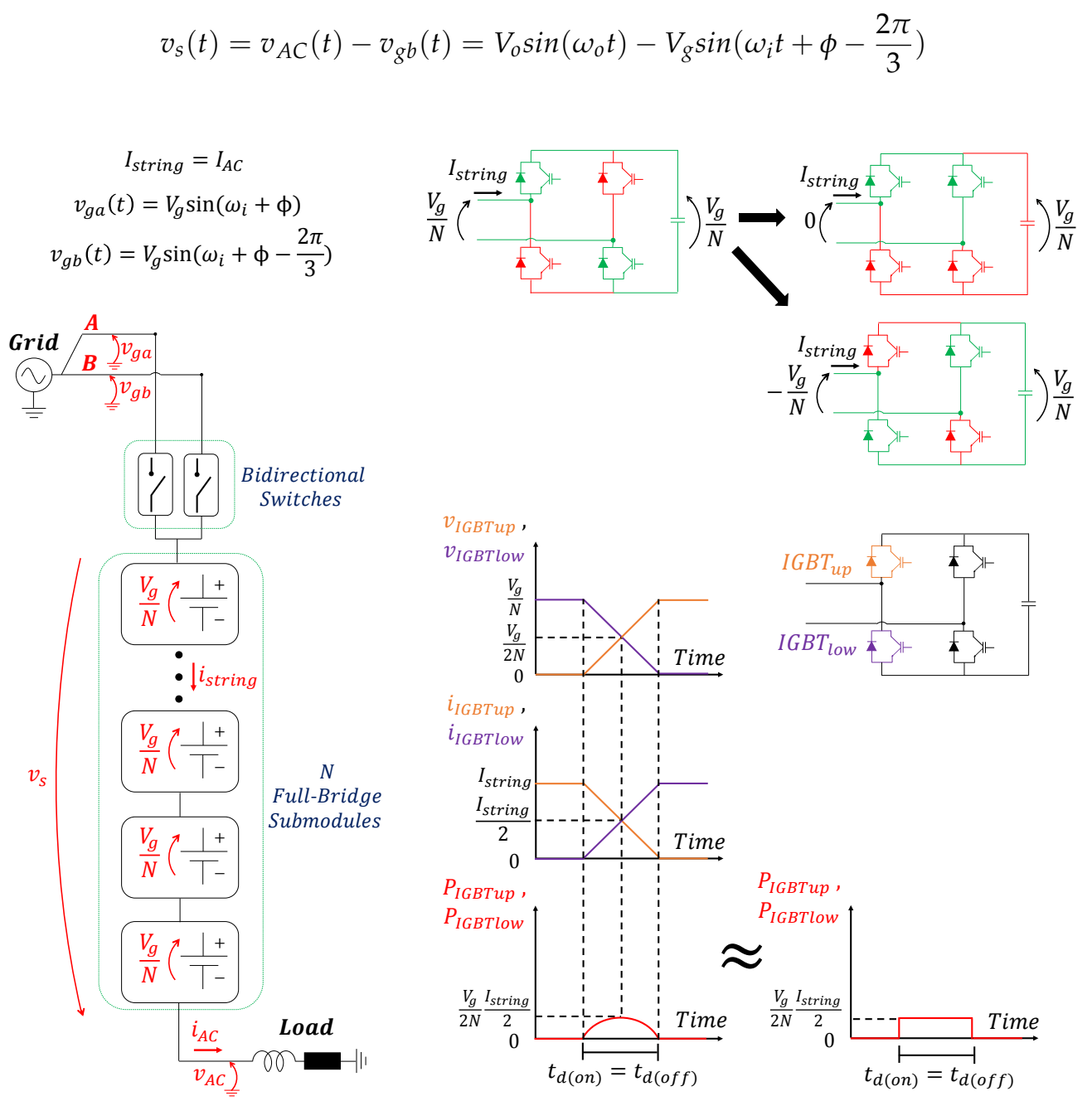

Figure 15. MMSC characteristics.

In this case, the absolute value of $v_{s}$ will necessarily be lower than $V_{g}$ and, thus, the MMSC maintains control over the load voltage. As an example, let us suppose that one wants to control the load voltage $\left(v_{A C}\right)$, according to a given reference $\left(v_{r e f}\right)$. In other words, $v_{A C}=v_{r e f}$. Let us also suppose that the voltage reference has frequency equal to $10 \mathrm{~Hz}\left(f_{o}=10 \mathrm{~Hz}\right)$ and amplitude equal to $10 \mathrm{kV}\left(V_{o}=10 \mathrm{kV}\right)$. In this case, let us suppose that the grid voltage has frequency equal to $50 \mathrm{~Hz}\left(f_{i}=50 \mathrm{~Hz}\right)$ and amplitude equal to $20 \mathrm{kV}\left(V_{g}=20 \mathrm{kV}\right)$. According to this example, the voltage reference $\left(v_{r e f}\right)$, phase $\mathrm{A}\left(v_{g a}\right)$ and phase $\mathrm{B}\left(v_{g b}\right)$ of the grid voltage are shown in Figure 16. If one observes the instant highlighted in Figure 16a, they will notice that at this moment, the absolute value of the voltage that needs to be synthesized in series $\left(\left|v_{s}\right|=\left|v_{r e f}-v_{g a}\right|\right)$ is higher than $V_{g}$, which is the maximum value that the converter is capable of synthesizing. However, if the submodule string is connected to phase $B$, then the absolute value of the new voltage that needs to be synthesized in series $\left(\left|v_{s}\right|=\left|v_{r e f}-v_{g b}\right|\right)$ will be lower than $V_{g}$. 


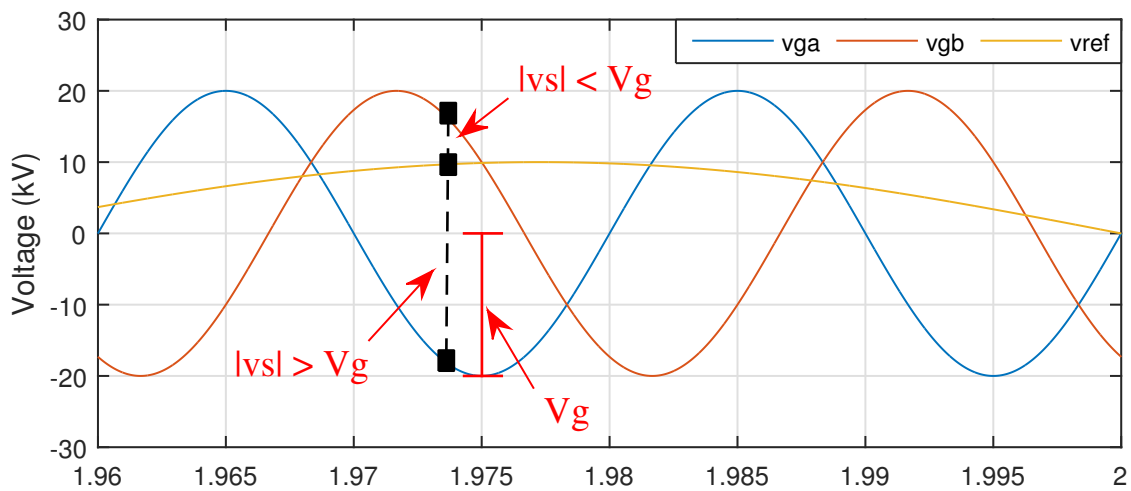

(a)

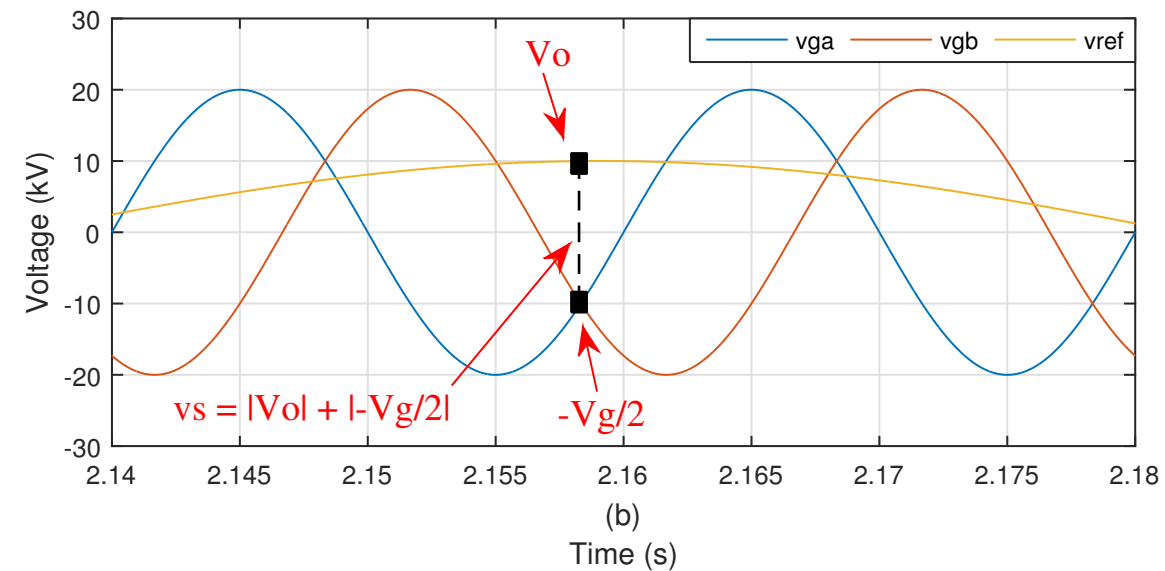

Figure 16. Design criteria explanation. $(\mathbf{a}, \mathbf{b})$ illustrate the phase-A grid voltage $\left(v_{g a}\right)$, the phase-B grid voltage $\left(v_{g a}\right)$ and the load-voltage reference $\left(v_{r e f}\right)$.

These curves define one of the design criteria of the converter as illustrated in Figure 16b. In other words, as previously mentioned, the maximum voltage value that the MMSC is capable of synthesizing in series is $V_{g}$. The instant that is highlighted in Figure 16b illustrates a situation in which the peak of the voltage reference meets the moment in which $v_{g a}$ and $v_{g b}$ have the same instantaneous value (equal to $\frac{V_{g}}{2}$ ) and opposite polarity in relation to the reference. This is the worst-case scenario that corresponds to the highest value of $v_{s}$, no matter if the string of submodules is connected to phase A or phase B of the grid. In this example, this moment corresponds to an instant in which the instantaneous value of the voltage reference is $v_{\text {ref }}=V_{o}=10 \mathrm{kV}$, and the instantaneous value of phase $\mathrm{A}$ and phase $\mathrm{B}$ of the grid voltage is equal to $v_{g a}=v_{g b}=-\frac{V_{g}}{2}=-\frac{20}{2}=-10 \mathrm{kV}$. Thus, at this moment, the voltage that must be synthesized in series would be equal to $\left|v_{\mathcal{S}}\right|=\left|V_{o}-\left(-\frac{V_{g}}{2}\right)\right|=20 \mathrm{kV}$, no matter if the string of submodules were connected to phase A or phase B of the grid. Fortunately, this is equal to the maximum voltage that the MMSC is capable of synthesizing in series in this case $\left(V_{\text {smax }}=V_{g}=20 \mathrm{kV}\right)$. For example, if the grid-voltage amplitude were equal $V_{g}=18 \mathrm{kV}$ instead, then, at the same moment illustrated in Figure 16b, the voltage to be synthesized in series would be equal to $\left|v_{s}\right|=\left|V_{o}-\left(-\frac{V_{g}}{2}\right)\right|=10+9=19 \mathrm{kV}$, but the maximum voltage that the MMSC would be able to synthesize would be equal to $V_{\text {smax }}=V_{g}=18 \mathrm{kV}$. Thus, the MMSC would lose control over the load voltage. To sum up, this analysis defines the minimum necessary value of the grid voltage, so that the MMSC can synthesize the desired load voltage for all the operation points. In other words: 


$$
V_{\text {smax }}=V_{g} \geq V_{o}+\frac{V_{g}}{2}
$$

And thus:

$$
V_{g} \geq 2 V_{o}
$$

This is a very important design criteria for the MMSC that defines the number of submodules connected in series in one string, as well as the number of series-connected semiconductor devices required to build the bidirectional-switch valves. This analysis will be used to calculate the number of components of the MMSC. As described in Figure 15, the FB submodules present three different possible states: inserted with positive polarity (terminal voltage equal to $\frac{V_{g}}{N}$ ), inserted with negative polarity (terminal voltage equal to $-\frac{V_{g}}{N}$ ) or by-passed (terminal voltage equal to 0 ). Every time one FB submodule is inserted or by-passed (terminal voltage changing from $\frac{V_{g}}{N}$ to 0 , or vice versa, or changing from $-\frac{V_{g}}{N}$ to 0 , or vice versa), two IGBTs change their switching states. In the commutation process, one IGBT changes from conducting $I_{\text {string }}=I_{A C}$ to conducting null current, and from blocking null voltage to blocking $\frac{V_{g}}{N}$, whereas the other IGBT changes from conducting null current to conducting $I_{\text {string, }}$, and from blocking $\frac{V_{g}}{N}$ to blocking null voltage. However, when a polarity inversion occurs (terminal voltage changing from $\frac{V_{g}}{N}$ to $-\frac{V_{g}}{N}$, or vice versa), four IGBTs change their switching states. In the commutation process, two IGBTs change from conducting $I_{\text {string }}$ to conducting a null current, and from blocking null voltage to blocking $\frac{V_{g}}{N}$, whereas the other two IGBTs change from conducting null current to conducting $I_{\text {string, }}$, and from blocking $\frac{V_{g}}{N}$ to blocking null voltage. During the commutation, all the IGBTs have current and voltage values different of zero. The switching losses are equal to the energy lost in this process, or the integration of the instantaneous power values of all IGBTs during the commutation period. According to the graphs shown in Figure 15, the peak of the power curve presents a value equal to:

$$
P_{I G B T}=\frac{V_{g}}{2 N} \frac{I_{\text {string }}}{2}
$$

The same approximations as in the MMC case are made: First it is considered that $t_{d(o n)}=t_{d(o f f)}$; The second is to consider that during the commutation, the power is a constant signal with value equal to the peak of the power curve as described in Equation (35) (see Figure 15). Instead of considering that two IGBTs present switching losses equal to the value described in (35), the authors consider that one equivalent IGBT presents double the losses, which is equal to:

$$
P_{I G B T}=\frac{V_{g}}{2 N} I_{\text {string }}
$$

Thus, every time a FB submodule is inserted or by-passed a switching loss occurs which is equal to:

$$
P_{\text {LossFB1 }}=\frac{V_{g}}{2 N} I_{\text {string }}
$$

And every time a FB submodule suffers a polarity inversion, a switching loss occurs which is equal to:

$$
P_{\text {LossFB2 }}=\frac{V_{g}}{N} I_{\text {string }}
$$

To consider the switching losses of the bidirectional-switch valves, one may observe Figure 17. Every time the submodule string is connected to a different phase of the grid, one of the bidirectional-switch valves changes from conducting null current to conducting the string current $\left(I_{\text {string }}\right)$ and from blocking the grid line-to-line voltage $\left(V_{g a b}\right)$ to blocking null voltage, while the other bidirectional-switch valve changes from conducting the string current $\left(I_{\text {string }}\right)$ to conducting null current and from blocking null voltage to blocking the grid line-to-line voltage $\left(V_{g a b}\right) . V_{g a b}$ is the 
rms value of the line-to-line grid voltage $\left(v_{g a b}\right)$. Then, each of the bidirectional-switch valves suffer a switching loss equal to:

$$
P_{B S}=\frac{V_{g a b}}{2} \frac{I_{\text {string }}}{2}
$$

Once again using the approximation of considering the switching losses in the commutation process to be equal to the peak value of the power curve (see Figure 17), as well as considering that $t_{d(o n)}=t_{d(o f f)}$. Instead of considering that every time the submodule string is connected to a different phase of the grid, two bidirectional-switch valves suffer a switching loss as described in (39), the authors consider that one equivalent bidirectional-switch valve suffers a switching loss equal to:

$$
P_{\text {Loss BS }}=\frac{V_{g a b}}{2} I_{\text {string }}
$$

Thus, every time a submodule string is connected to a different phase of the grid, through the bidirectional-switch valves, a switching loss occurs which is equal to (40).
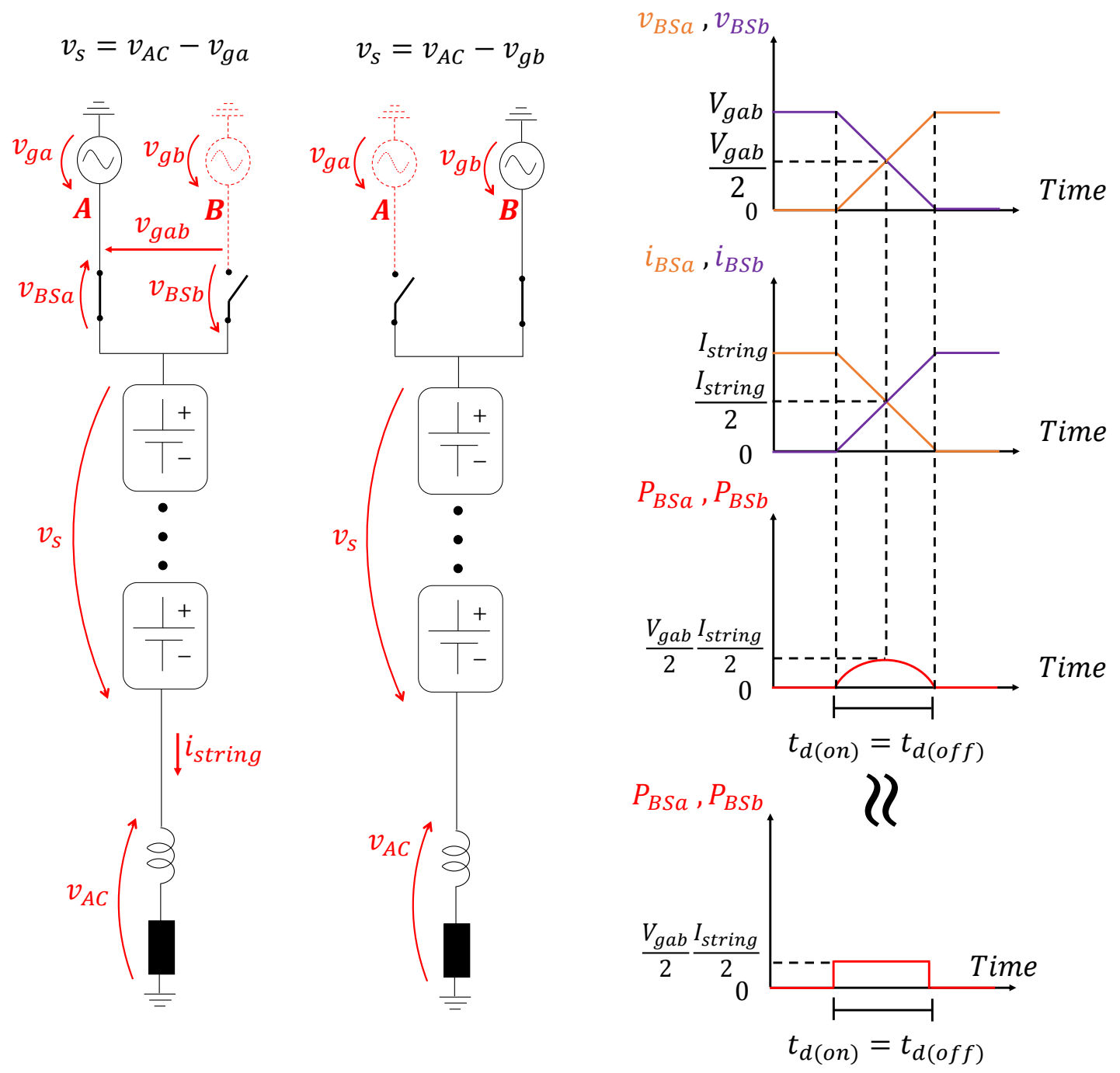

Figure 17. Bidirectional-switch-valve characteristics.

\subsubsection{Number of Components}

As previously explained, the value of the grid voltage should be designed according to Equation (34), which means that the optimal value of the grid voltage is equal to $V_{g}=20 \mathrm{kV}$. Then, 
considering that $V_{C E S}=2 \mathrm{kV}$ and considering that the submodule capacitor voltage must be equal to $\frac{V_{g}}{N}$ (see Figure 15), then the number of submodules in each arm can be calculated as follows:

$$
\frac{V_{g}}{N}=V_{C E S}
$$

which leads to $N=10$ submodules per string. The entire solution is composed of three strings. Each FB submodule is composed of four IGBTs, four diodes and one capacitor, besides DC-voltage sensor and driver. Thus, the total number of components composing the MMSC submodule strings is equal to $3 \times 10 \times 4=120$ IGBTs, 120 diodes and $3 \times 10 \times 1=30$ capacitors. Besides the submodule components, the components of the bidirectional-switch valves must also be considered. As previously mentioned and as will be further explained in this paper, the bidirectional switches in the MMSC operate with a very low switching frequency and, thus, both IGBTs in the bidirectional switch can be triggered simultaneously, in combination with a dead-time technique and with a snubber circuit, in order to avoid the complex multi-step commutation techniques usually used in matrix converters. Thus, the bidirectional switch, composed of two IGBTs plus two anti-parallel diodes, can be considered to be a single switch with double rated voltage. In other words, since two series-connected IGBTs with rated voltage equal to $V_{C E S}=2 \mathrm{kV}$ are used to compose one bidirectional switch, then each bidirectional switch can be considered to be an individual semiconductor device with rated voltage equal to $4 \mathrm{kV}$. The maximum voltage that each bidirectional-switch valve must be capable of blocking is equal to the line-to-line peak value of the grid voltage equal to $\sqrt{3} V_{g}=34.64 \mathrm{kV}$. Thus, the bidirectional-switch valve must be composed of $\frac{34.64}{4}=8.66 \approx 9$ bidirectional switches connected in series. Since each individual bidirectional switch is composed of two IGBTs and two diodes, then each bidirectional-switch valve is composed of $9 \times 2=18$ IGBTs and 18 diodes. The MMSC solution is composed of six of such bidirectional-switch valves. In other words, two bidirectional-switch valves connecting each of the submodule strings to two different phases of the grid (see Figure 2). Thus, the total number of components composing the MMSC bidirectional-switch valves is equal to $6 \times 18=108$ IGBTs and 108 diodes.

Finally, the total number of semiconductor devices of the MMSC is the sum of the devices that compose the submodule strings (120 IGBTs and 120 diodes) plus the devices that compose the bidirectional-switch valves (108 IGBTs and 108 diodes), which results in a total of 228 IGBTs and 228 diodes. Other components that should be considered, in the MMSC case, are the band-passfilter components.

\subsubsection{Conduction Losses}

The current that flows through each of the MMSC submodule strings is equal to:

$$
I_{\text {string }}=I_{A C}
$$

This current flows simultaneously through each of the three submodule strings. However, the two bidirectional-switch valves, which connect each submodule string to two different phases of the grid, operate in a complementary fashion. In other words, if one of them is conducting current, then the other one is in off state and, thus, no current flows through it. It means that three bidirectional-switch valves (one for each phase) conduct current simultaneously at any time. In the MMSC case, the submodules used are FB ones, which means that the current flows through two different IGBTs in each submodule, no matter if the submodule is inserted with positive polarity, with negative polarity or by-passed. Thus, the string current flows through $3 \times 10 \times 2=60$ IGBTs, simultaneously, only considering the submodule strings.

As previously defined, each bidirectional-switch valve is composed of 9 bidirectional switches. Each of these bidirectional switches are composed of two IGBTs connected in series along with their corresponding anti-parallel diodes. Thus, the string current will flow through 18 IGBTs in 
each bidirectional-switch valve. In total, the string current will flow through $3 \times 18=54$ IGBTs. This number is calculated by multiplying the number of bidirectional-switch valves that conduct current simultaneously, which is equal to 3 (one for each phase) by the number of series-connected IGBTs in each bidirectional-switch valve (equal to 18).

The total number of IGBTs conducting simultaneously the string current $\left(i_{\text {string }}\right)$ is obtained by summing the number of IGBTs that conduct this current in the submodule strings plus the number of IGBTs that conduct this current in the bidirectional-switch valves. The total number is equal to $60+54=114$ IGBTs. Finally, the total MMSC conduction losses can be calculated as follows:

$$
P_{\text {CLoss }}=114 V_{C E(s a t)} I_{\text {string }}
$$

By substituting (42) into (43), and by remembering that $V_{C E(s a t)}=2 \mathrm{~V}$ and $I_{A C}=100 \mathrm{~A}$, the following is obtained:

$$
P_{\text {CLoss }}=22.8 \mathrm{~kW}
$$

\subsubsection{Switching Losses}

To calculate the total switching losses of the MMSC, it is important to remember that the FB submodules present two different possible switching losses described in (37) and in (38). Moreover, the switching losses that occur when the bidirectional-switch valves act to change the phase connected to a submodule string is described in (40). Then, by substituting (42) into (37) and (38), and by remembering that $V_{g}=20 \mathrm{kV}, N=10$ and $I_{A C}=100 \mathrm{~A}$, the following is obtained:

$$
P_{\text {LossFB1 }}=100 \mathrm{~kW}
$$

And

$$
P_{\text {LossFB2 }}=200 \mathrm{~kW}
$$

By substituting (42) into (40), and by remembering that $V_{g a b}=\sqrt{3} V_{g}=34.64 \mathrm{kV}$ and $I_{A C}=100 \mathrm{~A}$, the following is obtained:

$$
P_{\text {LossBS }}=1.73 \mathrm{MW}
$$

The switching losses represented in equations (45), (46) and (47) occur for a period equal to $t_{d(\text { on })}=t_{d(\text { off })}=250 \mathrm{~ns}$. The switching losses presented in (45) correspond to the case in which any new submodule is inserted or by-passed and, thus, only two of the four submodule IGBTs change their switching state. The switching losses presented in (46) correspond to the case in which there is a polarity inversion in the FB submodule and, thus, all the four IGBTs of the submodule change their switching state. The energy that is lost every time a FB submodule is inserted or by-passed $\left(E_{o n F B 1}=E_{o f f F B 1}\right)$, considering $t_{d(o n)}=t_{d(o f f)}=250 \mathrm{~ns}$, can be calculated as follows:

$$
E_{\text {onFB1 }}=E_{\text {offFB1 }}=t_{d(o n)} P_{\text {LossFB1 }}=0.025 \mathrm{Ws}
$$

The energy that is lost every time a FB submodule suffers a polarity inversion $\left(E_{\text {onFB2 }}=E_{\text {offFB2 }}\right)$ can be calculated as follows:

$$
E_{\text {onFB2 }}=E_{\text {offFB2 }}=t_{d(\text { on })} P_{\text {LossFB2 }}=0.05 \mathrm{Ws}
$$

Finally, the energy that is lost every time one bidirectional-switch valve acts to connect a different phase of the grid to a submodule string $\left(E_{o n B S}=E_{o f f B S}\right)$ can be calculated as follows:

$$
E_{\text {onBS }}=E_{\text {offBS }}=t_{d(\text { on })} P_{\text {Loss BS }}=0.43 \mathrm{Ws}
$$

Considering that $V_{g}=20 \mathrm{kV}, V_{o}=10 \mathrm{kV}, N=10$ submodules per string and that the MMSC provides power to a RL load $(R=100 \Omega$ and $L=50 \mathrm{mH}$ illustrating the impedance of a high-power 
electrical machine), let us suppose that the frequency of the AC voltage to be synthesized assumes three different values equal to $f_{o}=1,10$ and $45 \mathrm{~Hz}$. These are the exact same assumptions adopted for the MMC switching-loss analysis. In Figure 18a-c, one can observe the MMSC insertion-index signal $(S(t))$ for the cases in which the synthesized AC voltage presents frequencies equal to $f_{o}=1,10$ and $45 \mathrm{~Hz}$, respectively. In Figure $18 \mathrm{~d}-\mathrm{f}$, one can observe the resulting AC synthesized voltages for the cases in which the load frequency is equal to $f_{o}=1,10$ and $45 \mathrm{~Hz}$, respectively. It is clear that for every frequency, the voltage is a high-power-quality signal with only high-order harmonic components that are easily filtered out, resulting in the currents shown in Figure 18g-i, for the cases in which the load frequency is equal to $f_{o}=1,10$ and $45 \mathrm{~Hz}$, respectively. These currents present equivalent total harmonic distortion (THD) as the currents obtained in the MMC case, as shown in Figure 14g-i, which means that the carrier frequency adopted for the LSC-PWM technique, in the MMC case, allows for a fair comparison regarding switching losses.
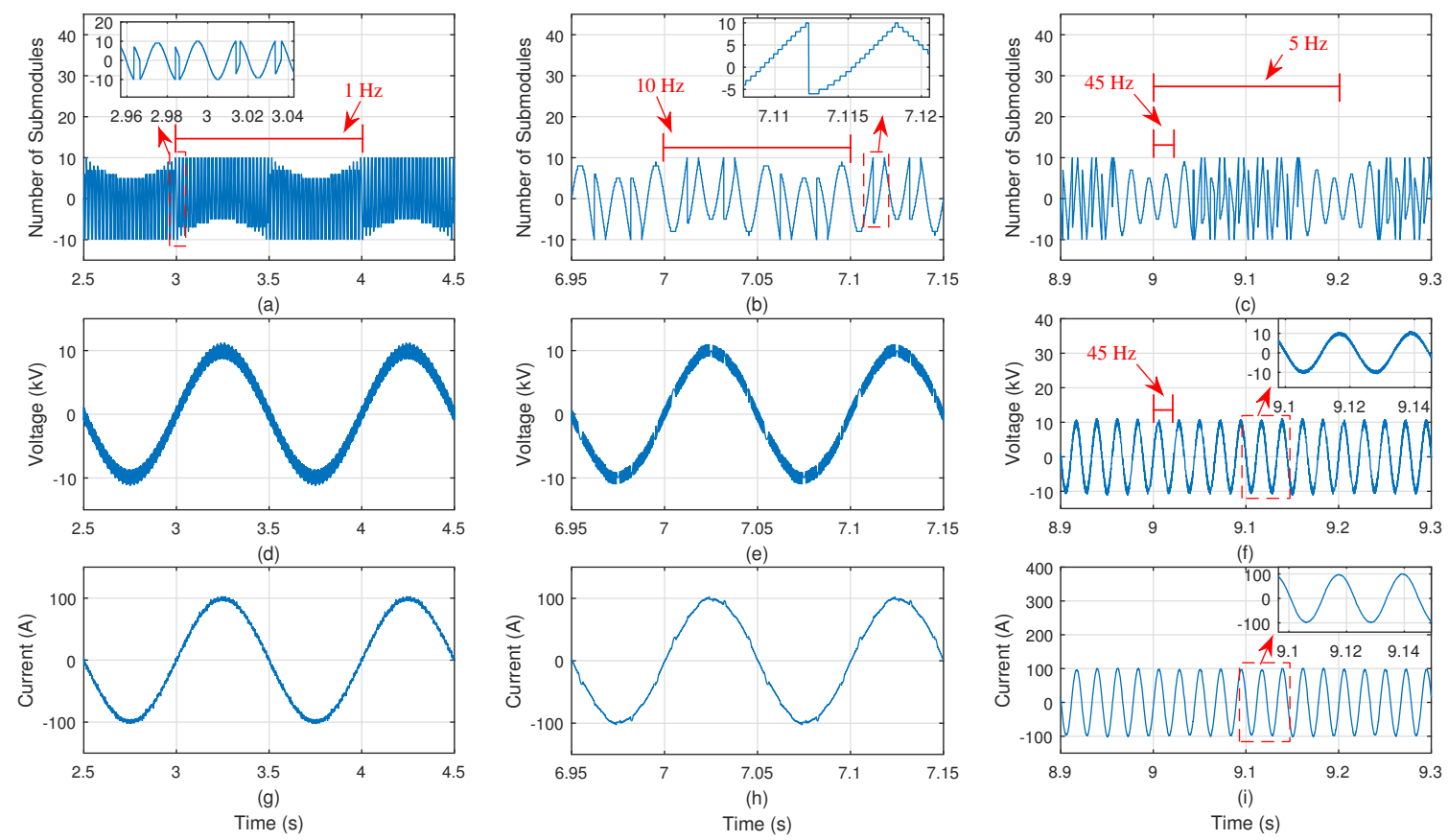

Figure 18. MMSC phase-A submodule-string insertion-index signal: (a) $f_{o}=1 \mathrm{~Hz}$, (b) $f_{o}=10 \mathrm{~Hz}$ and (c) $f_{o}=45 \mathrm{~Hz}$. MMSC load voltage: (d) $f_{o}=1 \mathrm{~Hz},(\mathbf{e}) f_{o}=10 \mathrm{~Hz}$ and (f) $f_{o}=45 \mathrm{~Hz}$. MMSC load current: (g) $f_{o}=1 \mathrm{~Hz}$, (h) $f_{o}=10 \mathrm{~Hz}$ and (i) $f_{o}=45 \mathrm{~Hz}$.

As an example, let us analyze the $f_{o}=10-\mathrm{Hz}$ case. In order to calculate the total switching losses of the MMSC, both the switching of the submodule strings and the switching of the bidirectional-switch valves must be considered. In Figure 19a, one can observe the MMSC insertion-index signal $(S(t))$, for the $10-\mathrm{Hz}$ case, which is the same signal illustrated in Figure 18b. Every time the insertion-index signal reaches the limits equal to -10 and 10 , the submodule string is connected to the other phase of the grid (phase $B$ in this case). While the insertion-index signal remains within the limits equal to -10 and 10, the FB submodules are inserted and by-passed in a one-by-one fashion and, thus, the switching losses in every new step are calculated according to Equation (45). When the insertion-index signal reaches the limits equal to -10 and 10 , however, many of the ten submodules inserted will suffer a polarity inversion, while others will only be by-passed. In other words, the insertion-index signal reaches a limit in which either all the submodules are inserted with positive polarity or all the submodules are inserted with negative polarity and, instantaneously, the voltage that must be synthesized in series changes polarity since the submodule string is connected to a different phase of the grid. The total switching losses in this case should be calculated by summing the losses of all 
the submodules that suffer polarity inversion (whose losses are calculated according to (46)) plus the losses of the submodules that are simply by-passed (whose losses are calculated according to (45)).

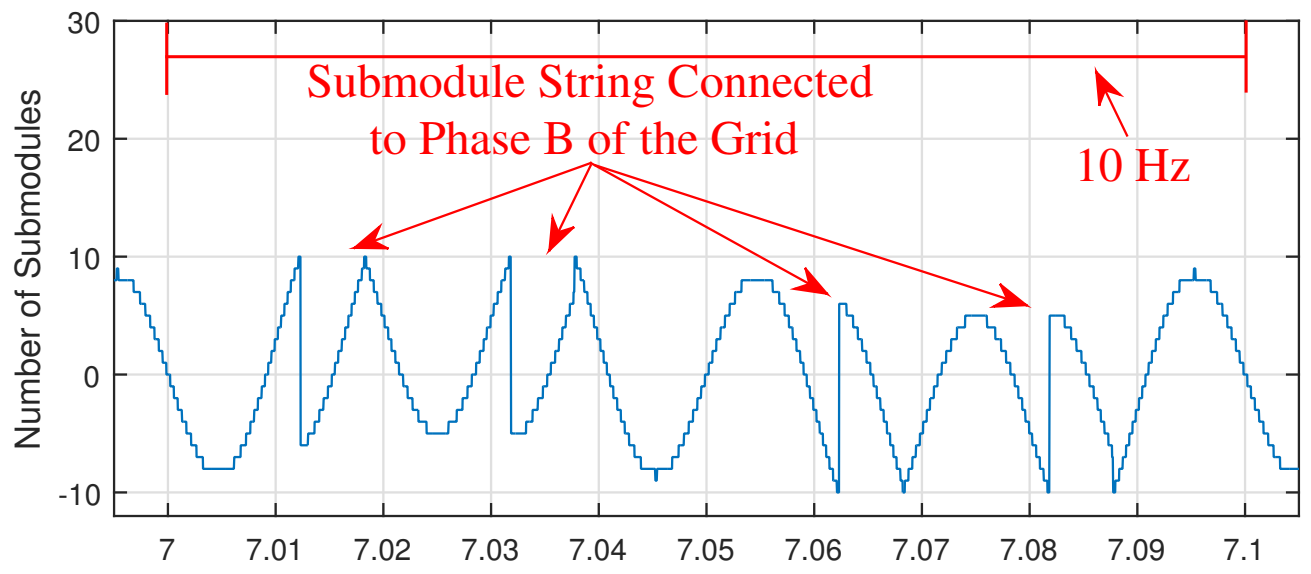

(a)

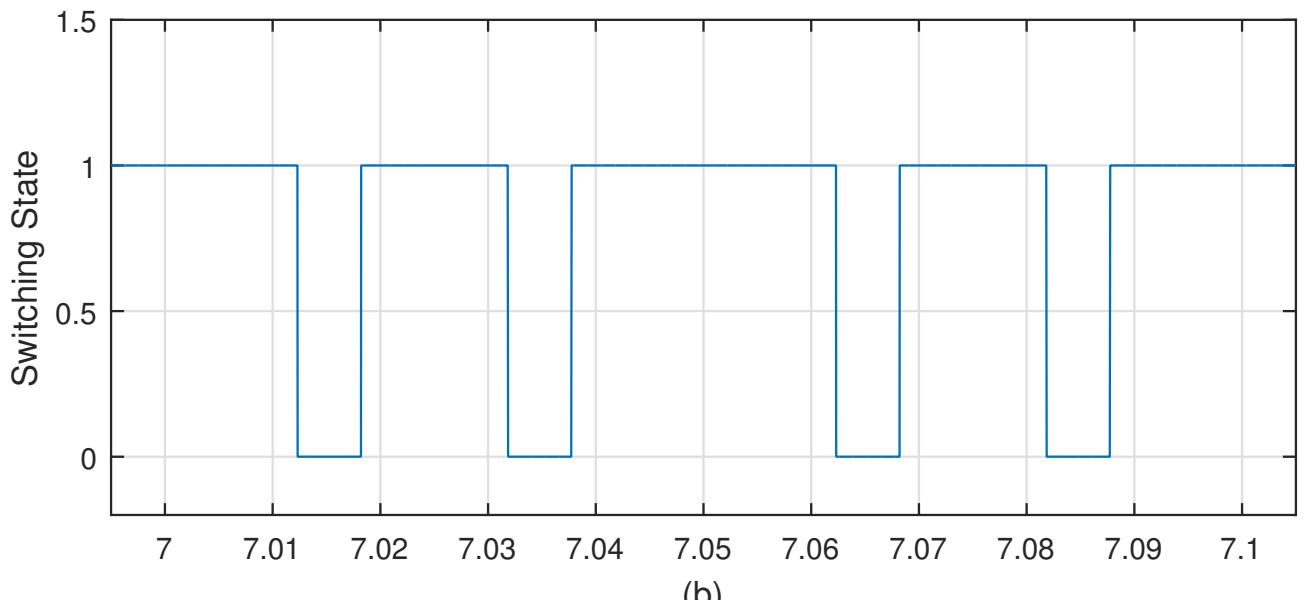

(b)

Time (s)

Figure 19. MMSC operation at $f_{o}=10 \mathrm{~Hz}$. (a) Phase-A submodule-string insertion-index signal and (b) switching state of bidirectional-switch valve that connects Phase-A submodule string to phase A of the grid.

By counting the number of steps in the insertion-index signal illustrated in Figure 19a, in one period of the fundamental frequency $\left(f_{o}=10 \mathrm{~Hz}\right)$, the result obtained is equal to 232 steps. Moreover, four polarity-inversion situations occur. Thus, in one period of the fundamental frequency $\left(f_{o}=10 \mathrm{~Hz}\right)$, the FB submodules will be inserted or by-passed, in a one-by-one fashion, 232 times. Every time there is one step change, one FB submodule is inserted or by-passed, which results in a power loss with value represented in Equation (45). However, this power loss only occurs for a short period of time equal to the commutation period $\left(t_{d(o n)}\right)$, and the total energy lost is the one represented in (48). In order to understand the actual switching losses, it is necessary to know the frequency in which the submodules are inserted or by-passed. The MMSC will present 232 step changes in the period of $t=\frac{1}{10 \mathrm{~Hz}}=0.1 \mathrm{~s}$. Since the MMSC is composed of 3 strings, then it is possible to say that there will occur $232 \times 3=696$ step changes in the period of $t=\frac{1}{10 H z}=0.1 \mathrm{~s}$. Thus, in $1 \mathrm{~s}$, there will occur 6960 step changes. In other words, it is possible to say that the FB submodules are inserted and by-passed with a frequency equal to $6960 \mathrm{~Hz}$, or that, in $1 \mathrm{~s}$, one new submodule will be inserted or by-passed 6960 times. Every time one new submodule is inserted or by-passed an energy 
loss occurs, which is represented by (48). Thus, the switching losses are equal to: $6960 E_{\text {onFB1 }}=174 \mathrm{~W}$. However, in order to complete the switching-loss analysis for the submodule strings, the polarity-inversion situations must be considered. Considering the four polarity-inversion situations, in one period of the fundamental frequency $\left(f_{o}=10 \mathrm{~Hz}\right)$, a total of 22 submodules suffer a polarity inversion, while a total of 18 submodules are simply by-passed. These numbers were obtained by counting. Since the MMSC is composed of three strings, then, in one period of the fundamental frequency $\left(f_{o}=10 \mathrm{~Hz}\right)$, a total of $3 \times 22=66$ submodules suffer a polarity inversion, whereas a total of $3 \times 18=54$ submodules are simply by-passed. Thus, in $1 \mathrm{~s}, 10 \times 66=660$ submodules suffer polarity inversion, while $10 \times 54=540$ submodules are simply by-passed. Then, the polarity-inversion switching losses are equal to $660 E_{\text {OnFB2 }}+540 E_{\text {OnFB1 }}=33+13.5=46.5 \mathrm{~W}$. Finally, the total switching losses related to the submodule strings are equal to $174+46.5=220.5 \mathrm{~W}$.

To fully describe the MMSC switching losses, the losses related to the bidirectional-switch-valves operation should be considered. In Figure 19b, one can observe the switching state of the bidirectional-switch valve that connects phase-A submodule string to phase A of the grid. If this signal is equal to 1 , it means that the submodule string is connected to phase A of the grid, whereas if this signal is equal to 0 , then the submodule string is connected to phase B of the grid. In one period of the fundamental frequency $\left(f_{o}=10 \mathrm{~Hz}\right)$, the bidirectional-switch valves, of one MMSC phase, switch eight times (see Figure 19b). Then, for the three-phase case, in one period of the fundamental frequency $\left(f_{o}=10 \mathrm{~Hz}\right)$, the bidirectional-switch valves switch 24 times. Thus, in $1 \mathrm{~s}$, the bidirectional-switch valves will operate $10 \times 24=240$ times. In other words, it is possible to say that the bidirectional-switch valves switch with a frequency equal to $240 \mathrm{~Hz}$. The bidirectional-switch losses are equal to: $240 E_{\text {onBS }}=103.2 \mathrm{~W}$. Finally, the total switching losses of the MMSC operating at $f_{o}=10 \mathrm{~Hz}$ is equal to:

$$
P_{\text {SLoss }}=220.5+103.2=323.7 \mathrm{~W}
$$

It is very important to notice that even though the bidirectional-switch valves must withstand the peak value of the line-to-line grid voltage, resulting in a high power value in the commutation period as described in Equation (47), these devices switch at very low frequencies and, thus, their contribution to the switching losses is very small. Following the same approach, the switching losses of the MMSC for different values of the load-voltage frequency are summarized in Section 5.3.

\subsection{Summary}

In this subsection, the comparison analysis between the MMC and the MMSC is summarized in tables. In Table 2, one can see the number of components of both converter topologies. The MMSC presents a $13 \%$ reduction in the number of semiconductor devices in relation to the MMC. Even more important, the MMSC presents a 75\% reduction in the number of capacitors in comparison to the MMC, which is a very expressive reduction. Moreover, since these converters are supposed to operate with variable frequency, reaching very low frequency values, then the submodule capacitors should have considerably high capacitances to withstand the voltage ripples. Thus, the MMSC should be a solution with reduced cost, and with considerably reduced size and weight, in comparison to the $\mathrm{MMC}$, due to the expressive reduction in the number of the bulky and heavy submodule capacitors. In this paper, it is considered that the effect of the potentially bulky band-pass filter of the MMSC that needs to withstand the load current, is equivalent to the effect of the bulky arm inductors of the MMC that need to suppress circulating currents and avoid short circuits, in the total weight of the converter topologies. In other words, it is considered that the impact of such elements, in the size and weight of the MMSC and the MMC, cancel each other out. 
Table 2. Number of Components.

\begin{tabular}{ccc}
\hline Component & MMC & MMSC \\
\hline IGBTs & 240 & 208 \\
Diodes & 240 & 208 \\
Capacitors & 120 & 30 \\
\hline
\end{tabular}

In Tables 3 and 4, one can observe the conduction and switching losses, respectively, of the MMC and the MMSC. As expected, since these are converter topologies with modular multilevel structure, the switching losses are low. It is very important to emphasize that even the bidirectional-switch valves, in the MMSC case, present very low switching losses because of their very low switching frequency. In other words, the conduction losses are much more influential in the total semiconductor-device losses of the converters.

Table 3. Conduction Losses $\left(P_{C L o s s}\right)[\mathrm{kW}]$.

\begin{tabular}{cc}
\hline MMC & MMSC \\
\hline 20.4 & 22.8 \\
\hline
\end{tabular}

Table 4. Switching Losses $\left(P_{S L o s s}\right)[\mathrm{W}]$.

\begin{tabular}{ccc}
\hline$f_{\boldsymbol{o}}[\mathbf{H z}]$ & MMC LSC-PWM $\left(f_{\boldsymbol{c}}=\mathbf{1 5 0 0} \mathbf{H z}\right)$ & $\mathbf{M M S C}$ \\
\hline 5 & 989.4 & 376.5 \\
10 & 655.35 & 323.7 \\
15 & 655.35 & 378 \\
20 & 645.15 & 413.55 \\
25 & 656.63 & 376.5 \\
30 & 663 & 435.3 \\
35 & 640.05 & 383.25 \\
40 & 645.15 & 429.3 \\
45 & 605.63 & 427.05 \\
\hline
\end{tabular}

In Table 5, the total semiconductor-device losses of the converter topologies are shown. These losses are obtained through the summing of the conduction and switching losses. In the last row of Table 5, it is possible to see the average losses of each topology, which is calculated as the average value of the losses obtained for the different frequency values.

Table 5. Total Semiconductor-Device Losses $\left(P_{T L o s s}\right)[\mathrm{kW}]$.

\begin{tabular}{ccc}
\hline$f_{\boldsymbol{o}}[\mathbf{H z}]$ & MMC LSC-PWM $\left(f_{\boldsymbol{c}}=\mathbf{1 5 0 0} \mathbf{H z}\right)$ & $\mathbf{M M S C}$ \\
\hline 5 & 21.39 & 23.18 \\
10 & 21.06 & 23.12 \\
15 & 21.06 & 23.18 \\
20 & 21.05 & 23.21 \\
25 & 21.06 & 23.18 \\
30 & 21.06 & 23.24 \\
35 & 21.04 & 23.18 \\
40 & 21.05 & 23.23 \\
45 & 21 & 23.23 \\
\hline Average & 21.09 & 23.19 \\
\hline
\end{tabular}

Clearly, the MMSC presents slightly higher losses in comparison to the MMC. Since $V_{o}=10 \mathrm{kV}$ and $I_{A C}=100 \mathrm{~A}$, then the nominal power of the converters is: 


$$
P_{\text {nom }}=\sqrt{3}\left(\frac{\sqrt{3}}{\sqrt{2}} V_{o}\right) I_{A C}=2.12 \mathrm{MW}
$$

Using the nominal power described in (52) and the average losses described in Table 5, the efficiency values of the MMC and the MMSC can be obtained as they are summarized in Table 6 .

Table 6. Efficiency [\%].

\begin{tabular}{cc}
\hline MMC LSC-PWM $\left(f_{c}=\mathbf{1 5 0 0} \mathbf{H z}\right)$ & MMSC \\
\hline 99.01 & 98.91 \\
\hline
\end{tabular}

Since the conduction losses of the MMSC is only slightly higher than the MMC ones, then the MMSC efficiency is also only slightly lower than the MMC one, as the two topologies present equivalent efficiency values.

\section{Simulation Results}

In this section, the MMSC (illustrated in Figure 2) is modeled in the software PSCAD/EMTDC and simulation analyses are carried out. The MMSC has 20 submodules per string $(N=20)$ and it is connected to a $V_{g}=35-\mathrm{kV}$ grid (phase-to-ground, peak value). The submodule capacitors have capacitance equal to $5 \mathrm{mF}$. The MMSC control, as depicted in the flowchart of Figure 8, is implemented in a C code with sampling frequency equal to $20 \mathrm{kHz}$. The bidirectional-switch valves are represented by simple bidirectional switches in this simulation. Both the submodule switches and the bidirectional switches are represented by IGBT models. The MMSC band-pass filter presents the following parameters: $R=25 \Omega, L=10.13 \mathrm{mH}$ and $1 \mathrm{mF}$, which corresponds to the Bode plot shown in Figure 7. From $t=0 \mathrm{~s}$ to $t=1 \mathrm{~s}$, all the submodule IGBTs are kept in off state and their capacitors are pre-charged, through the anti-parallel diodes, reaching a steady-state value equal to approximately $\frac{V_{g}}{N}$. At $t=1 \mathrm{~s}$, the submodule control is enabled; however the switching of the bidirectional switches is kept disabled, meaning that each phase of the grid is connected to its corresponding load phase (A to A, B to B and C to C). Initially, the output-voltage reference has amplitude equal to $V_{o}=12 \mathrm{kV}$ (phase-to-ground, peak value) and frequency equal to $f_{o}=1 \mathrm{~Hz}$. The MMSC provides power to a RL load $(R=100 \Omega$ and $L=0.1 \mathrm{H})$. At $t=2.2 \mathrm{~s}$, the bidirectional-switch control is enabled and the submodule strings start to commutate between two different phases of the grid during the MMSC operation. At $t=4 \mathrm{~s}$, the output-voltage-reference frequency changes to $f_{o}=10 \mathrm{~Hz}$. At $t=5 \mathrm{~s}$, an extra load is connected $(R=150 \Omega)$. Finally, at $t=6 \mathrm{~s}$, the output-voltage-reference frequency changes to $f_{o}=45 \mathrm{~Hz}$.

\subsection{MMSC Supplying Power to RL Load}

In Figure 20a, one can observe the output voltage $\left(v_{\text {oabc }}\right)$ along with its reference $\left(v_{\text {refabc }}\right)$. It is clear that the MMSC can only properly synthesize the output voltage when the bidirectional switches are operating. The MMSC can synthesize a high-power-quality voltage, without any output filter, for all the different frequencies under consideration $(1 \mathrm{~Hz}, 10 \mathrm{~Hz}$ and $45 \mathrm{~Hz})$. In other words, these high-power-quality waveforms are obtained, even though the MMSC does not have arm inductors and, even though no output-voltage filter was used in this simulation. The harmonic components, present in the voltage waveform, are high-order harmonics that can be easily filtered out. For all the three different values of frequency considered, the output voltage presents a total-harmonic-distortion (THD) value lower than $5 \%$. This high-power-quality behavior is reflected to the output current $\left(i_{\text {oabc }}\right)$ illustrated in Figure 20b. In Figure 21a, one can analyze the submodule-capacitor voltages of one string in which the pre-charge can be observed. Moreover, the zoom in the voltage signals reveals the balanced behavior of the capacitor voltages. The most important information in Figure 21a is the very small voltage ripple obtained for the 1-Hz operation when the bidirectional switches are enabled, which reveals the high performance of the MMSC at 
low frequencies. However, it is important to notice the high voltage ripples for the $45-\mathrm{Hz}$ operation that reveals the MMSC reduced performance when the output-voltage frequency approximates from the grid frequency. As one can observe in Figure $12 \mathrm{c}$, for the $45-\mathrm{Hz}$ case, the capacitor current $\left(i_{\text {cap }}\right)$ contains a $5-\mathrm{Hz}$ component that results in high voltage ripples. In Figure 21b, one can analyze the input $\left(P_{i}\right)$ and the output $\left(P_{o}\right)$ power. It is clear that their average values are equal, meaning that the power that is being supplied to the load comes from the grid, which can be confirmed by the fact that the average value of the submodule-capacitor voltages are kept constant and stable. In other words, the power supplied to the load never comes from the energy stored in the capacitors. When the new load is connected, at $t=5 \mathrm{~s}$, the average value of the capacitor voltages is kept constant, according to Kirchhoff's law and conservation of energy, and, thus, the grid power instantaneously increases in order to meet the new power value demanded by the load, preserving the power exchange between the grid and the load. The small difference between the output and input power are the losses in the input filter. A more efficient filter can be designed for an eventual real application. For the $45-\mathrm{Hz}$ case, the input power starts to pulsate as the used filter (2nd order band-pass filter tuned at $50 \mathrm{~Hz}$ ) is not capable of completely filtering the $45-\mathrm{Hz}$ current that flows to the grid.

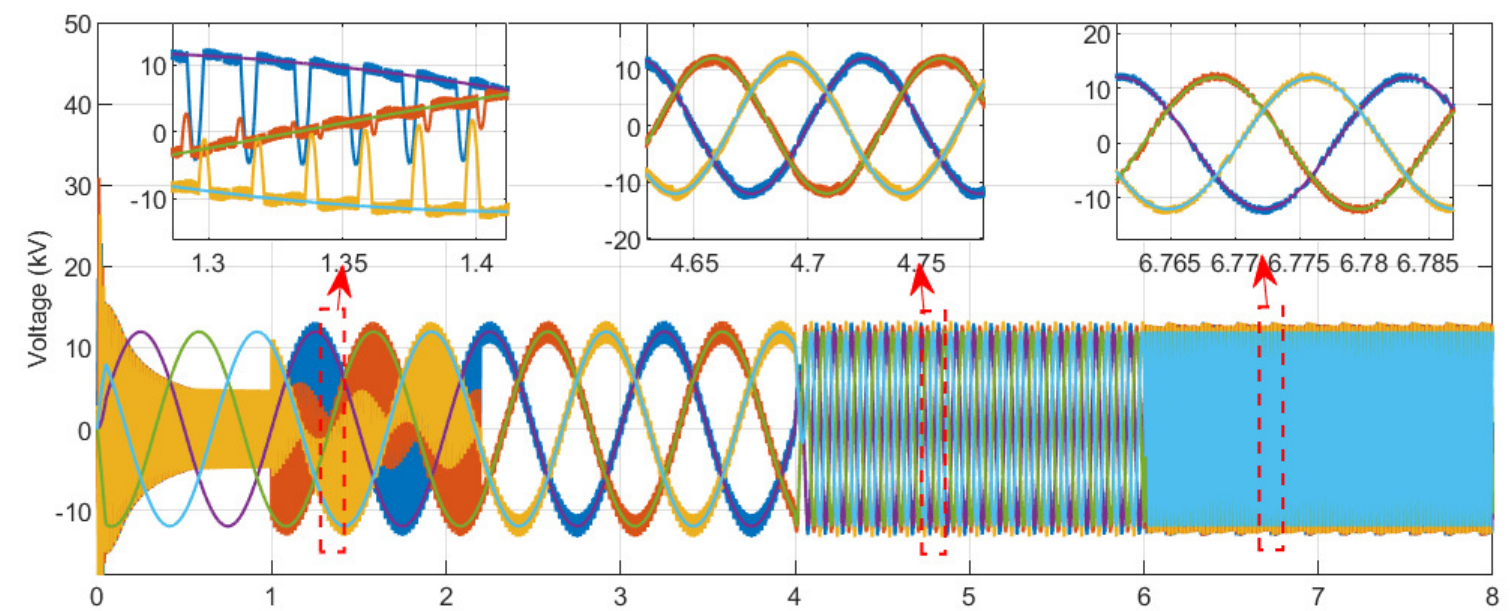

(a)

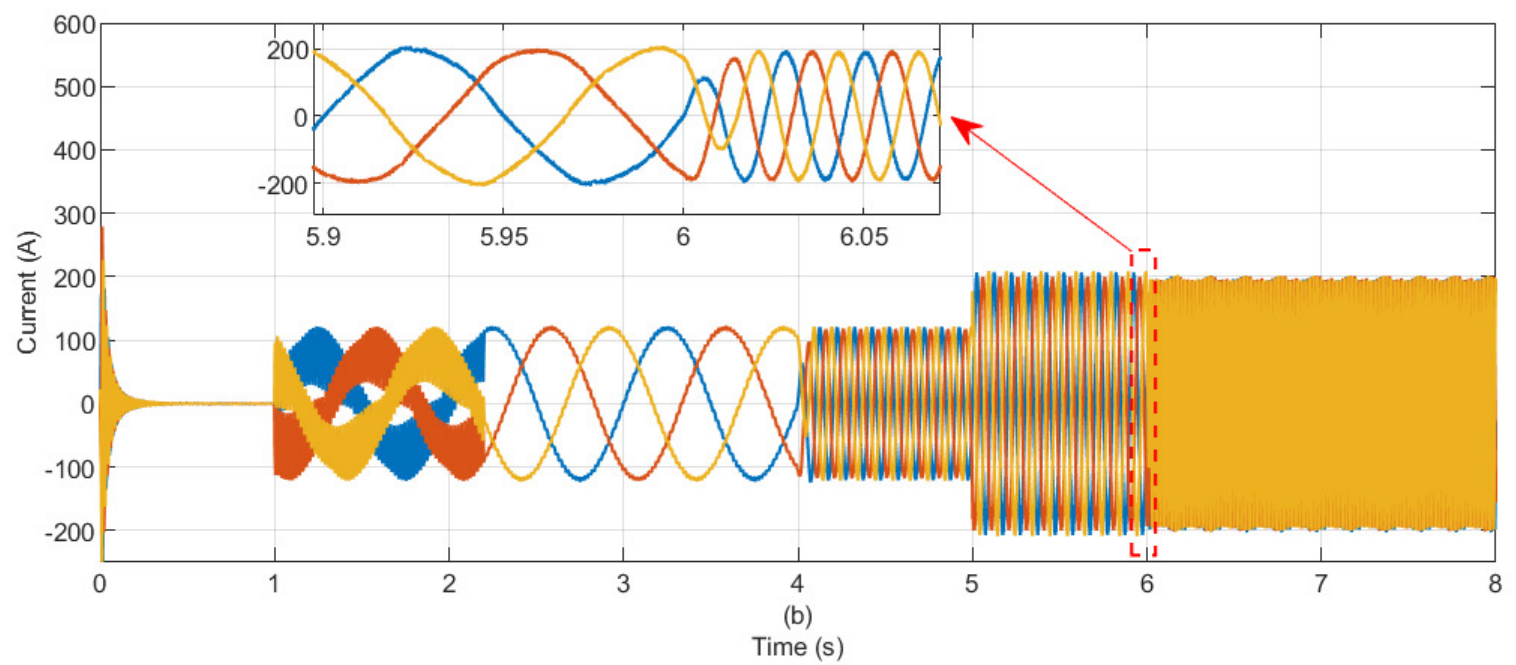

Figure 20. Simulation results. (a) load voltage $\left(v_{o a b c}\right)$ and load-voltage reference $\left(v_{\text {refabc }}\right)$ and (b) load current $\left(i_{o a b c}\right)$. 


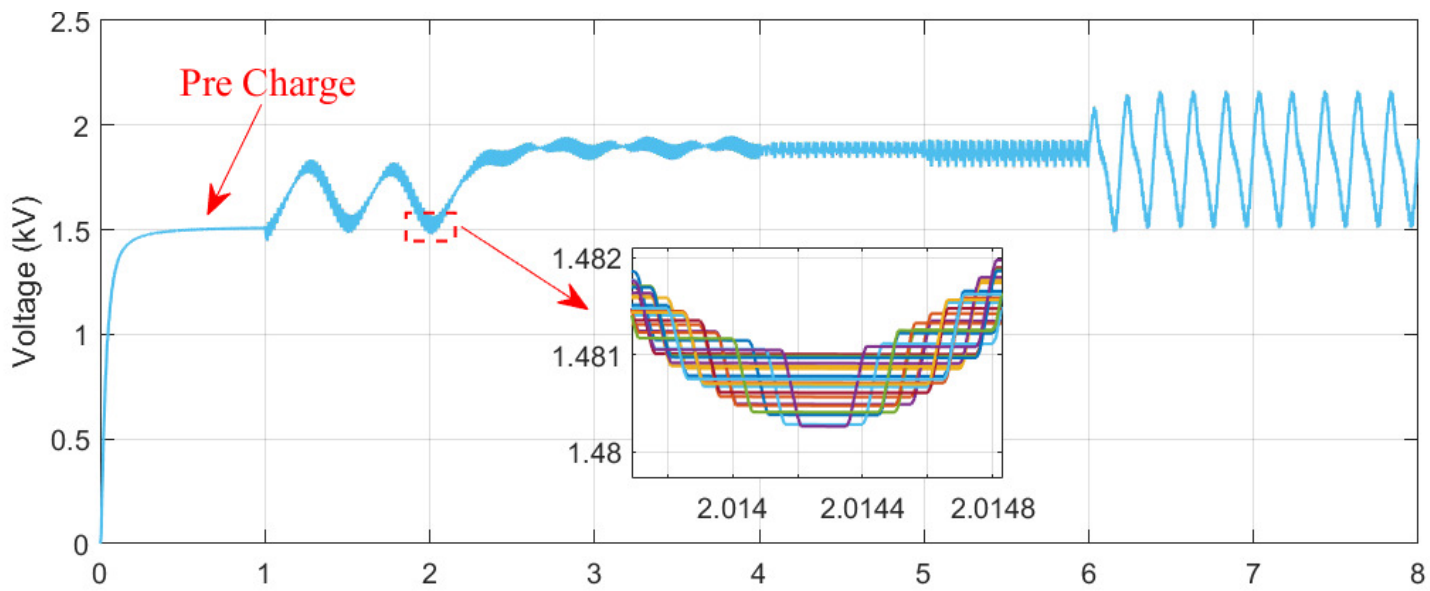

(a)

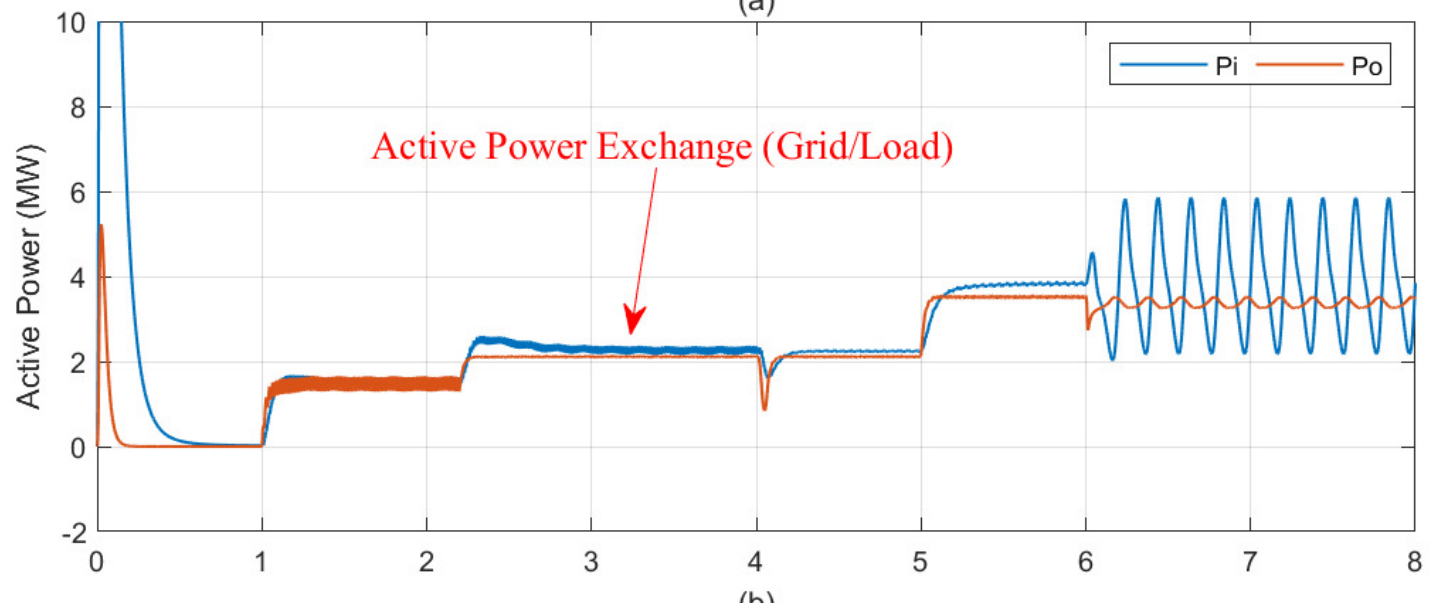

(b)

Time (s)

Figure 21. Simulation results. (a) submodule-capacitor voltages of one string and (b) grid and load power.

In Figure 22a, one can observe the phase-A grid current $\left(i_{g a}\right)$ along with the phase-A load current $\left(i_{o a}\right)$ for the $10-\mathrm{Hz}$ operation. The grid current $\left(i_{g a}\right)$ is a switched signal because there are four different connection possibilities for the phase A of the grid. both phase-A leg and phase-C leg can be connected to the phase A of the grid, at the same time, only one of the two legs can be connected to phase A of the grid or neither of them can be connected to phase A of the grid. Thus, the phase-A grid current $\left(i_{g a}\right)$ can be equal to phase-A load current $\left(i_{o a}\right)$, can be equal to phase-C load current $\left(i_{o c}\right)$, can be equal to a combination of the two currents or can be equal to zero. Phase-A leg and phase-C leg are connected to phase A of the grid through the switching of the bidirectional switches that operate with $50 \mathrm{~Hz}$, as will be explained later. Due to the $50-\mathrm{Hz}$ switching, a 50-Hz component appears in the grid current $\left(i_{g a}\right)$. Of course, that a $f_{o}-\mathrm{Hz}$ component $\left(10 \mathrm{~Hz}\right.$ in this case) will also be present in the grid current $\left(i_{g a}\right)$ since this is the load current that flows to the grid due to the series connection of the grid and the load. However, the $f_{0}-\mathrm{Hz}$ component can be filtered out, resulting in the current profile shown in Figure 22b, which is a $50-\mathrm{Hz}$ signal. The currents shown in Figure $22 \mathrm{~b}\left(i_{g f a b c}\right)$ are the currents that flow to the grid after the filtering process. These currents interact with the $50-\mathrm{Hz}$ grid voltage resulting in the active power exchanged with the load. 


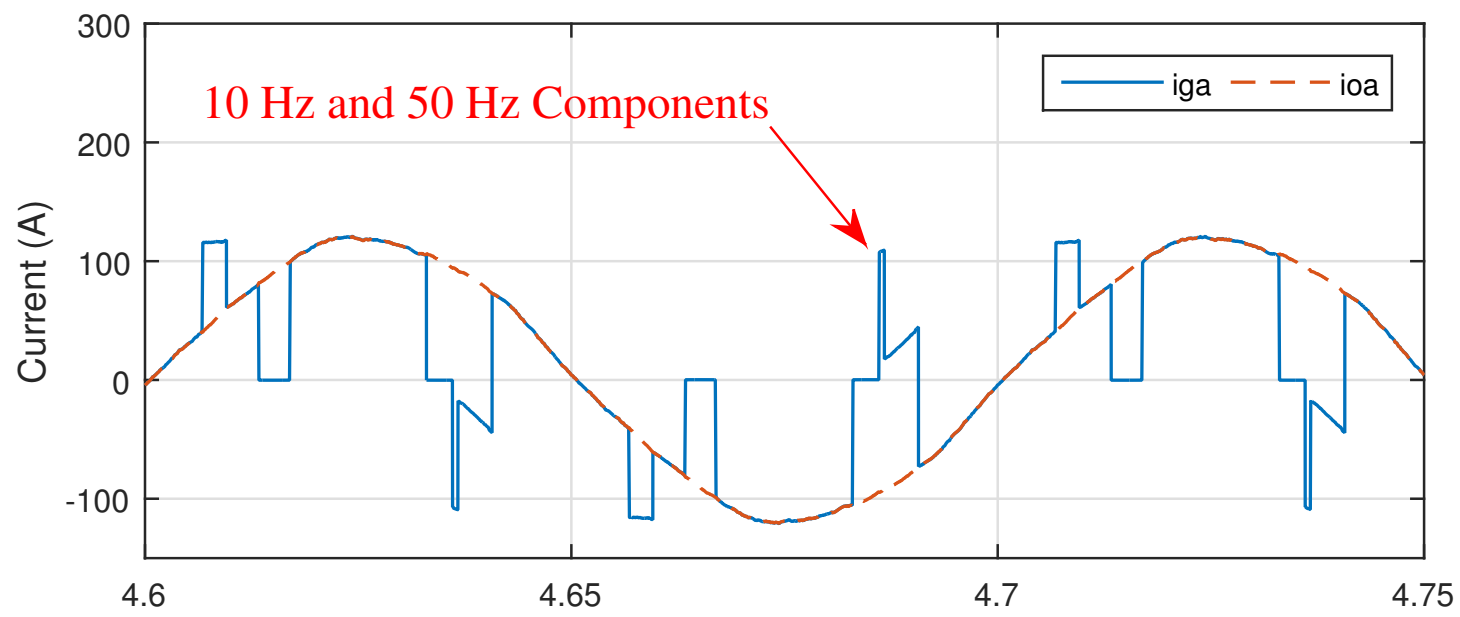

(a)

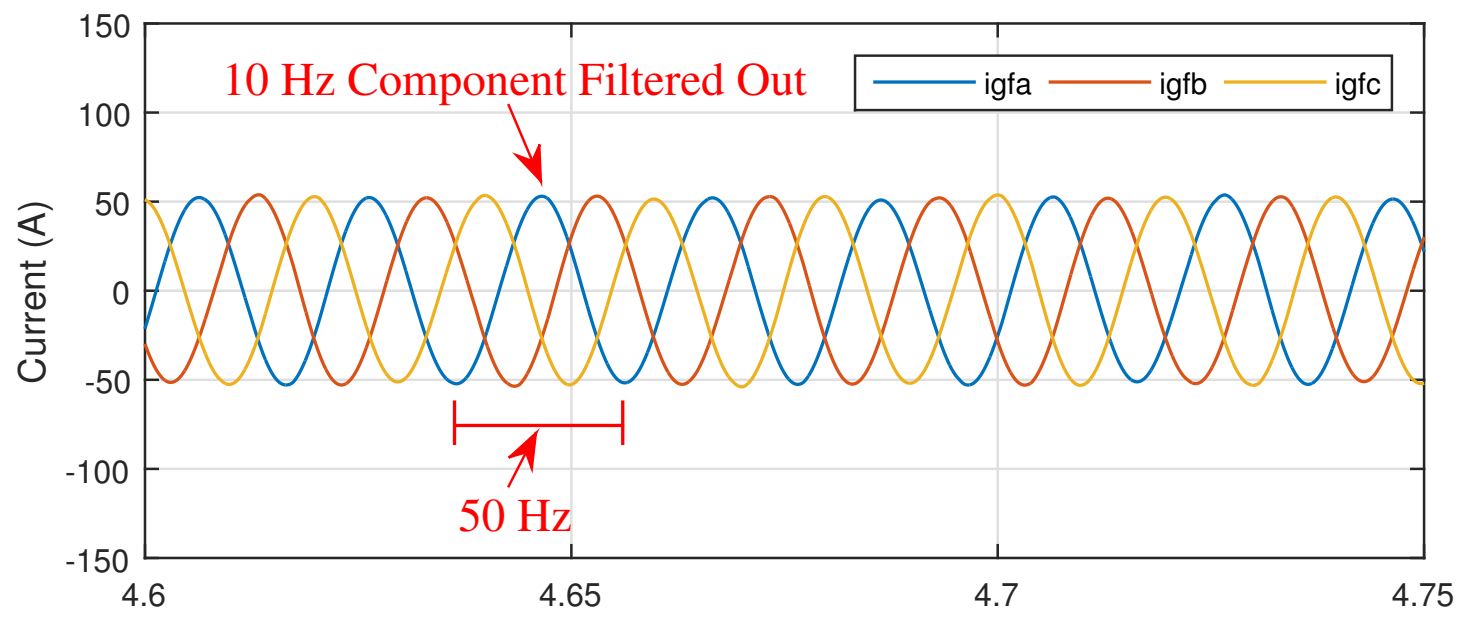

(b)

Time (s)

Figure 22. Simulation results. (a) phase-A grid current and phase-A load current and (b) filtered grid currents.

In Figure 23a, one can observe the error signal $(E)$, which corresponds to the voltage that should be added in series, along with two constant lines corresponding to $V_{g}$ and $-V_{g}$. If the bidirectional switches are disabled, when $|E|<V_{g}$ the MMSC can synthesize the correct voltage at the load terminal. However, when $|E|>V_{g}$ the load voltage deviates from its reference. This operation can be analyzed in Figure 23b in which the phase-A output voltage $\left(v_{o a}\right)$ is shown, along with its reference $\left(v_{r e f a}\right)$. In Figure 23b, it is clear that before $t=2.2 \mathrm{~s}$ (when the bidirectional switches are disabled), at some instants the output voltage deviates from its reference. However, as soon as the bidirectional switches start to operate, at $t=2.2 \mathrm{~s}$, the output voltage starts to follow the reference perfectly. It is interesting to observe the zoom in Figure 23a and notice that the moments in which $v_{o a}$ deviates from $v_{r e f a}$ in Figure 23b, correspond exactly to the moments in which $|E|$ exceeds $V_{g}$. In Figure 23c, one can see the switching state of the bidirectional switch that connects the phase-A leg to phase A of the grid $\left(S_{B I D a}\right)$. If this signal is equal to 1 , the string is connected to phase $\mathrm{A}$ of the grid, whereas if this signal is equal to 0 , the string is connected to phase $B$ of the grid through the other bidirectional switch. It is important to notice that the moments in which $|E|$ exceeds $V_{g}$, in Figure 23a, are the moments that the submodule string is connected to phase $\mathrm{B}$ of the grid. The signal $E$ is composed of $f_{i}=50 \mathrm{~Hz}$ and of $f_{o}=1 \mathrm{~Hz}$, in this case. It is important to notice that $|E|$ exceeds $V_{g}$ with the grid frequency $\left(f_{i}=50 \mathrm{~Hz}\right)$. 
Thus, the bidirectional switches operate with this low frequency, which is a very important feature of the proposed MMSC. The bidirectional switches must be able to withstand the grid voltage, which is a medium voltage in the applications considered. Then, series-connected IGBTs are required. However, since they operate at a low frequency (grid frequency), then snubber circuits can be used, with tolerable losses, to allow for a safe transient voltage balance among the series-connected switches. Moreover, a snubber circuit can also be used to facilitate the current commutation in the bidirectional switches, without the need for more complex commutation strategies.

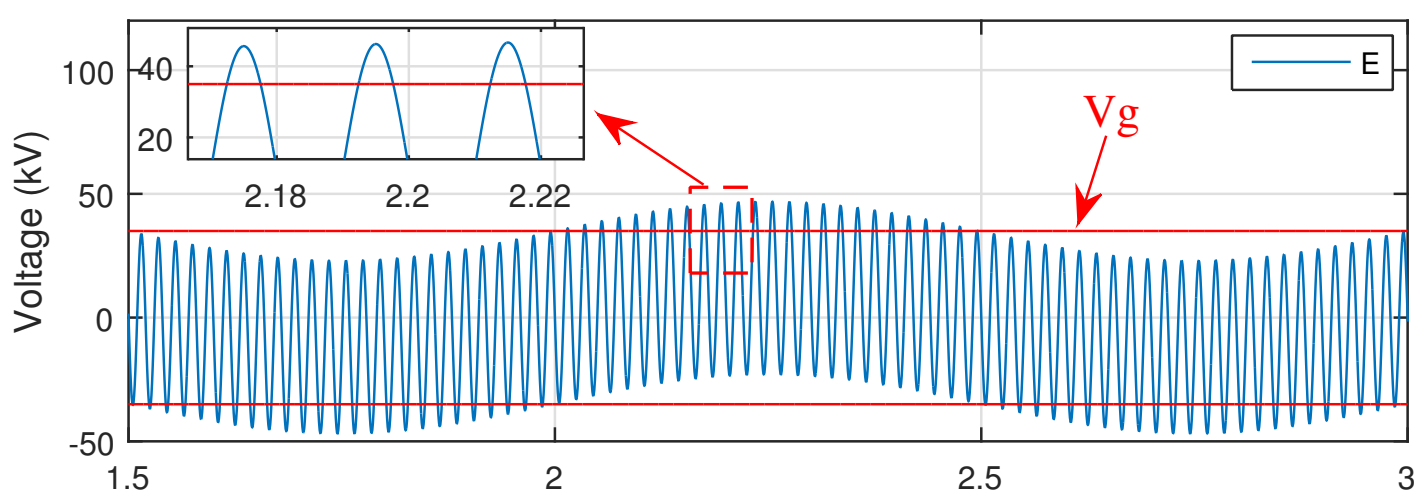

(a)

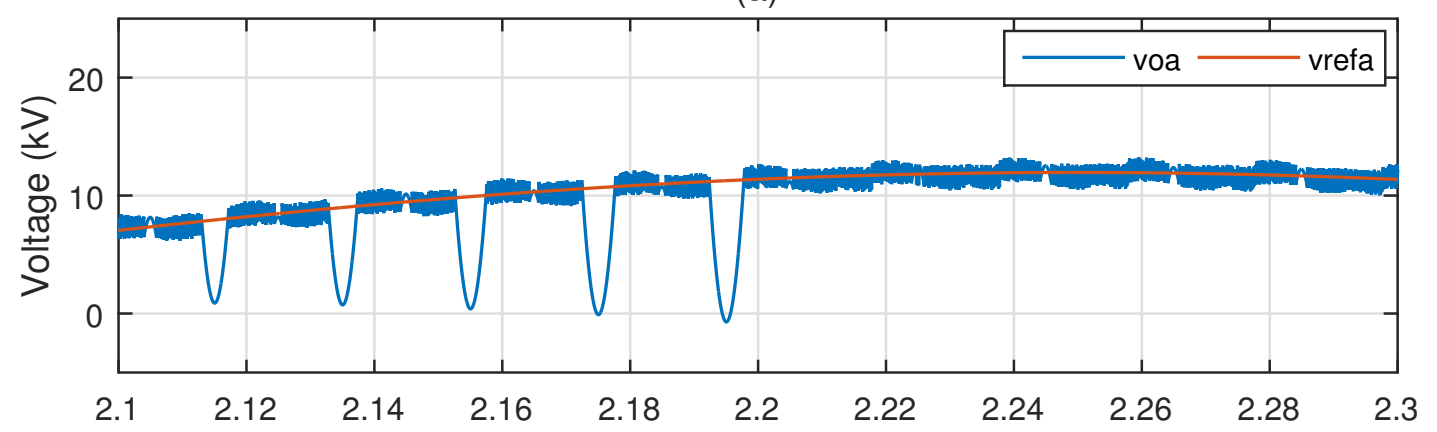

(b)

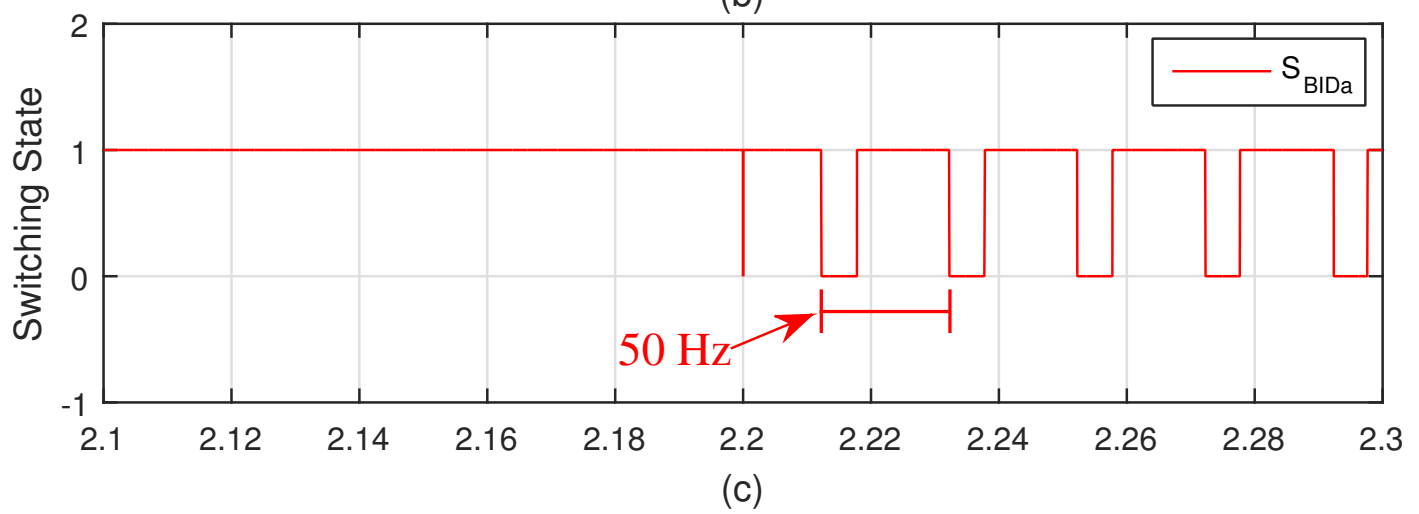

Time $(s)$

Figure 23. Simulation results. (a) Error $(E)$, (b) load voltage and load-voltage reference at the moment in which the bidirectional switches start to operate and (c) switching pattern of bidirectional switch that connects phase-A leg and phase A of the grid.

\subsection{Validation of the Submodule-Capacitor-Voltage-Ripple Analytical Description}

In Figure 24a, one can observe the normalized insertion index (for the 1-Hz case) calculated in Section 4 and illustrated in Figure 9e (referred to as "Calculated" in Figure 24a), along with the real normalized insertion index obtained in the PSCAD/EMTDC simulation (referred to as "PSCAD" in Figure 24a). The real normalized insertion index corresponds to the instantaneous values of $M$ 
(see Figure 8) in which $M$ is positive if $E$ is positive and $M$ is negative if $E$ is negative. It is interesting to notice how similar these two signals are, meaning that the analytical description proposed in Section 4 is accurate.

In Figure 25a, one can see the Fourier spectrum of the real normalized insertion index illustrated in Figure 24a. This Fourier spectrum is quite similar to the Fourier spectrum of the calculated insertion index that is illustrated in Figure 9f. In Figure 24b, one can analyze three different representations of the capacitor current $\left(i_{c a p}\right)$ (for the $1-\mathrm{Hz}$ case), which is the current that flows through the submodule capacitors generating the voltage ripples. One of the representations (referred to as "Calculated" in Figure 24b) is the value calculated in Section 4 according to Equation (12). Another representation (referred to as "PSCAD" in Figure 24b) is the real switched capacitor current, measured in the simulation.

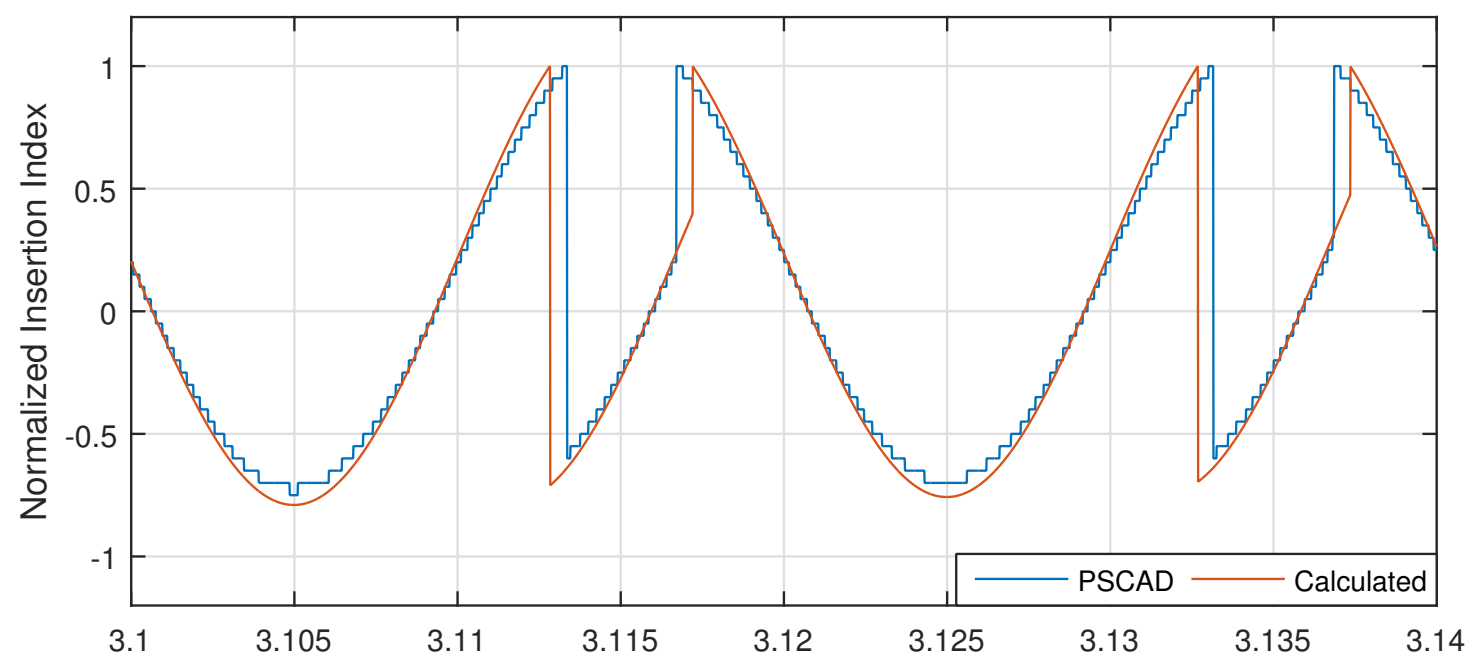

(a)

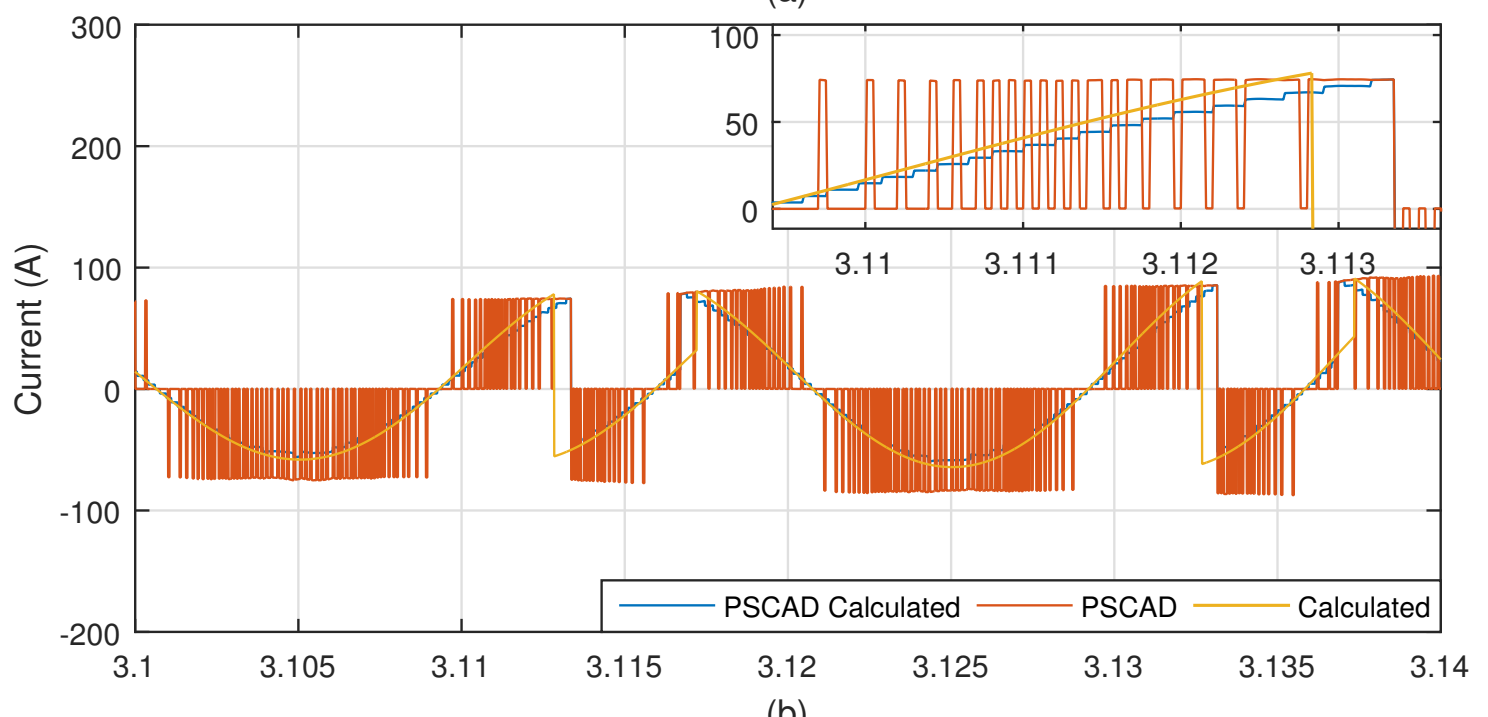

Time (s)

Figure 24. For the 1-Hz case. (a) PSCAD/EMTDC and calculated $S(t)$ and (b) PSCAD/EMTDC measured and calculated $i_{c a p}$ and calculated $i_{\text {cap }}$.

Finally, the third representation (referred to as "PSCAD Calculated" in Figure 24b) is obtained by multiplying the real normalized insertion index, obtained in the simulation and illustrated in Figure 24a, by the real load current $\left(i_{o a}\right)$ also measured in the PSCAD/EMTDC simulation. This product is executed according to Equation (12). It is interesting to notice how the signal referred to as "PSCAD 
Calculated" is a good approximation of the real switched signal referred to as "PSCAD". Moreover, the signal obtained through the analytical method proposed in Section 4, referred to as "Calculated" is a very accurate representation of the real current. This fact can be confirmed by analyzing the Fourier spectrum of the "PSCAD Calculated" and "PSCAD" current signals that are shown in Figure 25b and Figure 25c, respectively. These Fourier spectrum are quite similar to the Fourier spectrum of the "Calculated" current that is represented in Figure 12a. Another important issue to notice in Figure 25c is that in fact, the real capacitor current, obtained in simulation, does not contain the residual DC component obtained through calculations in Section 4.

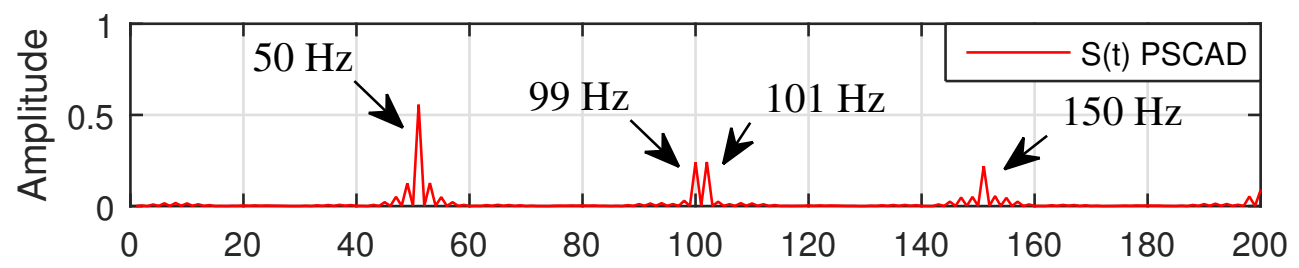

(a)

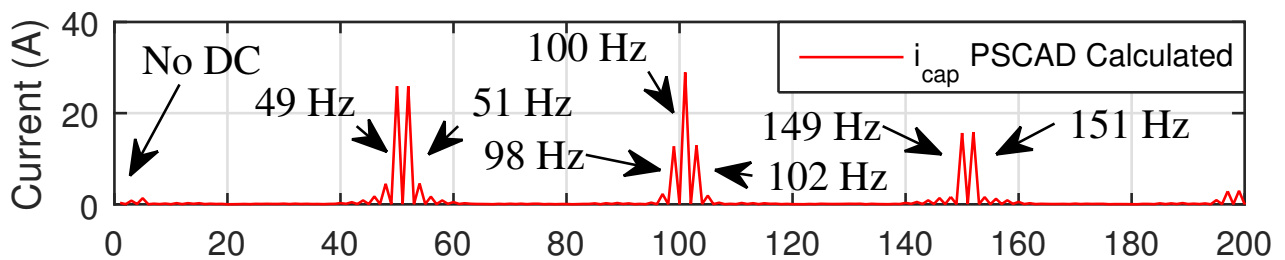

(b)

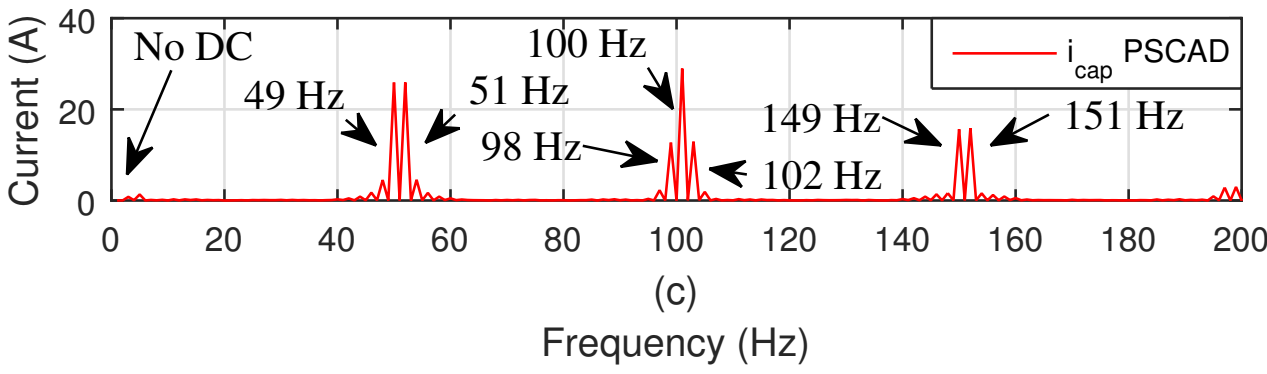

Figure 25. (a) Fourier spectrum of the real insertion index obtained in the PSCAD/EMTDC simulation and shown in Figure 24a, (b) Fourier spectrum of the capacitor current calculated, according to (12), using the PSCAD/EMTDC signals $\left(S(t)\right.$ and $\left.i_{o a}\right)$ and (c) Fourier spectrum of the real capacitor current measured in the PSCAD/EMTDC simulation.

\subsection{Analysis of the Band-Pass-Current-Filter Performance for Different Load-Voltage Frequencies}

In this subsection, a new simulation is carried out aiming at analyzing the performance of the band-pass current filter in properly filtering out the currents that are injected into the grid for different values of frequency of the load-voltage reference. In this simulation, the frequency of the output-voltage reference varies, assuming the following values: $f_{o}=5 \mathrm{~Hz}, f_{o}=10 \mathrm{~Hz}, f_{o}=15 \mathrm{~Hz}$, $f_{o}=20 \mathrm{~Hz}, f_{o}=25 \mathrm{~Hz}, f_{o}=30 \mathrm{~Hz}, f_{o}=35 \mathrm{~Hz}, f_{o}=40 \mathrm{~Hz}$ and $f_{o}=45 \mathrm{~Hz}$. In Figure 26, one can observe the filtered currents that are injected into the grid by the MMSC $\left(i_{g f a b c}\right)$ for the different values of frequency of the output voltage.

The band-pass filter used is the one whose Bode plot is shown in Figure 7 and it becomes clear that for the low-frequency values, the currents injected into the grid are high-power quality signals, with a small harmonic content, because of the high attenuation obtained with the filter. In other words, for the $f_{o}=5-\mathrm{Hz}, 10-\mathrm{Hz}, 15-\mathrm{Hz}, 20-\mathrm{Hz}, 25-\mathrm{Hz}$ and $30-\mathrm{Hz}$ cases, the corresponding $f_{o}$ current components that would flow to the grid are properly filtered out. However, for higher-frequency 
values $\left(f_{o}=35 \mathrm{~Hz}, 40 \mathrm{~Hz}\right.$ and $45 \mathrm{~Hz}$ ) the power quality of the currents injected into the grid starts to reduce. The reason for that is the fact that this band-pass filter is not capable of properly filtering out the $f_{o}=35-\mathrm{Hz}, 40-\mathrm{Hz}$ and $45-\mathrm{Hz}$ current components that flow to the grid, due to the series connection of the MMSC. For the $f_{o}=35-\mathrm{Hz}, 40-\mathrm{Hz}$ and $45-\mathrm{Hz}$ cases, the harmonic contents exceed the typical values allowed by grid codes as shown in detail in Table 7. This table illustrates the two higher harmonic components ( $f_{h 1}$ and $f_{h 2}$ ) present in the currents injected into the grid by the MMSC $\left(i_{g f a b c}\right)$, for each case depicted in Figure 26. It is important to notice that these are subharmonics and interharmonics of the fundamental frequency equal to $50 \mathrm{~Hz}$. In Table 7, one can observe that from $f_{o}=5 \mathrm{~Hz}$ until $f_{o}=30 \mathrm{~Hz}$, the highest harmonic component present in the grid current is lower than $5 \%$ of the fundamental component. From $f_{o}=35 \mathrm{~Hz}$, the power quality of the grid current is deteriorated as some harmonic components exceed the $5 \%$ limit. In Table 7 , one can notice that, as the load frequency increases, the most influential harmonic component, present in the grid current, is exactly the $f_{0}-\mathrm{Hz}$ component, which is the load current that flows to the grid. Moreover, Table 7 illustrates the reason a band-pass current filter is required. In other words, the harmonic components present in the current injected into the grid have frequency values both higher and lower than the fundamental frequency $\left(f_{i}=50 \mathrm{~Hz}\right)$. The band-pass filter is supposed to filter out both the components higher and lower than the fundamental frequency, while only allowing the fundamental component to flow to the grid. The filtering performance, obtained in this section, can be improved with an enhanced design of the band-pass current filter, which is not the main focus of this paper. Nonetheless, it is important to highlight that the MMSC presents high performance at low frequencies, regarding the voltage ripples in the submodule capacitors, and, thus, this converter would be suitable to applications that would normally operate within a lower frequency range. In this case, the band-pass filter used in this paper would be enough.
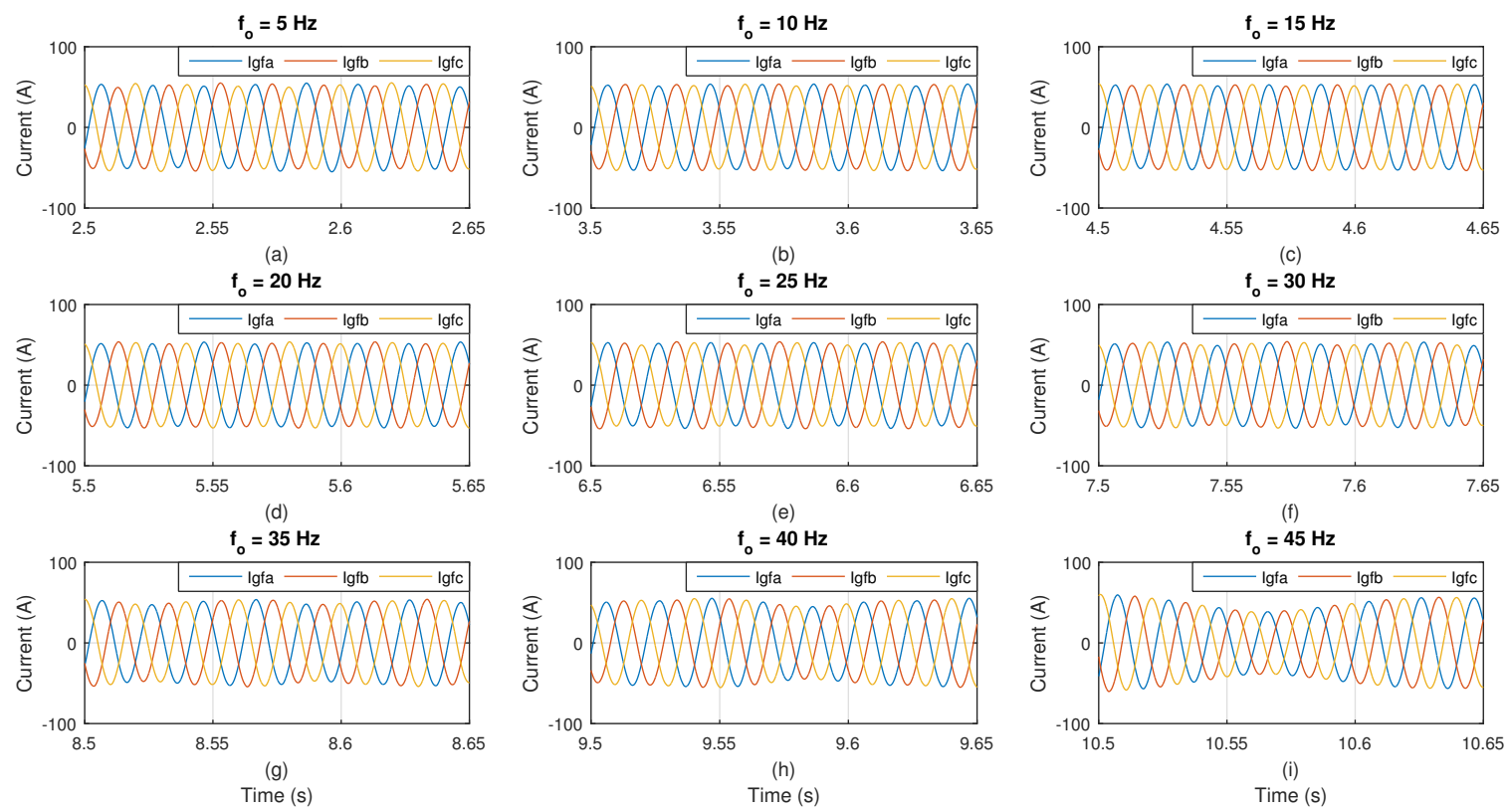

Figure 26. Currents injected into the grid after filtering $\left(i_{g f a b c}\right)$ for different values of frequency of the load voltage $\left(f_{o}\right)$. (a) $f_{o}=5 \mathrm{~Hz}$, (b) $f_{o}=10 \mathrm{~Hz},(\mathbf{c}) f_{o}=15 \mathrm{~Hz}$, (d) $f_{o}=20 \mathrm{~Hz},(\mathbf{e}) f_{o}=25 \mathrm{~Hz}$, (f) $f_{o}=30 \mathrm{~Hz},(\mathrm{~g}) f_{o}=35 \mathrm{~Hz}$, (h) $f_{o}=40 \mathrm{~Hz}$ and (i) $f_{o}=45 \mathrm{~Hz}$. 
Table 7. Two Most Influential Harmonic Components of MMSC grid current $\left(i_{g f a b c}\right)$.

\begin{tabular}{|c|c|c|}
\hline$f_{o}=5 \mathrm{~Hz}$ & & \\
\hline $\begin{array}{l}\text { Frequency } \\
\text { Harmonic Component as a Percentage of the Fundamental Component }(50 \mathrm{~Hz})\end{array}$ & $\begin{array}{c}f_{h 1}=40 \mathrm{~Hz} \\
3.14 \%\end{array}$ & $\begin{array}{c}f_{h 2}=95 \mathrm{~Hz} \\
1.48 \%\end{array}$ \\
\hline \multicolumn{3}{|l|}{$f_{o}=10 \mathrm{~Hz}$} \\
\hline $\begin{array}{l}\text { Frequency } \\
\text { Harmonic Component as a Percentage of the Fundamental Component }(50 \mathrm{~Hz})\end{array}$ & $\begin{array}{c}f_{h 1}=90 \mathrm{~Hz} \\
1.57 \%\end{array}$ & $\begin{array}{c}f_{h 2}=30 \mathrm{~Hz} \\
1.30 \%\end{array}$ \\
\hline \multicolumn{3}{|l|}{$f_{o}=15 \mathrm{~Hz}$} \\
\hline $\begin{array}{c}\text { Frequency } \\
\text { Harmonic Component as a Percentage of the Fundamental Component }(50 \mathrm{~Hz})\end{array}$ & $\begin{array}{c}f_{h 1}=85 \mathrm{~Hz} \\
1.67 \%\end{array}$ & $\begin{array}{c}f_{h 2}=15 \mathrm{~Hz} \\
1.54 \%\end{array}$ \\
\hline \multicolumn{3}{|l|}{$f_{o}=20 \mathrm{~Hz}$} \\
\hline $\begin{array}{c}\text { Frequency } \\
\text { Harmonic Component as a Percentage of the Fundamental Component }(50 \mathrm{~Hz})\end{array}$ & $\begin{array}{c}f_{h 1}=20 \mathrm{~Hz} \\
2.15 \%\end{array}$ & $\begin{array}{c}f_{h 2}=80 \mathrm{~Hz} \\
1.93 \%\end{array}$ \\
\hline \multicolumn{3}{|l|}{$f_{o}=25 \mathrm{~Hz}$} \\
\hline $\begin{array}{c}\text { Frequency } \\
\text { Harmonic Component as a Percentage of the Fundamental Component }(50 \mathrm{~Hz})\end{array}$ & $\begin{array}{l}f_{h 1}=25 \mathrm{~Hz} \\
3.15 \%\end{array}$ & $\begin{array}{c}f_{h 2}=75 \mathrm{~Hz} \\
2.22 \%\end{array}$ \\
\hline \multicolumn{3}{|l|}{$f_{o}=30 \mathrm{~Hz}$} \\
\hline $\begin{array}{c}\text { Frequency } \\
\text { Harmonic Component as a Percentage of the Fundamental Component }(50 \mathrm{~Hz})\end{array}$ & $\begin{array}{c}f_{h 1}=30 \mathrm{~Hz} \\
4.26 \%\end{array}$ & $\begin{array}{c}f_{h 2}=70 \mathrm{~Hz} \\
2.59 \%\end{array}$ \\
\hline \multicolumn{3}{|l|}{$f_{o}=35 \mathrm{~Hz}$} \\
\hline $\begin{array}{c}\text { Frequency } \\
\text { Harmonic Component as a Percentage of the Fundamental Component }(50 \mathrm{~Hz})\end{array}$ & $\begin{array}{l}f_{h 1}=35 \mathrm{~Hz} \\
6.11 \%\end{array}$ & $\begin{array}{c}f_{h 2}=65 \mathrm{~Hz} \\
3.33 \%\end{array}$ \\
\hline \multicolumn{3}{|l|}{$f_{o}=40 \mathrm{~Hz}$} \\
\hline $\begin{array}{c}\text { Frequency } \\
\text { Harmonic Component as a Percentage of the Fundamental Component }(50 \mathrm{~Hz})\end{array}$ & $\begin{array}{c}f_{h 1}=40 \mathrm{~Hz} \\
9.63 \%\end{array}$ & $\begin{array}{c}f_{h 2}=60 \mathrm{~Hz} \\
4.63 \%\end{array}$ \\
\hline \multicolumn{3}{|l|}{$f_{o}=45 \mathrm{~Hz}$} \\
\hline $\begin{array}{c}\text { Frequency } \\
\text { Harmonic Component as a Percentage of the Fundamental Component }(50 \mathrm{~Hz})\end{array}$ & $\begin{array}{c}f_{h 1}=45 \mathrm{~Hz} \\
19.44 \%\end{array}$ & $\begin{array}{c}f_{h 2}=55 \mathrm{~Hz} \\
8.85 \%\end{array}$ \\
\hline
\end{tabular}

\subsection{MMSC Performance Under Unbalanced Grid Conditions}

In this subsection a new simulation is carried out aiming at demonstrating the high performance of the MMSC under severe grid imbalance conditions. As with the simulation carried out in Section 6.1, the MMSC has 20 submodules per string $(N=20)$ and it is connected to a $35 \mathrm{kV}$ grid (phase-to-ground, peak value). The submodule capacitors have capacitance equal to $5 \mathrm{mF}$. From $t=0 \mathrm{~s}$ to $t=1 \mathrm{~s}$, all the submodule IGBTs are kept in off state and their capacitors are pre-charged, through the anti-parallel diodes, reaching an steady-state value equal to approximately $\frac{V_{g}}{N}$. At $t=1 \mathrm{~s}$, the submodules control is enabled; however the switching of the bidirectional switches is kept disabled, meaning that each phase of the grid is connected to its corresponding load phase (A to A, B to B and C to C). The output-voltage reference has amplitude equal to $12 \mathrm{kV}$ (phase-to-ground, peak value) and frequency equal to $10 \mathrm{~Hz}$. The MMSC provides power to a RL load $(R=100 \Omega$ and $L=0.1 \mathrm{H})$. At $t=2.2 \mathrm{~s}$, the bidirectional-switch control is enabled, and the submodule strings start to commutate between two different phases of the grid during the MMSC operation. In order to emulate a severe imbalance condition, at $t=4 \mathrm{~s}$, a phase-to-ground fault (through an impedance) is applied to phase A of the grid resulting in a $25 \mathrm{kV}$ voltage value (phase-to-ground, peak value), which corresponds to approximately $30 \%$ of voltage sag. At $t=6 \mathrm{~s}$, the fault is cleared.

In Figure $27 \mathrm{a}$, one can observe the grid voltage $\left(v_{\text {gabc }}\right)$ before and during the fault. In Figure $27 \mathrm{~b}$, it is possible to see the synthesized load voltage $\left(v_{o a b c}\right)$ along with its reference $\left(v_{\text {refabc }}\right)$. It is clear that the grid fault and the unbalanced conditions do not affect, at all, the performance of the MMSC in 
properly synthesizing the load voltage. In Figure $27 d-f$, one can observe the capacitor voltages in the submodules of phase-A leg, phase-B leg and phase- $\mathrm{C}$ leg, respectively. As expected, when the fault occurs, the average value of the capacitor voltages in the phase-A leg decreases. As previously mentioned, according to Kirchhoff's law and conservation of energy, there should be a new average value for the capacitor voltage that is equal to approximately $\frac{V_{g}}{N}=\frac{25}{20}=1.25 \mathrm{kV}$. The average voltage of the capacitors in the phase-B leg are not affected by the phase-A grid fault. The average voltage of the capacitors in the phase-C leg are slightly affected by the fault. The reason for that is the fact that the phase-C leg is connected to both phase $\mathrm{C}$ and phase $\mathrm{A}$ of the grid, through the bidirectional switches, during the MMSC operation. Nonetheless, at most of the time, the phase-C string is connected to phase $C$ of the grid, resulting in only a small voltage sag during the grid fault. One very important thing to notice is the fact that the capacitor voltages, in all three strings, are kept stable during these severe grid conditions, proving the high performance of the MMSC under unbalanced grid conditions. Moreover, the unbalanced conditions do not lead to an increase in the submodule-capacitor voltage ripples, which is a problem faced by the MMC and the MMMC, as negative-sequence currents flow through the submodule strings of such converters. Basically, the current flowing through the MMSC submodule strings is always the load current $\left(i_{o a b c}\right)$, which is not affected, at all, by the grid imbalance. Another issue that is very interesting to notice are the input and output power $\left(P_{i}\right.$ and $P_{0}$, respectively), shown in Figure 27c. When the voltage sag occurs, there should be a new balance value for the average voltages in the submodule capacitors of the phase-A leg, according to Kirchhoff's law and conservation of energy. Since the power supplied to the load is supposed to remain constant, then the grid power $\left(P_{i}\right)$ temporary decreases and, then, the power supplied to the load is temporary higher than the power coming from the grid, resulting in the reduction of the energy in the capacitors of the submodules in phase-A leg. Inversely, when the grid fault is cleared, the grid power instantaneously increases, becoming temporary higher than the load power, in order to recharge the capacitors in the submodules of the phase-A leg. This operation clearly shows how the average value of the capacitors in the submodule string is imposed by the grid-voltage amplitude, satisfying Kirchhoff's law and conservation of energy, and illustrating why the average capacitor voltages do not need to be controlled.
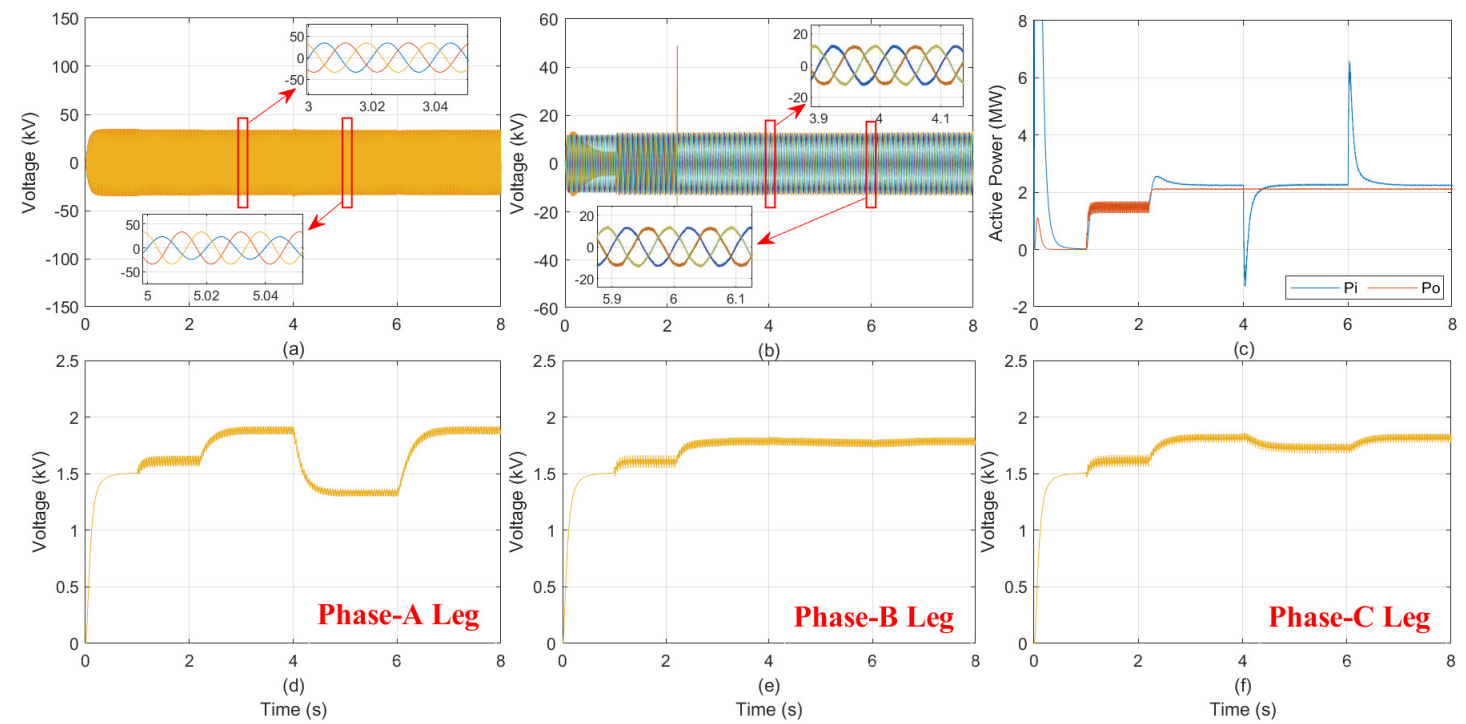

Figure 27. MMSC under unbalanced grid conditions. (a) Grid voltage, (b) load voltage and load-voltage reference, (c) input and output power, (d) capacitor voltages in submodules of phase-A leg, (e) capacitor voltages in submodules of phase-B leg and (f) capacitor voltages in submodules of phase-C leg. 


\section{Experimental Validation}

To validate the MMSC presented in this article, an experimental prototype of the converter was built as shown in Figure 28a. Since the MMSC is a three-phase converter composed of three completely independent single-phase converters (see Figure 3), in order to validate it, a single-phase structure was built. This structure is composed of a string of eight FB submodules (IGBTs) along with two bidirectional switches (IGBTs) connected to two different phases of the grid. The grid is emulated by the AC voltage source illustrated in Figure 28a and the converter supplies power to a $50 \Omega$ resistive load. In order to obtain a three-phase result, three different tests were executed for each of the three phases. In order to control the MMSC, a dSPACE is used with a $20 \mathrm{kHz}$ sampling frequency. The test setup diagram is shown in Figure 28b and its main parameters are summarized in Table 8.

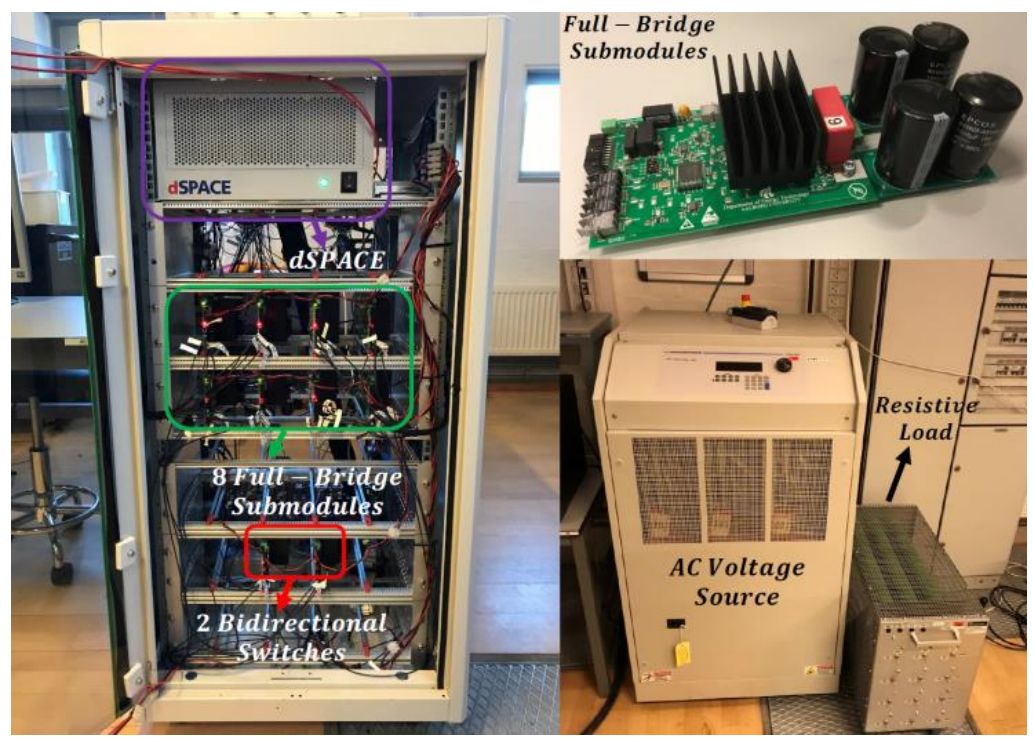

(a)

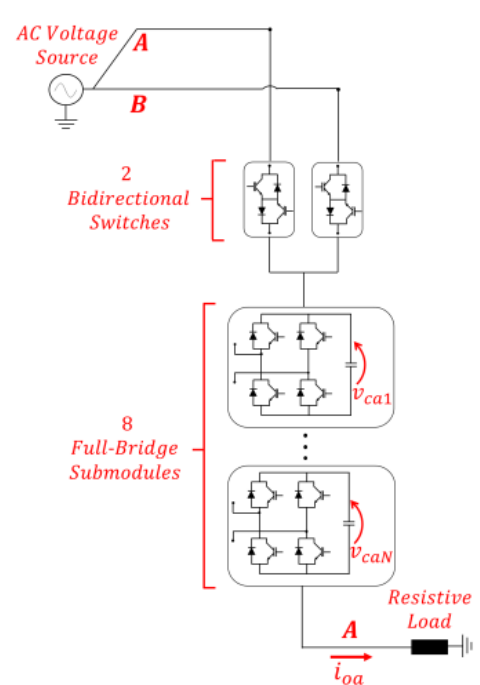

(b)

Figure 28. MMSC experimental prototype. (a) Real experimental test setup, (b) test setup diagram.

Table 8. Test Setup Parameters.

\begin{tabular}{cc}
\hline Parameter & Value \\
\hline Submodule-Capacitor Capacitance & $4 \mathrm{mF}$ \\
Snubber-Capacitor Capacitance & $2 \mathrm{mF}$ \\
Load Resistance & $50 \Omega$ \\
Grid-voltage Amplitude & $160 \mathrm{~V}$ (phase-to-ground/peak) \\
Grid-voltage Frequency & $50 \mathrm{~Hz}$ \\
Load-voltage Amplitude & $50 \mathrm{~V}$ (phase-to-ground/peak) \\
Control Sampling Frequency & $20 \mathrm{kHz}$ \\
\hline
\end{tabular}

In Figures 29 and 30, one can observe the experimental results obtained for six different tests. For all the tests, the input voltage (grid voltage) has amplitude equal to $160 \mathrm{~V}$ (phase-to-ground peak value) and frequency equal to $50 \mathrm{~Hz}$, and the output voltage (load voltage) has amplitude equal to $50 \mathrm{~V}$ (phase-to-ground peak value). In Figure 29a,c,e, one can observe the load voltage for the cases in which the output-voltage-reference frequency is equal to $1 \mathrm{~Hz}, 10 \mathrm{~Hz}$ and $45 \mathrm{~Hz}$, respectively, and the bidirectional switches are disabled. In Figure 30a,c,e, one can observe their corresponding capacitor voltages, respectively. In Figure $29 \mathrm{~b}, \mathrm{~d}, \mathrm{f}$, one can observe the load voltage for the cases in which the output-voltage-reference frequency is equal to $1 \mathrm{~Hz}, 10 \mathrm{~Hz}$ and $45 \mathrm{~Hz}$, respectively, and the bidirectional switches are enabled. In Figure $30 \mathrm{~b}, \mathrm{~d}, \mathrm{f}$, one can observe their corresponding capacitor voltages, respectively. 

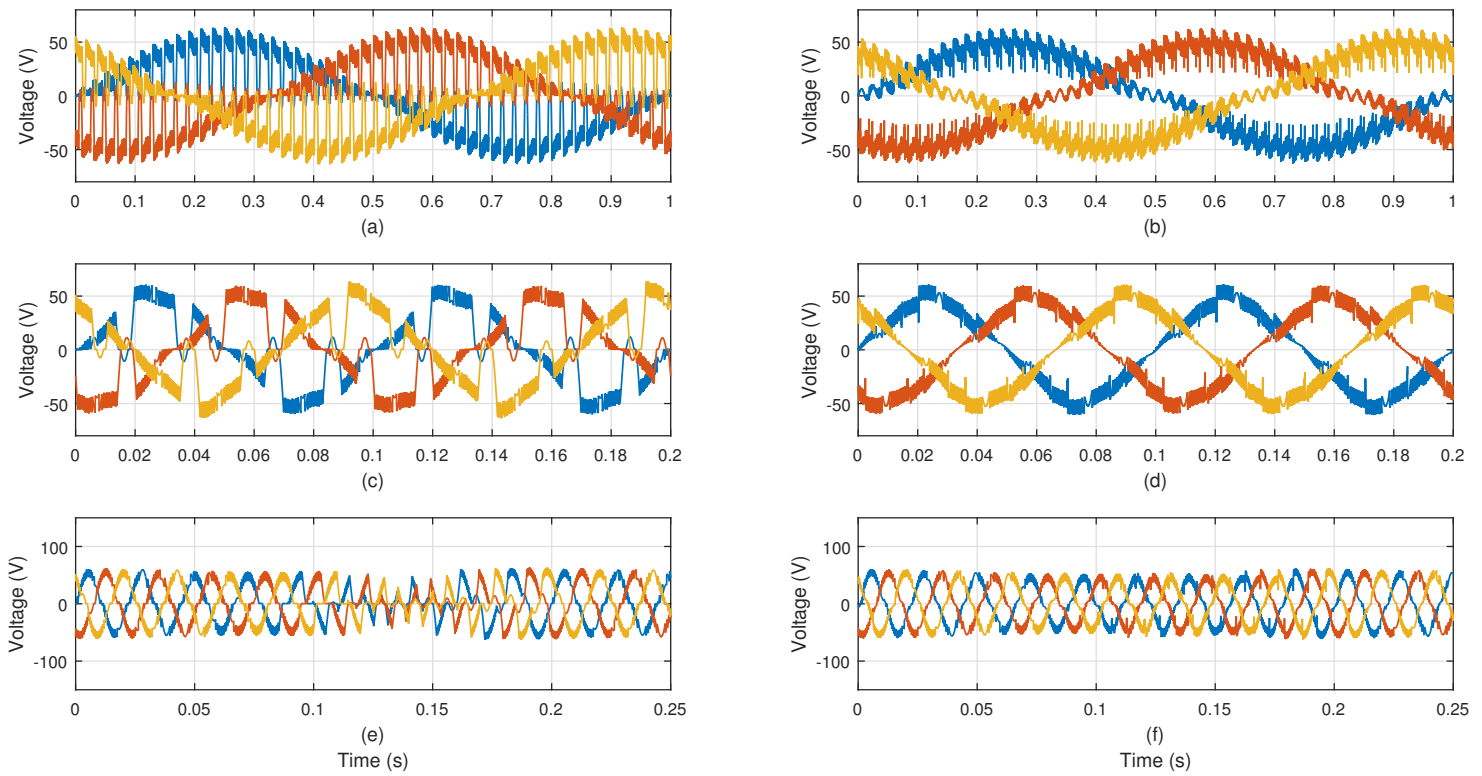

Figure 29. Experimental results of output voltages (load voltages). (a) 1-HZ-output-voltage reference with bidirectional switches disabled, (b) 1-HZ-output-voltage reference with bidirectional switches enabled, (c) 10-HZ-output-voltage reference with bidirectional switches disabled, (d) 10-HZ-output-voltage reference with bidirectional switches enabled, (e) 45-HZ-output-voltage reference with bidirectional switches disabled and (f) 45-HZ-output-voltage reference with bidirectional switches enabled.
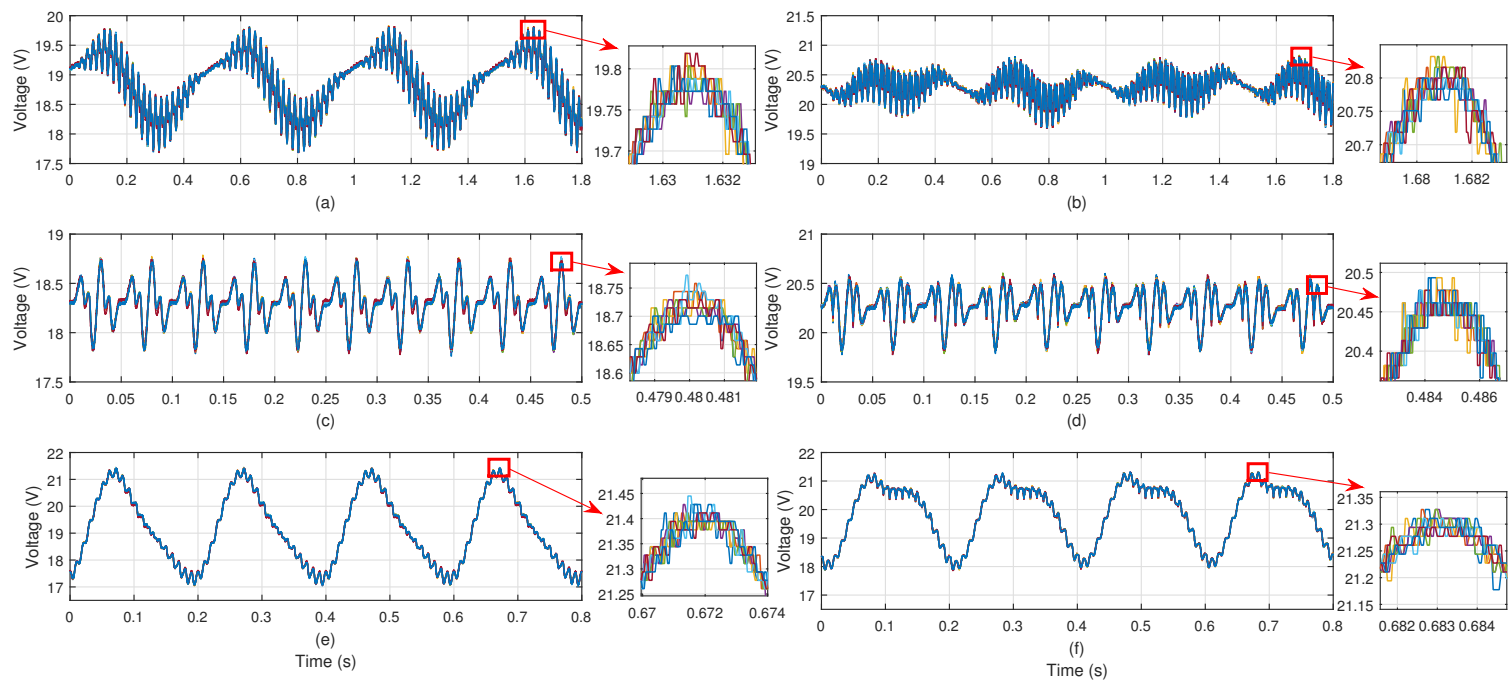

Figure 30. Experimental results of submodule-capacitor voltages. (a) 1-HZ-output-voltage reference with bidirectional switches disabled, (b) 1-HZ-output-voltage reference with bidirectional switches enabled, (c) 10-HZ-output-voltage reference with bidirectional switches disabled, (d) 10-HZ-output-voltage reference with bidirectional switches enabled, (e) 45-HZ-output-voltage reference with bidirectional switches disabled and (f) 45-HZ-output-voltage reference with bidirectional switches enabled.

It is important to notice that as expected, the MMSC is able to properly synthesize the output voltage, for every frequency considered, when the bidirectional-switch switching is enabled. It is important to emphasize that the MMSC does not have arm inductors nor an output-voltage filter was used in these experimental tests. The waveforms shown in Figure 29b,d,f are the actual output voltages without any intermediate filtering stage. It is possible to say that these are high-power-quality signals that would only require a very small filter to obtain a perfectly sinusoidal waveform, since the 
harmonic components present in the voltage signals are high-order harmonics. Moreover, a higher number of levels of submodules would further improve the output-voltage power quality.

The capacitor-voltage-ripple behavior is very similar to the one obtained in simulation. In fact, the capacitor-voltage ripples are quite low for the 1- $\mathrm{Hz}$ case, as shown in Figure 30b. Moreover, it is clear that the submodule-capacitor voltages are balanced in every case (observe zoom in the capacitor-voltage signals) proving the effectiveness of the voltage-balance control. Finally, the capacitor voltages are kept stable, meaning that the power supplied to the load comes entirely from the grid as these two are exchanging power.

\section{Conclusions}

This paper presented a completely new AC-AC converter solution called MMSC that uses a modular multilevel structure and that could be a very promising alternative to medium-voltage machine-drive applications such as pumped-hydro-storage systems, large wind turbines and industrial motor drives. The MMSC presents important structural and operational advantages in comparison to other alternative converter topologies. Some of these advantages are the reduced number of semiconductor devices and submodule capacitors, which could make the MMSC a very light and compact solution, and with reduced costs. In Section 5, a detailed analysis is carried out, comparing the proposed MMSC and the traditional MMC in terms of number of components, conduction and switching losses. This analysis concluded that the MMSC is a solution with a $13 \%$ reduction in the number of semiconductor devices and an expressive $75 \%$ reduction in the number of submodule capacitors, in relation to the MMC. Thus, the MMSC should be a solution with reduced cost and with an expressive size and weight reduction, since these are bulky capacitors. This could be a very important characteristic if the converter were to be used in an offshore wind-turbine application that requires lightness and compactness, due to the complex and expensive supporting structures of such systems. The comparison analysis also demonstrated that the MMSC and the MMC present equivalent efficiency.

Moreover, the MMSC presents straightforward control and modulation as explained in Section 3 of this paper. In other words, the MMSC only have one internal control loop, which is responsible for the submodule-capacitor-voltage balancing. This is an advantage in relation the MMC and the MMMC that require many different internal control loops such as the circulating-current-suppression control, the control of the average value of the capacitor voltages, aiming at maintaining these voltages regulated and stable under different grid conditions, and the voltage balance between upper and lower arms, in the MMC case.

In Section 4, a detailed analytical description of the voltage ripples in the MMSC submodule capacitors is presented, which demonstrates the high performance of the proposed converter under low-frequency operation. This is a very important feature that could make the MMSC a promising solution for high-power machine-drive applications that operate with low frequencies or even crossing the $0-\mathrm{Hz}$ operation point. It is important to emphasize that this is a crucial advantage in comparison to the MMC that presents poor performance at low frequencies.

In Section 6, simulation results are provided showing the steady-state and transient performance of the MMSC. These results show that the MMSC can generate a high-power-quality load voltage with variable frequency, while injecting a high-power-quality current into the grid, as the load and grid exchange power. Thus, this converter could be used to control the machine speed in a high-power machine-drive application. Simulation results also show the high performance of the MMSC under unbalanced grid conditions, which is an important advantage in comparison to the MMC and the MMMC that present poor performance under unbalanced grid conditions. The MMSC submodule-capacitor voltages are kept stable, during the unbalanced conditions, and no voltage-ripple increase is experienced, since the current that flows through the MMSC submodule strings is always the load current that is not affected by the grid imbalance. Simulation results are also provided to validate the mathematical model of the submodule-capacitor voltage ripples, proposed in Section 4. 
Finally, in Section 7, experimental results are presented validating the proposed control and modulation technique and proving that the MMSC is capable of synthesizing a high-power-quality load voltage with variable frequency, while exchanging power with the grid. In other words, the MMSC can operate as a controlled voltage source from the load perspective.

As described in this paper, a critical point of the MMSC are the bidirectional switches. These switches must be capable of blocking the grid voltage and, thus, series-connected semiconductor devices are required. However, the bidirectional switches, in the proposed MMSC, operate at very low switching frequency $(50 \mathrm{~Hz})$ and, thus, many different approaches can be adopted in order to obtain proper dynamic voltage sharing among the semiconductors connected in series, leading to a safe and reliable operation of the converter. Due to the low switching frequency, it is possible to operate the series-connected devices with tolerable switching losses, as emphasized in the switching-loss analysis presented in Section 5. Moreover, the complex multi-step commutation techniques, usually used in matrix converters, can be avoided because of the low switching frequency of the bidirectional switches. In other words, snubber circuits, in combination with a dead-time technique, can be adopted in the commutation process. Nonetheless, the bidirectional switch is a critical component of the MMSC that deserves special attention. Future works with a high-power test setup must be carried out to fully validate the proposed converter solution. These tests will require a specialized laboratory infrastructure to analyze the bidirectional switches operating under medium-voltage conditions and, thus, it will be possible to propose a safe and reliable solution for these switches.

Author Contributions: G.G. established the major part of this paper which includes conceptualization, formal analysis, investigation, methodology, modulation, simulation, experimental validation and was responsible for writing the original draft preparation. S.W. contributed with software and experimental validation. T.K. provided supervision and text review. R.T. provided supervision and text review. All authors have read and agreed to the published version of the manuscript.

Funding: This research received no external funding.

Conflicts of Interest: The authors declare no conflict of interest.

\section{References}

1. Sneed, A. Worlds Largest Wind Turbine Would Be Taller Than the Empire State Building; Scientific American, Springer Nature: New York, NY, USA, 2017.

2. Diaz, M.; Cárdenas, R.; Espinoza, M.; Mora, A.; Wheeler, P. Modelling and control of the modular multilevel matrix converter and its application to wind energy conversion systems. In Proceedings of the IECON 2016-42nd Annual Conference of the IEEE Industrial Electronics Society, Florence, Italy, 23-26 October 2016.

3. Van Hout, M.; Ozdemir, O.; Koutstaal, P. Large-Scale Balancing with Norwegian Hydro Power in the Future European Electricity Market; Technical Report; Energieonderzoek Centrum Nederland (ECN): Petten, The Netherlands, August 2017.

4. Killingtveit, A.; Solvang, E.; Harby, A. HydroBalance-A research project on the use of the Norwegian hydro reservoirs for large scale balancing of future wind power development in NE Europe. In Proceedings of the Hydro 2012, Bilbao, Spain, 29-31 October 2012.

5. Graabak, I.; Jaehnert, S.; Korpås, M.; Mo, B. Norway as a battery for the future European power system-impacts on the hydropower system. Energies 2017, 10, 2054. [CrossRef]

6. Graabak, I.; Korpås, M. Balancing of Variable Wind and Solar Production in Continental Europe with Nordic Hydropower-A Review of Simulation Studies. Energy Procedia 2016, 87, 91-99. [CrossRef]

7. Siemonsmeier, M.; Baumanns, P.; van Bracht, N.; Schönefeld, M.; Schönbauer, A.; Moser, A.; Dahlhaug, O.; Heidenreich, S. Hydropower Providing Flexibility for a Renewable Energy System: Three European Energy Scenarios; Technical Report December; HydroFlex: Trondheim, Norway, 2018. [CrossRef]

8. Basić, M.; Silva, P.C.O.; Dujić, D. High Power Electronics Innovation Perspectives for Pumped Storage Power Plants. In Proceedings of the Hydro 2018, Gdansk, Poland, 15-17 October 2018.

9. Vasiladiotis, M.; Baumann, R.; Häderli, C.; Steinke, J. IGCT-based Direct AC/AC Modular Multilevel Converters for Pumped Hydro Storage Plants. In Proceedings of the 2018 IEEE Energy Conversion Congress and Exposition (ECCE), Portland, OR, USA, 23-27 September 2018. 
10. Steimer, P.K.; Senturk, O.; Aubert, S.; Linder, S. Converter-Fed Synchronous Machine for Pumped Hydro Storage Plants. In Proceedings of the 2014 IEEE Energy Conversion Congress and Exposition (ECCE), Pittsburgh, PA, USA, 14-18 September 2014; pp. 4561-4567.

11. Pou, J.; Ceballos, S.; Konstantinou, G.; Agelidis, V.G.; Picas, R.; Zaragoza, J. Circulating current injection methods based on instantaneous information for the modular multilevel converter. IEEE Trans. Ind. Electron. 2015, 62, 777-788. [CrossRef]

12. Picas, R.; Ceballos, S.; Pou, J.; Zaragoza, J.; Konstantinou, G.; Agelidis, V.G. Closed-loop discontinuous modulation technique for capacitor voltage ripples and switching losses reduction in modular multilevel converters. IEEE Trans. Power Electron. 2015, 30, 4714-4725. [CrossRef]

13. Hagiwara, M.; Hasegawa, I.; Akagi, H. Start-up and low-speed operation of an electric motor driven by a modular multilevel cascade inverter. IEEE Trans. Ind. Appl. 2013, 49, 1556-1565. [CrossRef]

14. Antonopoulos, A.; Ängquist, L.; Norrga, S.; Ilves, K.; Harnefors, L.; Nee, H.P. Modular multilevel converter AC motor drives with constant torque from zero to nominal speed. IEEE Trans. Ind. Appl. 2014, 50, 1982-1993. [CrossRef]

15. Ou, Z.; Wang, G.; Lanhua, Z. Modular Multilevel Converter Control Strategy Based on Arm Current Control Under Unbalanced Grid Condition. IEEE Trans. Power Electron. 2018, 33. [CrossRef]

16. Guo, C.; Yang, J.; Zhao, C. Investigation of small-signal dynamics of modular multilevel converter under unbalanced grid conditions. IEEE Trans. Ind. Electron. 2019, 66, 2269-2279. [CrossRef]

17. Merlin, M.M.C.; Green, T.C.; Mitcheson, P.D.; Trainer, D.R.; Critchley, R.; Crookes, W.; Hassan, F. The Alternate Arm Converter: A New Hybrid Multilevel Converter With DC-Fault Blocking Capability. IEEE Trans. Power Deliv. 2014, 29, 310-317. [CrossRef]

18. Adam, G.P.; Davidson, I.E. Robust and Generic Control of Full-Bridge Modular Multilevel Converter High-Voltage DC Transmission Systems. IEEE Trans. Power Deliv. 2015, 30, 2468-2476. [CrossRef]

19. He, L.; Zhang, K.; Xiong, J.; Fan, S. A repetitive control scheme for harmonic suppression of circulating current in modular multilevel converters. IEEE Trans. Power Electron. 2015, 30, 471-481. [CrossRef]

20. Bahrani, B.; Debnath, S.; Saeedifard, M. Circulating Current Suppression of the Modular Multilevel Converter in a Double-Frequency Rotating Reference Frame. IEEE Trans. Power Electron. 2016, 31, 783-792. [CrossRef]

21. Darus, R.; Pou, J.; Konstantinou, G.; Ceballos, S.; Agelidis, V.G. Controllers for eliminating the ac components in the circulating current of modular multilevel converters. IET Power Electron. 2016, 9, 1-8. [CrossRef]

22. Glinka, M.; Marquardt, R. A new AC/AC multilevel converter family. IEEE Trans. Ind. Electron. 2005, 52, 662-669. [CrossRef]

23. Muneshima, M.; Nishida, Y. A multilevel AC-AC conversion system and control method using Y-connected H-bridge circuits and bidirectional switches. In Proceedings of the 2013 IEEE Energy Conversion Congress and Exposition, ECCE 2013, Denver, CO, USA, 15-19 September 2013; pp. 4008-4013.

24. Thitichaiworakorn, N.; Hagiwara, M.; Akagi, H. A single-phase to three-phase direct AC/AC modular multilevel cascade converter based on double-star bridge-cells (MMCC-DSBC). In Proceedings of the 1st International Future Energy Electronics Conference, IFEEC 2013, Tainan, Taiwan, 3-6 November 2013; pp. 476-481.

25. Liu, B.; Meng, Y.; Bai, S. A novel high-power AC/AC modular multilevel converter in y configuration and its control strategy. In Proceedings of the Asia-Pacific Power and Energy Engineering Conference, APPEEC, Xi'an, China, 25-28 October 2016; pp. 973-977.

26. Dargahi, V.; Corzine, K.A.; Enslin, J.H.; Sadigh, A.K.; Rodriguez, J.; Blaabjerg, F. Modular-Concatenated-Cell (MCC) Multilevel Converter: A Novel Circuit Topology and Innovative Logic-Equations-Based Control Technique. In Proceedings of the 2018 IEEE Energy Conversion Congress and Exposition, ECCE 2018, Portland, OR, USA, 23-27 September 2018; pp. 2970-2975.

27. Lei, M.; Li, Y.; Li, Z.; Zhao, C.; Xia, B.; Wang, P. Exploration of a Modular Multilevel Converter for Direct AC-AC Conversion. In Proceedings of the 2018 IEEE International Power Electronics and Application Conference and Exposition (PEAC), Shenzhen, China, 4-7 November 2018; pp. 1-6.

28. Diab, M.S.; Massoud, A.M.; Ahmed, S.; Williams, B.W. A Dual Modular Multilevel Converter with High-Frequency Magnetic Links Between Submodules for MV Open-End Stator Winding Machine Drives. IEEE Trans. Power Electron. 2018, 33, 5142-5159. [CrossRef]

29. Thitichaiworakorn, N.; Hagiwara, M.; Akagi, H. A Medium-Voltage Large Wind Turbine Generation System Using an AC/AC Modular Multilevel Cascade Converter. IEEE J. Emerg. Sel. Top. Power Electron. 2016, 4, 534-546. [CrossRef] 
30. Hammond, P.W. A new approach to enhance power quality for medium voltage AC drives. IEEE Trans. Ind. Appl. 1997, 33, 202-208. [CrossRef]

31. Islam, M.R.; Guo, Y.; Zhu, J.G. 11-kV Series-Connected H-Bridge Multilevel Converter for Direct Grid Connection of Renewable Energy Systems. J. Int. Conf. Electr. Mach. Syst. 2012, 1, 70-78. [CrossRef]

32. Rastogi, M.; Osman, R.H.; Fukuta, Y. Variable-Frequency Drive with Regeneration Capability. U.S. Patent 7,508,147, 24 March 2009.

33. Diaz, M.; Cardenas, R.; Espinoza, M.; Rojas, F.; Mora, A.; Clare, J.C.; Wheeler, P. Control of Wind Energy Conversion Systems Based on the Modular Multilevel Matrix Converter. IEEE Trans. Ind. Electron. 2017, 64, 8799-8810. [CrossRef]

34. Erickson, R.W.; Al-Naseem, O.A. A new family of matrix converters. In Proceedings of the IECON Proceedings (Industrial Electronics Conference), Denver, CO, USA, 29 November-2 December 2001; pp. 1515-1520.

35. Kawamura, W.; Akagi, H. Control of the modular multilevel cascade converter based on triple-star bridge-cells (MMCC-TSBC) for motor drives. In Proceedings of the 2012 IEEE Energy Conversion Congress and Exposition, ECCE 2012, Raleigh, NC, USA, 15-20 September 2012; pp. 3506-3513.

36. Kawamura, W.; Hagiwara, M.; Akagi, H. Control and experiment of a modular multilevel cascade converter based on triple-star bridge cells. IEEE Trans. Ind. Appl. 2014, 50, 3536-3548. [CrossRef]

37. Kawamura, W.; Chen, K.L.; Hagiwara, M.; Akagi, H. A Low-Speed, High-Torque Motor Drive Using a Modular Multilevel Cascade Converter Based on Triple-Star Bridge Cells (MMCC-TSBC). IEEE Trans. Ind. Appl. 2015, 51, 3965 - 3974. [CrossRef]

38. Fan, B.; Wang, K.; Wheeler, P.; Gu, C.; Li, Y. A Branch Current Reallocation Based Energy Balancing Strategy for the Modular Multilevel Matrix Converter Operating Around Equal Frequency. IEEE Trans. Power Electron. 2018, 33, 1105-1117. [CrossRef]

39. Karwatzki, D.; Mertens, A. Generalized Control Approach for a Class of Modular Multilevel Converter Topologies. IEEE Trans. Power Electron. 2018, 33, 2888-2900. [CrossRef]

40. Fan, B.; Wang, K.; Wheeler, P.; Gu, C.; Li, Y. An Optimal Full Frequency Control Strategy for the Modular Multilevel Matrix Converter Based on Predictive Control. IEEE Trans. Power Electron. 2018, 33, 6608-6621. [CrossRef]

41. Blaszczyk, P. Hex-Y-A New Modular Multilevel Converter Topology for a Direct AC-AC Power Conversion. In Proceedings of the 2018 20th European Conference on Power Electronics and Applications, EPE 2018 ECCE Europe, Riga, Latvia, 17-21 September 2018; pp. P.1-P.10.

42. Erickson, R.W.; Al-Naseem, O.A.; Fingersh, L.J. Variable-Speed Wind Power System with Improved Energy Capture via Multilevel Conversion. U.S. Patent 6,900,998, 31 May 2005.

43. Gontijo, G.; Soares, M.; Tricarico, T.; Dias, R.; Aredes, M.; Guerrero, J. Direct matrix converter topologies with model predictive current control applied as power interfaces in AC, DC, and hybrid microgrids in islanded and grid-connected modes. Energies 2019, 12, 3302. [CrossRef]

44. Gontijo, G.F.; Tricarico, T.C.; Franca, B.W.; Da Silva, L.F.; Van Emmerik, E.L.; Aredes, M. Robust Model Predictive Rotor Current Control of a DFIG Connected to a Distorted and Unbalanced Grid Driven by a Direct Matrix Converter. IEEE Trans. Sustain. Energy 2019, 10, 1380-1392. [CrossRef]

45. Behrouzian, E.; Bongiorno, M. Investigation of negative-sequence injection capability of cascaded h-bridge converters in star and delta configuration. IEEE Trans. Power Electron. 2017, 32, 1675-1683. [CrossRef]

46. Liu, S.; Saeedifard, M.; Wang, X. Analysis and control of the modular multilevel matrix converter under unbalanced grid conditions. IEEE J. Emerg. Sel. Top. Power Electron. 2018, 6, 1979-1989. [CrossRef]

47. Sharifabadi, K.; Harnefors, L.; Nee, H.P.; Norrga, S.; Teodorescu, R. Design, Control, and Application of Modular Multilevel Converters for HVDC Transmission Systems; John Wiley \& Sons: Hoboken, NJ, USA, 2016.

48. Jacobson, B.; Karlsson, P.; Asplund, G.; Harnefors, L.; Jonsson, T. VSC-HVDC Transmission with Cascaded Two-Level Converters; CIGRE: Paris, France, 2010.

49. Gerster, C. Fast High-Power/High-Voltage Switch Using Series-Connected IGBTs with Active Gate-Controlled Voltage-Balancing. In Proceedings of the 1994 IEEE Applied Power Electronics Conference and Exposition-ASPEC'94, Orlando, FL, USA, 13-17 February 1994; pp. 469-472.

50. Baek, J.W.; Yoo, D.W.; Kim, H.G. High-Voltage Switch Using Series-Connected IGBTs With Simple Auxiliary Circuit. IEEE Trans. Ind. Appl. 2001, 37, 1832-1839. [CrossRef] 
51. Tanabe, S.; Kobayashi, S.; Sampei, M. Study on Overvoltage Protection in HVDC LTT Valve. IEEE Trans. Power Deliv. 2000, 15, 545-550. [CrossRef]

52. Wheeler, P.W.; Rodríguez, J.; Clare, J.C.; Empringham, L.; Weinstein, A. Matrix Converters: A Technology Review. IEEE Trans. Ind. Electron. 2002, 49, 276-288. [CrossRef]

53. Malekjamshidi, Z.; Jafari, M.; Zhang, J.; Zhu, J. Design and Analysis of Protection Circuits for Safe Operation of Direct Matrix Converters. In Proceedings of the 2017 20th International Conference on Electrical Machines and Systems, ICEMS 2017, Sydney, NSW, Australia, 11-14 August 2017. [CrossRef]

54. Song, Q.; Liu, W.; Li, X.; Rao, H.; Xu, S.; Li, L. A steady-state analysis method for a modular multilevel converter. IEEE Trans. Power Electron. 2013, 28, 3702-3713. [CrossRef]

(C) 2020 by the authors. Licensee MDPI, Basel, Switzerland. This article is an open access article distributed under the terms and conditions of the Creative Commons Attribution (CC BY) license (http:/ / creativecommons.org/licenses/by/4.0/). 